\title{
The political economy of meat regulation and the sustainability of alternative food networks
}

by

Emily Norgang Woodward

A thesis submitted to the Faculty of Graduate and Postdoctoral Affairs in partial fulfillment of the requirements for the degree of Master of Arts

in

Political Economy

Carleton University

Ottawa, Ontario

(C) 2011, Emily Norgang Woodward 
Library and Archives

Canada

Published Heritage Branch

395 Wellington Street

Ottawa ON K1A ON4

Canada
Bibliothèque et

Archives Canada

Direction du

Patrimoine de l'édition

395, rue Wellington

Ottawa ON K1A ON4

Canada
Your file Votre référence

ISBN: 978-0-494-83078-9

Our file Notre référence

ISBN: 978-0-494-83078-9
NOTICE:

The author has granted a nonexclusive license allowing Library and Archives Canada to reproduce, publish, archive, preserve, conserve, communicate to the public by telecommunication or on the Internet, loan, distribute and sell theses worldwide, for commercial or noncommercial purposes, in microform, paper, electronic and/or any other formats.

The author retains copyright ownership and moral rights in this thesis. Neither the thesis nor substantial extracts from it may be printed or otherwise reproduced without the author's permission.
AVIS:

L'auteur a accordé une licence non exclusive permettant à la Bibliothèque et Archives Canada de reproduire, publier, archiver, sauvegarder, conserver, transmettre au public par télécommunication ou par l'Internet, prêter, distribuer et vendre des thèses partout dans le monde, à des fins commerciales ou autres, sur support microforme, papier, électronique et/ou autres formats.

L'auteur conserve la propriété du droit d'auteur et des droits moraux qui protège cette thèse. $\mathrm{Ni}$ la thèse ni des extraits substantiels de celle-ci ne doivent être imprimés ou autrement reproduits sans son autorisation.
In compliance with the Canadian Privacy Act some supporting forms may have been removed from this thesis.

While these forms may be included in the document page count, their removal does not represent any loss of content from the thesis.
Conformément à la loi canadienne sur la protection de la vie privée, quelques formulaires secondaires ont été enlevés de cette thèse.

Bien que ces formulaires aient inclus dans la pagination, il n'y aura aucun contenu manquant. 


\begin{abstract}
The shift towards large-scale production, processing and distribution is seen in Canada's livestock agriculture, with the effects of decreasing numbers of small-scale abattoirs rippling throughout all points on food supply chains. This paper looks at the loss of small-scale abattoirs in British Columbia, arguing that federal and provincial regulations have limited the possibilities at local levels and suppressed the food sovereignty of producers, processors, and consumers. This loss is the result of regulations that reflect dominant neoliberal discourses of 'standardization equals safety,' 'bigger is better,' and 'one-size-fits-all.' These discourses are normalized and facilitated through scalar relations and embedded neoliberal tendencies, enabling the systematic reproduction of the neoliberal hegemony. These factors define and limit the potential for resistance, creating tensions between stakeholders and encouraging responses to recreate the very systems that caused the crisis. Fortunately, new possibilities for resistance have been opened that hold the potential of building a counter-hegemonic movement.
\end{abstract}




\section{Acknowledgements}

Thank you, Peter Andrée, for your support, guidance and knowledge. You introduced me to community based research and provided me with opportunities to learn and grow. Your kindness encouraged me and your intellect inspired me.

Thank you, Lisa Mills, Iain Wallace and Trevor Purvis, for your thought-provoking comments, challenging questions and, most of all, for your words of support. You provided me with a stimulating and compassionate environment in which to reflect and improve.

Thank you, Donna Coghill, for your continual support that sustained me throughout my studies. You guided me through the process and gave endless personal and intellectual support. Thank you for being there for me.

Thank you, Janet Siltanen and Rianne Mahon, for creating a challenging, supportive and rewarding atmosphere for learning. Also, I am thankful for all the work you've both done for the Institute of Political Economy.

Thank you to all the participants who trusted me with their stories and knowledge, and inspired me to represent their lives and perspectives in a manner that provokes thought and action.

Thank you to my friends and colleagues for all your wisdom, activism, insight, and inspiration. Also, thank you for helping me relax and endure through the hard parts, especially Amanda, Besmira, Bracken, Carol, Chelsea, David, Francesca, JaJackt, JP, Layla, Leanne, Miranda, Morgan, Peter, Putno, Rebecca, Sam, Sarah, Sara, Stéfan, Tarek, the Tribe, and William.

Thank you to my family - my mom, Audrey, my dad, Tom, my sisters Erin, Michelle and Jessica, and my aunt Gloria Samten - for endless support, love, and inspiration. I couldn't have done this without you. 


\section{Table of Contents}

Abstract...............................................................

Acknowledgements...................................................... ii

Table of Contents........................................................ iii

List of Appendices........................................................... v

Acronyms.................................................................... vi

1 Chapter: Introduction and Methodology................................ 1

$1.0 \quad$ Introduction ............................................ 1

$1.1 \quad$ Context ................................................. 3

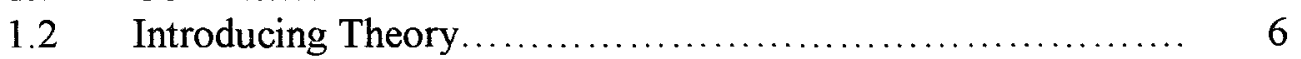

$1.3 \quad$ Research Question...................................... 8

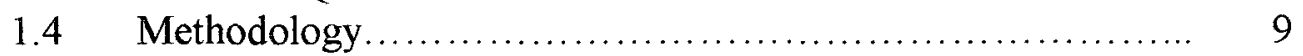

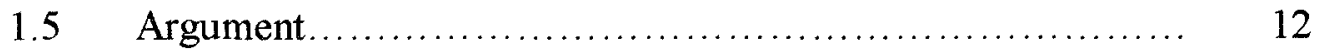

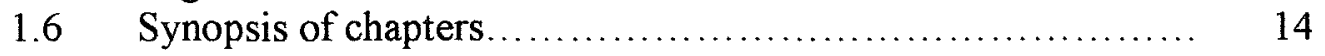

2 Chapter: Theoretical Framework and Key Concepts................... 18

$2.0 \quad$ Introduction .......................................... 18

2.1 Political Economy: Marx, Polanyi and Gramsci.............. 19

2.2 Discourse: Foucault ..................................... 22

$2.3 \quad$ Scalar Analysis....................................... 25

2.4 Combining Theories in Neoliberalization ..................... 26

$2.5 \quad$ Response and Resistance................................... 32

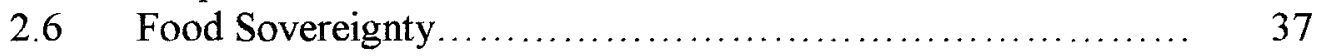

$2.7 \quad$ Conclusion ........................................... 38

3 Chapter: Small-scale Agriculture in BC Before and After the MIR.... 40

$3.0 \quad$ Introduction ............................................. 40

3.1 Meat Production in the Canadian Context.................. 40

3.2 The Role of Small-Scale Agriculture and AFNs in BC ........ 44

3.3 The Enactment of the MIR and its Effects................... 49

$3.4 \quad$ Conclusion ......................................... 57

4 Chapter: The MIR as a Reflection of Dominant Discourses ............. 59

$4.0 \quad$ Introduction ............................................... 59

4.1 Standardization equals Safety: Managing risk and Claiming Truth 59

4.2 Bigger is Better: Prioritizing Large-Scale Production and Economies 64 
4.3 One Size Fits All: Failing to Scale Appropriately .............. 69

$4.4 \quad$ The Illusion of Laissez Faire .............................. 75

4.5 Conclusion............................................. 84

5 Chapter: From Roll-Out to Zombie Neoliberalism..................... 86

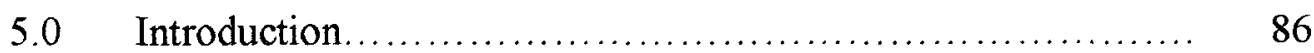

5.1 Scalar Relations and Roll-Out Neoliberalization............. 88

5.2 The Emergence of the Zombie.............................. 93

5.3 Outcome-Based Regulation ................................. 97

$5.4 \quad$ Zombie Apocalypse? ................................... 102

5.5 Conclusion......................................... 103

6 Chapter: Implications for a Response and Counter Hegemony ......... 105

$6.0 \quad$ Introduction............................................ 105

6.1 Resistance, Compliance, Adjustment...................... 106

6.2 Individual and localized "Successful" Responses................ 107

6.3 New Avenues and Possibilities................................. 112

6.4 Limits of Neoliberalization and Perceived Tensions............. 118

6.5 The Centrality of Scale and Need for its Recognition........... 129

6.6 Conclusion.................................................. 135

Chapter 7: Conclusions.................................................. 138

$7.0 \quad$ Introduction.......................................... 138

$\begin{array}{lll}7.1 & \text { Factors that may have influenced research process and findings } & 139\end{array}$

$7.2 \quad$ Future Research........................................... 145

7.3 Conclusion and Overview............................... 150

Appendices

Appendix A: Glossary.................................... 153

Appendix B: Meat Inspection Regulation...................... 156

Appendix C: MIR Requirements............................ 171

Interviews.................................................................... 173

References......................................................................... 174 


\section{List of Appendices}

Appendix A: Glossary .............................................. 153

Appendix B: Meat Inspection Regulation........................... 156

Appendix C: MIR Requirements .................................. 171 


\section{Acronyms}

\begin{tabular}{|l|l|}
\hline ACRONYM & TITLE \\
\hline AAFC & Agriculture and Agri-Food Canada \\
\hline AFN & Alternative Food Networks \\
\hline BC & British Columbia \\
\hline BCAA & British Columbia Abattoir Association \\
\hline BCCA & British Columbia Cattlemen's Association \\
\hline BCFPA & British Columbia Food Processing Agency \\
\hline BFF & Beyond Factory Farming \\
\hline BSE & Bovine Spongiform Encephalopathy \\
\hline CCGD & Canadian Council of Grocery Distributors \\
\hline CFIA & Canadian Food Inspection Agency \\
\hline CFIG & Canadian Federation of Independent Grocers \\
\hline CDC & Canadian Disease Control \\
\hline CIELP & Canadian Institute for Environmental Law and Policy \\
\hline CPC & Canadian Pork Council \\
\hline CMC & Canadian Meat Council \\
\hline HACCP & Hazard Analysis and Critical Control Points \\
\hline MAFF & Ministry of Agriculture Fisheries and Food (UK) \\
\hline MIR & Meat Inspection Regulation \\
\hline MoE & Ministry of Environment \\
\hline OMAFRA & Ontario Ministry of Agriculture, Food, and Rural Affairs \\
\hline SMO & Social Movement Organization \\
\hline SRM & Specified Risk Material \\
\hline
\end{tabular}




\section{Chapter: Introduction and Methodology}

\subsection{Introduction}

Since the Industrial Revolution, agricultural production has evolved in the direction of large-scale mechanized operations. In Canada this evolution has affected not only farming practices, but also the structure of rural communities and the ways in which Canadians en masse relate to food. One area where this transformation to large-scale industrial agriculture is clearly taking place is in the meat industry's slaughtering and processing facilities.

At present, the Canadian meat industry is dominated by three large companies; Cargill, Tyson, and XL, that together control $89 \%$ of Canada's beef processing market (National Farmers Union, 2008). This concentration, combined with a variety of other factors, including increasingly stringent federal and provincial regulatory policies, have stressed all scales of production and led to a drastic reduction of small-scale abattoirs across Canada. This loss of small-scale abattoirs has greatly affected the sustainability of local food supply chains and alternative food networks (AFNs), described below. The damage to the middle point on food supply chains has severely affected small-scale producers who are increasingly forced to give up farming. The disruption also presents challenges to consumers who support these food networks for any number of reasons, including product quality, health, animal diversity and welfare, environmental sustainability, food sovereignty, and resistance to the corporatization and dominance of large-scale food and agricultural production. 
Alternative Food Networks have been described as niche markets for products that are embedded with information and marketed through unique connections with consumers in ways that are different than those practiced by mainstream agri-food business (Harris E, 2008; Ilbery et al. 2005) ${ }^{1}$. A common type of AFN is the 'local food supply network' that has come to represent the phenomenon wherein entire food chains (production, distribution, and consumption) occur within $200 \mathrm{~km}$ of each other $^{2}$. AFNs emphasize relationships between the different links in the chain and have a flexibility that can address the unique needs of small-scale producers. The loss of these networks has rapidly changed the rural landscape: the loss of small-scale farms and the increase of urbanization has caused a great deal of tension and strife among individuals, families, and communities.

Although this phenomenon is occurring across Canada, the province of British Columbia $(\mathrm{BC})$ presents a clear example, not only because its agricultural landscape consists of diverse types and scales of livestock agriculture, but also due to the recent enactment of the provincial government's Meat Inspection Regulation (MTR). ${ }^{3}$ Upon the implementation of the MIR in 2004, there was a sudden and drastic loss of small-scale abattoirs across the province. Additionally, although the MIR is a provincial regulation, it is drafted very broadly, thus encouraging open and varying interpretation by inspectors. Incidentally, the $\mathrm{BC}$ government has contracted the Canadian Food Inspection Agency (CFIA) to implement the MIR, thereby transferring its provincial authority to a federal

\footnotetext{
${ }^{1}$ See Appendix A for a detailed description of alternative food networks

${ }^{2}$ This distance can vary depending on the circumstances

${ }^{3}$ See Appendix A for a detailed description of MIR
} 
agency. This jurisdiction circumnavigation has the potential to create problems and contradictions when federal values conflict with provincial values.

Before moving on to the main argument of this paper, this chapter first describes the role of small-scale abattoirs in the Canadian context, the structure of Canada's meat inspection regulations, and the case of $\mathrm{BC}$ 's Meat Inspection Regulation. These three sections address key factors in the wider political-economic agricultural context in Canada, such as past and present agricultural trends, regulatory systems, and government and non-government organizations.

\subsection{Context}

The structure of Canada's meat regulations play an important role in the case of the MIR and the loss of small-scale abattoirs in BC and Canada, as it has both enabled and limited the possibilities for abattoirs of all scales. Canada's current meat inspection system is structured in a way that divides abattoirs into provincially and federally inspected facilities. Federal inspection is required if meat is to be traded inter-provincially or internationally, whereas provincial inspection is necessary if the product remains within the province (Carter-Whitney, 2008, 24). Federally inspected plants dominate the processing market and only $10 \%$ of Canada's total slaughter takes place in provincially inspected plants. The four largest plants account for $75 \%$ of the entire federally inspected cattle kill (MacLachlan, 2001, 163). Although there are exceptions, for the most part small-scale abattoirs are provincially regulated, whereas the larger facilities fall under federal jurisdiction. This division is a necessary and effective way to ensure food safety while respecting Canada's federalist system; however it is recognized as problematic for 
small-scale producers and processors for a variety of reasons, which will be discussed throughout this paper.

In 2004, the Meat Inspection Regulation (MIR) was implemented under the Food Safety Act, requiring that all meat and meat products be processed at a licensed slaughter establishment (Ministry of Health, 2011). The MIR was in part established in response to national food-borne illness outbreaks that originated in large-scale facilities in other provinces and led consumers ${ }^{4}$ to distrust Canada's meat industry, forcing the federal government to develop strategies of risk management to secure Canada's export market. Part of this strategy included pressuring $\mathrm{BC}$ 's government to implement a meat inspection regulation. This regulation in turn rippled down to the ground level, even though not a single case of food safety problems has been recorded in the province's small-scale operations.

Under the MIR, abattoirs must comply with the BC Centre for Disease Control's (CDC) plant construction, equipment and operation guidelines, and an abattoir code of good practice (Ministry of Healthy Living and Sport, 2009). The original MIR divided these guidelines into two classes of licenses, Class A which allowed both slaughter and cut and wrap services, and Class B which allowed only slaughter. Shortly after its implementation a Class $\mathrm{C}$ license was established, which was a transitional license for those working towards a Class A or B facility. Abattoirs were able to apply for funding and financial assistance from BC's Meat Transition Assistance Program to build or upgrade their facilities (Ministry of Healthy Living and Sport, 2009), as will be analyzed

\footnotetext{
${ }^{4}$ Consumers vary widely from individual consumers to corporate procurement, both on local, regional, provincial, national, and international scales
} 
further below, these measures have proven inadequate in supporting the majority of abattoirs throughout the process.

Since the implementation of the regulation there have been two amendments. The first amendment was to protect the people who were first to attain licensing by disallowing others to apply for a license if they were within a $200 \mathrm{~km}$ radius of the licensed facility $(\mathrm{I}-21,2011)$. The second amendment enacted class $\mathrm{D}$ and $\mathrm{E}$ licenses which are designed to provide options for producers in rural and remote areas who do not have access to class A or B licensed facilities and where livestock numbers are not high enough to warrant the construction of a class A or B facility ${ }^{5}$. The class $\mathrm{D}$ licenses permit the slaughter of up to 25 animal units per year that can be sold both at farm gate and to retail establishments. Class D licenses are only available to nine designated regional districts where there are no Class A or B licensed facilities. Class E licenses permit the slaughter of up to 10 animal units per year and can only be sold at the farm gate.

There have been two key players in the implementation of the MIR, the Canadian Food Inspection Agency (CFIA) and the British Columbia Food Processor's Association (BCFPA). The CFIA has been contracted by the provincial government to implement the regulations within the abattoirs. The BCFPA is responsible for organizing and providing resources and support to abattoirs attempting to transition into a licensed facility. The BCFPA played a major role in the consultation process and design of the class $\mathrm{D}$ and $\mathrm{E}$ licenses. Although, on paper, this licensing process seems fairly straightforward, unfortunately this is far from the case and led to a closure of two-thirds to three-quarters of abattoirs throughout the province (BCFPA, 2008). This paper analyzes the factors

\footnotetext{
${ }^{5}$ These amendments came about, in part, due to an increased awareness of the incompatibility of the MIR to the needs of rural and remote regions, which is discussed further in the chapter 6.
} 
behind these losses, including the dominant discourses that did not leave room for smallscale production and the neoliberal tendencies that contributed to this loss. The analysis of this case draws on neo-Gramscian, Foucauldian, and scalar theory to help understand the case of the MIR.

\subsection{Introducing Theory}

Neo-Gramscian, Foucauldian, and scalar theories may prove useful in helping to understand the current realities of neoliberalization as well as conceptualize possibilities for resistance and capacity building ${ }^{6}$. These theories are combined with the concept of food-sovereignty, which maintains that the right of people to define their agricultural and food policy should be central to Canada's understanding of healthy and sustainable food systems. This theoretical framework is developed fully in the next chapter, but is first introduced here in brief.

Gramsci's work, and that of his followers rooted in the Marxist tradition, introduces the concepts of hegemony and counter-hegemony. These concepts may help to understand the tensions among the interests of various groups of people as they relate to three sets of "relations of force" (Gramsci, 1971, 181-184). These are the material forces of production, relations of political (or ideological) forces, and relations of institutional

\footnotetext{
${ }^{6}$ Capacity building has become a central concern of community and organization development, experts, funding agencies, and implementing organizations, and is now seen as a necessary condition for the development, implementation, and maintenance of effective community-based programs (Goodman et al., 1998). Literature on capacity building has demonstrated that building capacity to develop evidence and engage in public processes contributes to "the broader social goal of creating a public able to engage in collective social action and political life, and the idea of active citizenship" (Smith et al., 2001). Langille et al. draw out the three levels of capacity building; individual, organizational, and community (Langille et al., 2008). Langille at al. also point to the importance of both internal and external collaborative capacity (Langille et al., 2008). Capacity building is thus a complex and dynamic process that not only involves a combination of methods, but that is also greatly affected by its interdependence with both internal and external factors, including the sociopolitical context (Langille, et al. 2008).
} 
forces (Andrée, 2011). This framework is further illuminated by Foucault's concepts of governmentality and discourse. These concepts can be used to analyze the emergence of a neoliberal discourse of jurisdiction and veridiction, and show us how this discourse can normalize and award a truth-value to facets of the current policy landscape which are clearly value-laden and benefit some actors over others. These concepts may help to analyze the discourses surrounding meat inspection in Canada. These theories are further combined with a scalar analysis that rethinks conventional understandings of scale, viewing it as produced, whether purposefully or erratically, through social, economic, political, and cultural actions. Scalar theory may prove useful to understanding the relations between various scales of government, regulatory systems, and markets, as well as possibilities for resistance.

Neo-Gramscian, Foucauldian and scalar theories are brought together to provide a deeper understanding of neoliberalization and especially the recent emergence of what Peck, Theodore, and Brenner call "Zombie Neoliberalism." Neoliberalism can be defined succinctly as "the doctrine that market exchange is an ethic in itself, capable of acting as a guide for all human action" (Harvey, 2005, p.i) or as Peck, Theodore and Brenner describe it, a "flexibly mutating regime of "market rule" (Peck, Theodore, Brenner, 2009, 95). Zombie Neoliberalism, on the other hand, is used to describe a new expression of neoliberalism in which "residual neoliberal impulses are sustained not by intellectual and moral leadership, or even by hegemonic force, but, by underlying macroeconomic and macroinstitutional conditions-including excess capacity and overaccumulation at the world scale, enforced public austerity and global indebtedness, and growth-chasing, beggar-thy-neighbor modes of governance," also known as "living dead" phase (Peck, 
Theodore, \& Brenner, 2009). Zombie neoliberalism may help to illuminate the forces behind the design, enactment and implementation of the MIR. Combining Gramscian, Foucauldian, and scalar theories in the era of neoliberalism, specifically drawing on the state's redefined role as facilitator, risk management, and high politics, may allow for a deeper analysis of the MIR.

These theories are also used in this work to help illuminate the ways in which resistance has not only been shaped by neoliberal tendencies, but also how new avenues of resistance have been opened in this new era. The discussion on response and resistance draws on the neo-Gramscian concept of counter-hegemony, helping to understand the real and perceived tensions that have arisen between achieving individual success and contributing to the wider counter-hegemonic movement. Through the combination of Foucauldian, Gramscian, and scalar theories, this thesis aims to explore how the case of BC's MIR is an outcome of the current realities of neoliberalization, as well as the possibilities for resistance and capacity building in this neoliberal context. These theories may help to answer research questions that have guided this research.

\subsection{Research Question}

The theoretical framework that informs this research may enable me to effectively answer my main research questions: how are the global, national, and local trends towards rollout neoliberalization, governmentality, and scalar politics connected to the loss of small to mid-sized abattoirs across Canada? What does this dynamic mean for supporting a sustainable network of small to mid-sized abattoirs? To answer these questions, I use a methodology that analyzes academic literature in order to provide a theoretical base to my research, combined with an analysis of grey literature and stakeholder interviews. 


\subsection{Methodology}

The methodology used throughout this research process has been carefully chosen and revisited to ensure that my findings are engaging and relevant both academically and on a practical level by combining primary and secondary resources including government reports, news articles, and academic literature, with a series of over 30 interviews. Throughout the process of my research I also used the Strategic Analysis System (SAS) model. Chevalier and Buckels believe that "universities should rethink the nature of thinking and learning" and use skilful means to engage creatively with problems (Chevalier and Buckels, 2008). This means using people-based enquiry and evidence based thinking to mediate and manage different views and knowledge systems, achieve a sense of purpose and grounding, navigate methods of data gathering and analysis, scaling or calibrating levels and kinds of evidence needed in each situation, and interpreting complex information and situations (Chevalier, J.M. \& Buckels D.J., 2008). Throughout the process I have remained aware of the factors that shape policy outcomes, such as power, interests and legitimacy (Chevalier, J.M. \& Buckels D.J., 2008). I have accounted for the unpredictability and uncertainty by planning to an appropriate level of detail and time, using a working hypothesis, and testing it throughout the process (Chevalier, J.M. \& Buckels D.J., 2008). This method was especially relevant because of my engagement with both government, industry, civil society, and local representatives, and has enabled me to effectively combine academic literature with these individual perspectives in a way that has produced a comprehensive and complete analysis of my research problem.

It has been extremely important that the perspectives of a diverse range of individuals and groups are adequately represented, with an emphasis in presenting the 
voices that are often marginalized and not heard, as discussed below. Interviewing key stakeholders has been one of my key methods of research. I interviewed 38 participants that I categorized into the following groups: producers, processors, distributors, consumers, civil society groups, industry representatives, politicians and government officials at municipal, provincial, and federal levels. Due to the sensitive nature of the information gathered, I have not revealed the names or specific locations of any of the informants. These interviews have been extremely valuable to my research because they have given me an understanding of the theoretical positions, perceptions, beliefs, and ideologies of key stakeholders (Richard, D., 1996), and have allowed for a diversity of voices to be heard. These interviews have helped me to interpret documents and reports, interpret personalities involved in relevant decisions, and have provided me with information that is not available otherwise (Richard, D., 1996). Furthermore, by engaging a diverse range of individuals I have been able to draw out the perspectives of individuals who, for various reasons, have been excluded from policy discussions.

The structure of these interviews were based on the in-depth interview style, also known as the unstructured interview (Berry, 1999). This style of interviewing aims to "achieve a holistic understanding of the interviewee's point of view or situation" by using open-ended questions and probing techniques (Berry, 1999). During the interview process I remained aware that the interviewee may be influenced by preconceptions of the interviewer, such as race, gender, ethnicity, skin colour, age, socio-economic class and occupation (Hubbell, L.D., 2003). Although this may be seen to create challenges to research, I felt that, due to my status as a student, I was actually able to use such preconceptions to my advantage, and was given information that stakeholders may have 
otherwise been uneasy about providing to interviewers from other areas.

The interviews took the form of either telephone interviews or personal interviews at the interviewee's home, workplace, or in a public setting. Many of the interviews with officials on the federal level took place in Ottawa, Ontario and there a number of telephone interviews with social movement organizations across Canada. The bulk of my interviews took place in $\mathrm{BC}$ and took part in three separate regions of the province; 1) The North Okanagan, ${ }^{7}$ 2) Powell River ${ }^{8}$ and 3) the Gulf Islands. ${ }^{9}$ Chapter three outlines some of the unique qualities of these different regions.

One important factor that was taken into consideration during the interview process was the involvement of traditionally marginalized people. This is one area that has often been overlooked due to its tendency to involve alternative methods of governance and communication (Van der Plaat, M \& Barrett, G. 2006). Rural citizens and communities are one group that often feel excluded from participating in planning and policy processes that shape their future (RCIP Project, 2005; Langille et al. 2008). This thought was confirmed during my interview process when a local politician pointed to the discomfort among many farmers and processors at entering into political discussions, explaining that it is always the same people who come out to meetings while there are tens of thousands who never give input $(I-23,2010)$. Most farmers I interviewed confirmed this point, expressing concern that they had been stigmatized and their perspectives were not being respected or included in the decision making process. For these reasons, I have made a

\footnotetext{
${ }^{7}$ Interviews and research that were conducted in the North Okanagan included the regions of Kelowna, Armstrong, Vernon, Kamloops, and Falkland.

${ }^{8}$ Interviews in Powell River represented the isolated regions and islands which includes isolated regions along the mainland's coast; Sunshine Coast, Powell River, Bella Bella, and Bella Coola, and remote islands; Texada, Lasqueti, and Haida Gwaii.

${ }^{9}$ Interviews and Research were conducted on Salt Spring, Gabriola, and Galiano Islands. This region includes the following islands: Salt Spring, Gabriola, Galiano, Saturna and Pender.
} 
great effort to include these voices in my research. Furthermore I remained aware of language and styles of interviewing, in order to be as inclusive as possible.

A final topic that needs to be addressed is the issue of power relations and researcher vulnerability. Although a great deal has been written on the marginalized populations that are involved in research projects, very little attention has been given to research students as being "highly vulnerable themselves" (Ballamingie \& Johnson, 2011). Ballamingie and Johnson challenge the notion that researchers are in positions of privilege, drawing on the factors that make researchers both powerful and vulnerable (Ballamingie \& Johnson, 2011). During the research process I faced many instances in which I felt vulnerable, including: participants refusing to allow me to use information they have provided until they have approved the context; personal attacks based on my appearances and being construed as the "other" (Ballamingie \& Johnson, 2011); needing to conceal my personal ethics and in some cases needing to engage in activities that are opposed to my ethics in order to gain access to information; facing restricted access to key social actors; and requiring to use consent forms prescribed by the universities ethics department that distanced key actors. These issues put me in a vulnerable situation and may have affected the results of this research. By remaining aware of these limitations, I am able to effectively apply to this methodology in a way that allows for a deep analysis of the case of the MIR in BC.

\subsection{Argument}

This thesis argues that the drastic loss of small and medium-scale abattoirs in BC and across Canada is a result of federal and provincial policies and regulations that are implemented with the intention to support Canada's trade and production capacity, which 
are facilitated through government and corporate scales, limiting the possibilities at local levels. Not only has this loss directly and indirectly caused devastation in the lives of individuals and communities through the destruction of local and alternative food supply networks, but it has also limited food sovereignty as expressed not only through the right to produce and consume healthy and quality food, but also through the maintenance of skills and knowledge, animal diversity and welfare, and the ability to engage in environmentalism and resistance to the corporatization and industrialization of food agriculture. This paper further argues that the implementation of the MIR, which led to the loss of small- and medium-scale abattoirs, reflects four factors that are central to neoliberal discourse. The first three factors reflect the productive elements of the neoliberal discourse and include the dominant discourse of 'standardization equals safety,' 'bigger is better,' and 'one size fits all.' The fourth factor reflects the modes by which discourse is normalized and reproduced drawing out neoliberal tendencies. At the federal level, the state acts as 'scale manager' facilitating the needs of trade requirements through the complex web of scalar relations. At the provincial level, neoliberal tendencies are reflected through 'Zombie Neoliberalism,' in which actors, organizations and discourses have unintentionally reproduced the current hegemony through the design and implementation of the MIR. Finally, this paper argues that the above factors have implications on the response by simultaneously defining, limiting, and opening up new avenues and possibilities for resistance and capacity building. This argument will be demonstrated throughout this paper, which has been divided into seven chapters. 


\subsection{Synopsis of chapters}

Chapter two discusses the theoretical framework and key concepts. It begins with a discussion of political economy, drawing on Marx's historical materialism and Gramsci's hegemony. The discussion then leads to Foucault's concept of discourse that is informed by concepts of governmentality, jurisdiction and veridiction, risk management and disciplines of audit. The chapter then uses scalar theory, which rethinks conventional understandings of scale, viewing it as produced, whether purposefully or erratically, through social, economic, political, and cultural actions. These three theoretical frameworks are brought together in a discussion of neoliberalization, outlining the new wave of roll-out neoliberalization, the state's redefined role as "scale manager," tools of governance, risk management and high politics. The chapter then examines Foucauldian, neo-Gramscian, and scalar views of resistance to understand the ways in which such responses are affected by neoliberal trends, but also how new avenues of resistance can be opened. This discussion draws heavily on the neo-Gramcian concept of counterhegemony, discussing the real and perceived tensions between achieving individual wins and contributing to a broader counter-hegemonic movement. This framework is then combined with the concept of food-sovereignty as expressed by small farming movements associated with the international peasant movement Via Campesina.

Chapter three explores the empirical realities of the MIR in the context of Alternative Food Networks (AFN) and the previous regime for meat production in BC. This is demonstrated by first looking at meat production in the Canadian context, discussing the shift to large-scale agriculture and the resiliency of small scale abattoirs. The chapter then looks at BC's agricultural landscape and the central of role small-scale 
agriculture and AFNs, reflecting discourses of food sovereignty. The chapter then outlines the three options that were available to producers and processors upon the enactment of the MIR, as well as discussing the devastation that the MIR caused throughout BC's rural and agricultural communities.

Chapter four argues that the MIR was poorly designed and implemented, because it reflected three dominant discourses under the current neoliberal hegemony, which are: standardization equals safety; bigger is better; and one size fits all. These three discourses are prevalent under neoliberalization, especially at the federal level, and draw out the interconnections between industry and government, demonstrating the ways regulations are used as "tools of governance" (Dunn, 2005, 186) and have allowed state intervention in the market while maintaining the neoliberal illusion of laissez-faire.

Chapter five uses scalar analysis to provide a deeper and broader understanding of roll-out neoliberalization, arguing that the state, specifically the federal government, has taken the role of "scale manager" (Mahon \& Keil, 2009) to facilitate the scales and interactions between various government and institutional players, with the intention of supporting Canada's production and export markets. On the one hand, the provincial government has also played a role in this facilitation process, through the outcome-based design of the Meat Inspection Regulation (MIR) and their choice to contract the implementation of the MIR to the CFIA, reflecting roll-out neoliberalization. On the other hand we are also seeing the emergence new expressions of neoliberalism, such as 'Zombie Neoliberalization' (Peck, Theodore and Brenner, 2009). Zombie Neoliberalism is described as the "living dead" phase, in which "residual neoliberal impulses are sustained not by intellectual and moral leadership, or even by hegemonic force, but, by 
underlying macroeconomic and macroinstitutional conditions" (Peck, Theodore, \& Brenner, 2009). Thus despite the lack of gusto for large-scale export oriented agriculture at the provincial level, because of deeply embedded neoliberal tendencies that allow the system to be operational as a structural model, it continues to push forward its agenda despite its lack of clear drivers, in the form of political leadership on the provincial level. This section argues that although the case of the MIR in $\mathrm{BC}$ reflects tendencies of roll-out neoliberalization, it also points to expressions of Zombie Neoliberalization in which, despite the increased attention drawn to the weaknesses of industrial agriculture, the embedded structure has pushed forward a regulation that is contradictory to these intentions.

Chapter six discusses the various responses to the MIR and the implications that neoliberalism has had on limiting and defining the avenues and possibilities for response and resistance. The chapter begins with an analysis of three responses to the MIR, which were found to be resistance, compliance, or adjustment. This chapter argues that due to the increased authority of social movement organizations (SMOs), and the power of market-based responses, neoliberalism has opened new possibilities for responses and resistance, allowing for individuals and groups to attain localized successes. Nevertheless a political-economic and discourse analysis draws out remaining tensions that have been left unexamined, further arguing that tensions have arisen between the ability to attain localized success that can address unique needs of individual actors and the ability to engage in more widespread resistance that can act as a counter-hegemony to the root causes of the MIR's implementation. These tensions result from neoliberalism's ability to limit and define responses, allowing it to capitalize on and grow from the very crisis 
situations that it has created. Left unexamined, this phenomenon could potentially lead to an increasingly dichotomized and subjugated food landscape. However, this chapter finally argues that through a scalar approach to resistance individuals and groups in $\mathrm{BC}$ could not only work towards localized solutions that take into account their unique needs, but could also begin developing the networks and building the capacity to respond to the root causes of the MIR leading to more long-term, broad-reaching, counter-hegemonic opportunities that reflect food sovereignty and improve the sustainability and strength of Canadian food systems and communities. 


\section{Chapter: Theoretical Framework and Key Concepts}

\subsection{Introduction}

This chapter aims to outline and review the key theories and concepts that are drawn on throughout this paper, demonstrating the value of developing a theoretical framework that builds on critical political economy, neo-Gramscian, Foucauldian, and scalar theories. Furthermore, this chapter explores the discourse and theoretical concept of food sovereignty, pointing to ways in which the case of the MIR might connect to a larger global movement and showing how it has informed this research process and outlook. This chapter begins with a discussion of political economy, which builds on Marxist and Gramscian thinking and uses concepts of the state and hegemony. The discussion then moves on to discuss Foucault's concept of discourse that is informed by concepts of governmentality, jurisdiction and veridiction, risk management and disciplines of audit. The chapter then brings in scalar theory and the concepts of boundary objects and scale jumping. These three theoretical frameworks are brought together in a discussion of neoliberalization, concluding with the implications for response and resistance. This chapter thus demonstrates the importance of combining Gramscian, Foucauldian, and scalar theory in an analysis of neoliberalization and resistance in a way that demonstrates how both discourse and organizations have shaped our current political-economic systems and the regulatory structures that have altered the direction of food production, processing, distribution and consumption throughout Canada. 


\subsection{Political Economy: Marx, Polanyi and Gramsci}

A political economy approach is useful to the analysis of the loss of small- and mediumscale abattoirs in $\mathrm{BC}$ and across Canada by emphasizing the ways economic and political factors interrelate and shape each other, providing a deeper understanding of the power dynamics that are present throughout government and society and the importance in understanding how these power dynamics have been manifested in policy design and governance. The critical political economy perspective introduced here draws on the work of Antonio Gramsci, adopting a neo-Gramscian approach rooted in the Marxist tradition.

Marxism is a theoretical approach that "assumes the centrality of the struggles that capitalist relations of production engender in contemporary politics" (Andrée, 2011, 175). Central to Marx's thinking was a recognition that capitalism is not an autonomous system and that primitive accumulation is a violent process ( $\mathrm{Li}, 2007)$. Rather than connecting "laissez-faire" to the growth of capitalism, Marx saw government intervention as a key factor in the production and perseverance, understanding that "the laws that support private property, enforce exclusion, and produce "free" labor are violent by other means" (Li, 2007). Karl Polanyi, a Hungarian intellectual that drew on Marxism in his book, The Great Transformation, demonstrated that despite the 1830s crusading passion for laissez faire, "there was nothing natural about laissez-faire; free markets could never have come into being merely by allowing things to take their course" $(1944,144-145)$. Furthermore, it was the creation of a market for land and labour that provoked what Polanyi termed a "countermovement," which was a push-back against this domination grounded in the recognition that "leaving the fate of soil and people to the market would 
be tantamount to annihilating them" (Polanyi, 1944, 131). Thus, Marx and Polanyi understand that, although the state promotes growth because it is convinced that it is beneficial to the population at large, "interventions that set the conditions for growth simultaneously set the conditions for some sections of the population to de dispossessed. Winners and losers do not emerge naturally through the magic of the market, they are selected" (Li, 2007).

Antonio Gramsci follows the Marxist traditions, although for him abstract concepts, such as labour and capital, could not answer the question of how a collective, critical practice emerges. Instead, it has to take into account the multiple positions that people occupy, and the diverse powers they encounter ( $\mathrm{Li}, 2007)$. Gramscians differ from 'economistic' Marxists by dismissing the assumption that the material base necessarily defines the ideological superstructure and instead encourage the analysis of the interplay of three sets of 'relations of force'- material, institutional, and discursive - across three levels of political activity: civil society, the State, and global order (Gramsci, 181-184). Although, Gramsci sees the State as a key sphere of 'direct domination' of one social group by another (Gramsci, 1971, 10), he interprets the state more broadly, describing an "extended" or "integral" state that is made up of "both the apparatuses of government and the judiciary and the various voluntary and private associations and para-political institutions which make up civil society" (Andrée, 2011), which he defines as,

all the 'so-called private' organizations such as churches, trade unions, political parties and cultural associations which are distinct from the process of production and from the public apparatuses of the state. All the organizations which make up civil society are the result of a complex network of social practices and social relations, including the struggle between the two fundamental classes, capital and labour. (Simon, 1982, 69) 
Central to Gramsci's thinking is his concept of hegemony and counter hegemony, which rely on a "conjecture of discourses that regulate, normalize, and produce subjectivities" (Hall, 1998) and "conceptualizations of what is "right" and "wrong" in positioning of individuals and groups in relation not only to the "economy", but also to ideas of and relations to the non-human, biophysical world" (Prudham, S., 2008, 184). Hegemony is neither natural nor automatic, but is instead politically constructed and contingent and is dependent on both coercion and consent, with coercion found in the state and institutions and consent in the realm of ideas (Andrée, P., 2007, 21). Through understanding ideologies as embedded in social relations and employed strategically to "generate consensus around a particular group's interests" (Andrée, P. 2007, 23), we can understand that the goal of hegemony formation is to "transcend a particular form of common sense and to create another which [is] closer in conception of the world of the leading group" (Gramsci, A., 1971, 423).

A 'historical bloc' is central to the production and reproduction of common sense and is defined by Neo-Gramscians in two ways, first as "an alliance of social groups around a set of material practices and justificatory discourses for which they seek to establish widespread acceptance" and second "to the convergence of material forces of production, coercive forces of the State, and supportive discourses that together 'stabilise and reproduce relations of production and meaning"' (Andrée, 2011, 176). Thus historical blocs attempt to consolidate hegemony through the convergence of the three sets of relations of force, discussed above. In order to change or preserve the status quo, one must develop strategies in each of the three areas, creating what he terms "wars of position" (Andrée, P., 2007, 21), which is analyzed further below in a discussion on 
resistance. It is at this point where Foucault's thoughts of discourse and governmentality complement a neo-Gramscian approach.

\subsection{Discourse: Foucault}

Foucault's discourse analysis complements Gramsican thought by analyzing more deeply the complex interrelations of power that shape the discourses that produce and reproduce historical blocs and hegemony. Foucault understands discourse as playing an important role in producing and shaping the dominant ideology, understanding discourse as "politically constructed and produced through discourse and actions by contending moves for self-constituted autonomies" (Prudham, S., 2008, 190). Bourdieu points out that it is strong discourses that are behind "all the powers of a world of power relations" and because of such discourse that "this initially desocialized and dehistorisized theory" has, now more than ever, the means of making itself true" (Bourdieu, 1998, 95). This can be explained through Foucault's discussion of jurisdiction and veridiction.

Foucault writes of the ways in which knowledge and power reinforce one another, creating and reproducing notions of norms and standards of truth (Foucault, 1980, 98). He demonstrates this using the terms jurisdiction and veridiction to describe two axes of codification/prescription and the formulation of true or false, respectively (Foucault, 1991, 79). These two axes are important to understanding "how men govern (themselves and others) by the production of truth" (Foucault, 1991, 79). Foucault further clarifies the terms jurisdiction and veridiction, as "the rules of right that provide a formal delimitation of power" and "the effects of truth that this power produces and transmits, and which in their turn reproduces this power," respectively (Foucault, 1980, 93). 
There are 2 points that must be acknowledged about the ways in which discourses are embedded in social relations. First that they are shaped through the shared medium of language and second that influence goes both ways, thus "discourses are tied to, and reinforced by, particular social and institutional practices that make them visceral in daily life" (Andrée, 2007, 23). Shaping discourse is therefore a "truth claiming activity, working to normalize power in politics" (Andrée, 2007, 24). Discourse can be both disciplinary and productive, for example it disciplines by restricting boundaries of what makes sense, defining what is acceptable and restricting avenues of legitimate resistance, while on the other hand being productive by defining what does make sense and producing new possibilities (Andree, 2007, 24). This analysis of discourse and the importance of jurisdiction and veridiction, play an important role in Foucault's understanding of government.

The term governmentality reflects the field of power Michael Foucault termed 'government', which he defined succinctly as the "conduct of conduct" (Li, 2007, 5). $\mathrm{He}$ explained government's purpose as securing the "welfare of the population, the improvement of its condition, the increase of its wealth, longetvity, health, etc." (Foucault, 1991, 100). Foucault understands government as "the attempt to shape human conduct by calculated means" ( $\mathrm{Li}, 2007,5)$, explaining a "shift from government to governance," where government is the "power and rule of the state" and governance is the use of "non-state mechanisms of regulation" and the "employment of tools that indirectly encourage subjects to act in particular ways" (Guthman, 2007, 466). Distinguishing forms of governance from discipline, "which seeks to reform designated groups through detailed supervision in confined quarters (prisons, asylum, schools)" the 
concern of government is the well-being of the population at large. Since at the population level, it is not possible to coerce every individual, instead the government operates "by educating desires and configuring habits, aspirations and beliefs," ( $\mathrm{Li}, 2007$, 5) setting conditions "artificially so arranging things so that people, following their own self-interest, will do as they ought" (Scott, 1995, 202). Rather than seeking to govern solely through the use disciplinary tactics throughout society, governmentality reflects the state's ability to govern "through the regulated choices of individual citizens" (Rose, 1996, 41). Foucault explains the ways in which governments have pushed forward their agendas not by coercion, but instead by producing subjects who will adopt certain behaviors in their everyday life (Guthman, 2008) It must be noted that discipline has not been completely replaced by governance, but instead has been reserved for sub-groups (Li, 2007).

The use of governmentality in political economy is a useful framework for analyzing the use of regulatory structures in the governance of individuals. Governmentality has been adopted by political scientists such as Barry, Osborne, Rose, Dunn and Guthman who understand its "particular significance today because recent political strategies have attempted to govern neither through centrally controlled bureaucracies (hierarchies) nor through competitive interactions between producers and consumers (markets), but through such self-organizing networks" (Barry, Osborne, Rose, 1996, 10). Although using neo-Gramscian and Foucauldian theories creates an excellent base for analysis, what is missing from these theories is the important role that scale takes in an ever-globalized and neoliberal era. 


\subsection{Scalar Analysis}

Throughout the study of political economy, many theorists are realizing that it is "increasingly impossible to explain social developments in non-spatial terms and to devise appropriate strategies for social change if space itself is treated as an unproblematic category" (Keil \& Mahon, 2009, 7). Scalar analysis thus deals with this barrier by rethinking the conventional understanding of scale, viewing it as "socially produced and reproduced through a myriad, sometimes purposeful, sometimes erratic, social, economic, political, and cultural actions" (Keil \& Mahon, 2009, 8), therefore being "both the result and the outcome of social struggle for power and control" (Swyngedouw, 1997, 140). It is important to consider the "relativisation of scale," which means to look at scale in terms of other scales (Keil \& Mahon, 2009, 8, 12) and to recognize it as being "highly fluid and dynamic." Scale is "produced, conflictual, and contested" and "embodies and expresses power relationships" (Swyngedouw, 1997, 140).

The political economy of scale understands hierarchy as consisting of five main elements (Keil \& Mahon, 2009, 17). First the "units are not fixed but are mutable" thus being "shaped and reshaped by socioeconomic processes and political struggles" (Keil \& Mahon, 2009, 17). Second, "causality does not begin at the smallest scale but runs in all directions" (Keil \& Mahon, 2009, 17). Third, there are a multiplicity of hierarchies, rather than one single hierarchy, because "processes of scalar structuration do not produce a single nested scalar hierarchy, an absolute pyramid of neatly interlocking scales, but are better understood as a mosaic of unevenly superimposed and densely and interlayered scalar geometries" (Brenner, 2001, 606). Fourth, "while there may be a plurality of hierarchies, pluralism does not prevail" (Keil \& Mahon, 2009, 18). Finally, "it is possible 
and desirable to ask how scaled processes can be shaped in ways that promote equality and democratic control" because "dealing with the world 'as it is' does not rule out thinking about the way the world ought to (and can) be" (Keil \& Mahon, 2009, 18). Scalar analysis is thus important to understanding scale as a process that is produced with "direct implications for the constitution of social struggle, in terms of both setting the 'rules of the game' and shaping the capacities of agents and institutions to effect change" (Miller, 2009, 62). Analyzed below in the discussion on resistance, it can also be concluded that through strategies, such as "scale jumping" (Smith, 1992), scale can also be used as a form of resistance. This new understanding of scale, combined with a neoGramscian and Foucauldian understanding of hegemony and discourse, can provide a comprehensive framework for analyzing the present political-economic era of neoliberalization.

\subsection{Combining Theories in Neoliberalization}

Since its emergence into the national and international political-economic sphere in the 1970s, neoliberalization has shifted from being a form of reactive politics concerned with the "active deconstruction and discreditation" of Keynesianism to the now "purposeful construction and consolidation of neoliberalized state forms, modes of governance, and regulatory relations" (Peck \& Tickell, 2002, 383). Holding the status of the "most powerful ideological political project in global governance to arise in the wake of Keynesianism" (McCarthy \& Prudham, 2003, 275), neoliberalization has managed to penetrate all aspects of political, economic, and social relations due its incessant ability to adapt and shift in ways that allows it to reproduce and spread across national and 
international spheres. Thus, on the one hand, neoliberalization is clearly defined as "the doctrine that market exchange is an ethic in itself, capable of acting as a guide for all human action" (Harvey, 2005, p.i), made up of an assemblage of ideological commitments and institutional practices rooted in the Washington Consensus including: the self-regulating market, trade liberalization, deregulation, limited state involvement, excludable private property rights, and homo-economicus (McCarthy \& Prudham, 2003). On the other hand, neoliberalization is not homogenous in all of these qualities, but instead acts as "a constantly shifting landscape" of experimentation and restructuring (Peck \& Tickell, 2002, 396). Thus, although Harvey originally associated neoliberalization with the "rolling-back" of the state and de-regulation, due to the analyses of theorists such as Peck and Tickell, it is now understood that "in practice neoliberalization has produced significant re-regulation: new rules, new rule-making bodies, and new spheres of rule making" (Guthman, 2007, 466) in this new wave of "rollout neoliberalization" (Peck, 2002, 336). Guthman describes these new rules and forms of regulation as a "bait and switch, allowing the appearance of no government when, indeed, the state has grown considerably and society is more rule-bound than ever" (Guthman, 2007, 466). An important aspect to this new era of neoliberalization is the redefined role of the state.

Theorists such as Peck and Tickell and Miller, have added to this discussion by demonstrating the way that state responsibilities and capacities have been rescaled, awarding the state the role of facilitator (Miller, 2009, 59). The tendency to view state and provincial borders as mostly fixed, has been replaced with an increased hybridization of jurisdiction and control between different levels of government and non-state 
organizations (Amin, 2002, 396) and the "permeability of state borders, however, changes with regulatory regimes" (Miller, 2009, 60). In this new era "local institutions and actors are being given responsibility without power" and "international institutions and actors are gaining power without responsibility" (Peck and Tickell, 2002, 386). In order to sufficiently analyze the power dynamics that are involved in understanding the state as a "scale manager," it is important to view the state's interest as "part of a machine," rather than viewing it as holding a hidden agenda, which would narrow the analysis too much (Li, 2007, 8-9). Dunn furthers this thought looking specifically at the state's use of tools of governance, explaining that it is not the state's primary intention to limit small-scale production, nevertheless, they do recognize that it is happening and continue to follow through their agenda (Dunn, 2005).

A key factor to the state's ability to govern and play the role of facilitator in the era of neoliberalization is the use of what has been termed "tools of governance" (Dunn, $2005,186)$. Drawing on Foucault's analysis of discourse and governmentality, 'tools of governance' allow states to "govern individuals without violating their formal rights to autonomy, and control enterprises without impeding their abilities to act in an open market" (Dunn, 2005, 186). This employs Foucault's discussion of 'acting at a distance' reflecting the argument that "when power operates at a distance, people are not necessarily aware of how their conduct is being conducted, or why, so the question of consent does not arise" ( $\mathrm{Li}, 2007,5)$. One type of 'tool of governance' that can be used to understand governance through the use of regulatory structures is the concept of "boundary objects" or "immutable mobiles" (Dunn, 2005; Ransom, 2006). Boundary objects are defined as objects that are transferred from one community to another, thus 
having "transformative effects without being transformed themselves" (Dunn, 2005, 176177). This ability to transfer standards from one geography to another not only allows for regulations to cross scales from the supranational to the individual (Dunn, 2005, 180, 186), but, in terms of state capacities, "powers, functions, and roles migrate (literally) downward to local and regional bodies, upward to translocal and transnational networks" (Peck, 2002, 339). This can be understood through the scalar analysis' term "scale jumping" or "scale shifting," which is becoming more widely recognized as one of many strategies used by both political and social groups in contentious politics (Miller, 2009, 54). Miller explains that "through constitutional, legislative, judicial, administrative, and fiscal measures, higher-level institutions can establish and delimit the scope and policy and action at lower-level scales, enabling or preventing the implementation of democratically made decisions" (Miller, 2009, 55). Peck discusses this phenomenon stating that "highly exposed localities are pitched in an asymmetrical competitive battle against an unyielding global market, their only realistic response being to adapt" (Peck, $2002,334)$. The use of 'tools of governance' and the acceptance of 'boundary objects' have played a key role in the government strategies of risk management.

Tactics of risk management reflect Foucault's concepts of jurisdiction and veridiction in the ways that scientific discourse has become increasingly adopted into policy-making because of its ability to make risks manageable and to support and legitimize political decisions. First, using science in risk analysis techniques transforms risk into something that is manageable (Andrée, 2007, 77), thus transforming a dangerous and uncertain situation into one that can be rationally overcome. Second, science can be used to justify and legitimize chosen policies, in which case advisors are not chosen for 
advise, but instead for authoritative support for policies (Van Zwanenberg \& Millstone, 2005, 27). Despite risk management being presented as objective, this paper defines it as highly subjective, being used by policy makers to justify normative positions by adopting language and tools of science, resulting in "questions of value" being debated as “questions of fact" (Andrée, 2007). Tania Murray Li's understanding of improvement adds to the discussion of risk management, identifying two necessary practices for government action; problematization and rendering technical $(\mathrm{Li}, 2007,7)$. These two practices are connected since identifying a problem is connected to the availability of a solution and rendering technical de-politicizes the problem $(\mathrm{Li}, 2007)$. Explaining 'rendering technical' as a reflection of a whole set of practices concerned with representing "the domain to be governed as an intelligible field with specifiable limits and particular characteristics" (Locher-Scholten, 107) connects the authority given to scientific discourse in risk management and the ability to then remove items from the realm of politics, labeled as the anti-politics, as a deliberate measure to limit debate and "contain a challenge to the status quo" $(\mathrm{Li}, 2007,8)$

Peck, Tickell, Barry and Beck have added to this discussion of governance and discourse by understanding the ways that "an increasing importance of measurement and information in the economy" has adopted a dominant role in discourse and has arguably had "anti-political effects" (Barry, 2009, 279). Barry builds on Foucault's understanding of jurisdiction and veridiction to analyze the ways that the delegation of government qualities to "experts" has suppressed "potential spaces of contestation; placing limits on the possibilities for debate and confrontation" and in doing so has reduced "the potential space of political conflict" (Barry, 2009, 270, 273, 280), which Beck terms "high 
politics". Hubert Dreyfus and Paul Rabinow add to this discussion explaining the ways that 'high politics' is self-reinforcing and that "resistance, or failure to achieve a program's stated aims, comes to be "construed as further proof of the need to reinforce and extend the power of experts" (Dreyfus and Rabinow, 1982, 196). The internalization of scientific norms across many industries and governments has "empowered those with technical resources in this area of truth, according governments, corporations, intergovernmental bodies, and universities with the financial resources and skills needed to undertake scientific research" an element of authority that awards their interpretations of risk and the management of risk a strong position in the development of regulations and policy (Andrée, 2007, 76).

Analyzing regulatory policies from this perspective allows us to revisit topics that have been superficially depoliticized and attained a "privileged status of a taken-forgranted or foundational policy orientation" when in reality a "deeply interventionist agenda is emerging" (Peck, J. \& Tickell, A, 2002, 389). Through a discourse analysis, one can critically examine the authority awarded to scientific discourse, and the ability for states with a strong neoliberal agenda to use such discourse to indirectly promote their economic agenda, through "metaregulation" while simultaneously defining themselves as anti-regulation (Peck, J. \& Tickell, A, 2002, 400). The authority of "experts" and consequential anti-political effects, combined with the above discussion of the shifting and re-scaling of responsibilities and power has meant that neoliberalization has "demonstrated an ability to absorb or displace crisis tendencies, to ride - and capitalize upon - the very economic cycles and localized policy failures that it was complicit in creating, and to erode the foundations upon which generalized or extralocal resistance 
might be constructed" (Peck and Tickell, 2002, 400). Although neoliberalization has, on the one hand, been able to use its self-created crises to further its agenda, the dynamics of the neoliberal structure has also led to new spaces in which resistance can be formed and awarded new authority to social movement organizations (Peck J \& Tickell, 2002).

Before moving on to a discussion of resistance within neoliberalism it is important to point to a new era of "hang-over" neoliberalism that has been suggested by Peck, Theodore, and Brenner, termed "Zombie neoliberalism" (Peck, Theodore, \& Brenner, 2009). Responding to the claims that the 2008 financial crisis would signal the "Berlin wall moment" of neoliberalism, it is argued that neoliberalism is far from dead, but is instead entering a "living dead" phase, in which "residual neoliberal impulses are sustained not by intellectual and moral leadership, or even by hegemonic force, but, by underlying macroeconomic and macroinstitutional conditions" (Peck, Theodore, \& Brenner, 2009). Neoliberal tendencies have been embedded so deeply in systems, institutions and discourses, that they are capable of recreating the neoliberal order, despite any clear driver. Although this is a valuable insight which will be analyzed further throughout this paper, it is also important to note that despite expressions of "Zombie Neoliberalism" we are nevertheless experiencing remnants of the old system.

\subsection{Response and Resistance}

The combination of Foucauldian, Neo-Gramscian and scalar theories can provide a useful framework for understanding resistance under neoliberalism not in a way that presents a clear and structured understanding of resistance, but instead as a way of demonstrating 
and tolerating the "untidiness" $(\mathrm{Li}, 2007)$ and complexity that is central to the current era of neoliberalization.

From a Foucauldian perspective, societal change requires an understanding of a distinct government rationality that is not in the pursuit of one dogmatic goal, but instead a "whole series of specific finalities" that must be achieved through "multiform tactics" (Foucault, 1991, 93). For Foucault a "program of intervention is not invented ab initio" and is "not the product of a singular intention of will," but instead "draws upon and is situated within a heterogeneous assemblage or dispotif that combines" (Li, 2007, 6) "forms of practical knowledge, with modes of perception, practices of calculation, vocabularies, types of authority, forms of judgment, architectural forms, human capacities, non-human objects and devices, inscriptions, techniques and so forth" (Foucault, 1980, 194).

Rather than seeing resistance as encompassing one dogmatic goal, Foucault sees it as a series of finalities (Li, 2007, 6). For Foucault the problem is not "changing people's consciousness... but the political, economic, [and] institutional regime for the production of truth" (Foucault, 1980, 133). Although this is an important and valuable insight, on its own it does not lend well for the purposeful organization of resistance, thus this paper will also draw on insights of Antonio Gramsci "to attend to the ways people become mobilized to contest the truths in the name of which they are government, and the change the conditions under which they live" $(\mathrm{Li}, 2007,6)$.

Gramsci understands resistance as the amalgamation of coercion and consent $(\mathrm{Li}$, 2007) in the realm of counter-hegemonic politics. A counter-hegemony requires what Gramsci terms a "war of position" that is "waged in every sphere of society and at every 
level of intervention" $(\mathrm{Li}, 2007)$. "Trench warfare" reflects an important aspect of wars of position, explaining that struggles are both offensive and defensive, in which the key terrain for trench warfare is in the realm of ideas and beliefs (Adkin, 2009). A "war can only be won by the efforts of countless individuals who sacrifice, plan, and work for every advance" (Adkin, 2009, 13). As mentioned above, 'historical blocs' play an important role in trench warfare as "the main tasks of the counter-hegemonic forces are to call into question the legitimacy and naturalness of the ruling order and to replace these with a vision and a program of their own" $(\mathrm{Li}, 2007)$. Gramsci

considered the fundamental groups driving social transformation to be classes differentiated by their access to the means of production. Yet he understood that the actual social groups engaged in situated struggles are far more diverse, reflections of their fragmentary experiences, attachments, and embedded cultural ideas. Thus for him, the question of how a collective, critical practice emerges could not be answered with reference to abstract concepts such as labour and capital. It had to be addressed concretely, taking into account the multiple positions that people occupy, and the diverse powers they encounter. ( $\mathrm{Li}, 2007)$

Thus a Gramscian approach to resistance must take into account the three sets of relations of force - material, institutional and discursive - (Gramsci, 1971) and movements of resistance must reflect these realms by being "specific, situated, and embodied" ( $\mathrm{Li}$, 2007).

A scalar analysis demonstrates neoliberalism's ability to capitalize upon the economic and policy failures that it was complicit in creating, and to limit the avenues in which resistance might take place (Peck J \& Tickell A, 2002). However, it can also be used to understand the ways in which scale has opened new avenues for resistance. A scalar approach offers a way in which resistance can be organized that will support a network of local abattoirs. The concept of "jumping scale" points to the ways in which 
social and political groups can shift scales, either upwards or downwards, as part of resistance strategies to challenge existing power relations in contentious politics by bringing in, or excluding, contestants and resources (Keil \& Mahon, 2009, 19; Miller, 2009; Smith, 1992).

Peck and Tickell further the discussion about resistance within the neoliberal age stating that "while one of the partial conspicuous strengths of roll-back neoliberalization was its capacity to disorganize sources of (actual and potential) political opposition, rollout neoliberalization is becoming just as conspicuously associated with disruption and resistance, as the process of deep neoliberalization has created new basing points, strategic targets, and weak spots" (Peck J \& Tickell A, 2002, 399). Despite these new avenues for resistance, neoliberalization has nevertheless shaped the relations of power within which resistance takes place (Peck, Theodore, \& Brenner, 2009). This final point reflects Guthman's discussion of the tendency for social movements to adopt specific neoliberal tactics and language that are valued within neoliberal discourse and economic structures (Guthman, 2007). For example, social movement organizations looking to affect policy change must often adopt scientific language and market-based strategies into their struggles, thus running the risk of further solidifying and reproducing the very order that has caused their plight in the first place (Guthman, 2008). Not only does the adoption of dominant discourses hold the risk of reproducing the dominant order, but also "neoliberalism's view of the good citizen (the self-reliant individual) which equates individual autonomy with independence from the state and fails to recognize relational identities or social solidarities" (Adkin, 2009, 4). Barry and Adkin add to this discussion 
by suggesting ways in which, this reproduction can be avoided by engaging in radicalized oppositional practices.

In reference to "green states" Barry argues that resistance must entail informed and radicalized citizens and their oppositional practices, which include civil disobedience (Barry J, 2006). Adkin furthers this point by highlighting the importance of "active participatory politics that take place in the public sphere - including non-violent direct action - are absolutely central to any conception of an environmental citizen" (Adkin, 2009, 6). She refers to Gilbert and Phillips,' arguing that 'citizenship should be critically understood not only as rights granted by a government, but also as practices through which the limits of established rights are (re)defined and (re)affirmed... citizenship is therefore not only a set of formal rights, but rather is a continual process of construction and constitution" (Adkin, 2009, 14) using environmental struggles to identify the ways in which "democracy must be extended or radicalized" (Adkin, 2009, 14). Andrée has also used the realm of environmental politics to analyze the role of resistance under neoliberalism.

Despite the challenges present under neoliberalization, academics such as Andrée have demonstrated that by recognizing the centrality of political economy one can examine "broader range of political and economic forces to understand both contextual factors and social movement organization (SMO) pathways of influence" (Andrée, 2011, 184, 175). Drawing on the discussion above of new avenues for resistance under neoliberalism, Andrée points to the power of SMOs, which can be defined as social groups that pursue broad agendas of social change with the intention of transforming modes of production and consumption, as well as social organization, values and personal 
lives (Ford 2005; Magnan, 2007). Andrée argues for the incompleteness of hegemony, illustrating that "Gramsci's integral state is also potentially a divisible one in times of conflict" (Andrée, 2011, 186). Addressing the non-State academics and expert bodies as part of the regulatory arms of the "integral state," Andrée demonstrates ways in which SMOs can shift the formal response of the coercive arms of the State itself (Andrée, 2011, 186). Looking at the adoption of multiple strategies in the forms of material, organization and discursive tactics and their interrelations, Andrée demonstrates that by forming wider alliances of SMOs and developing broad bases of public support, counterhegemonic groups can shift the outcome of a debate (Andrée, 2011). Andrée also points to the importance of engaging academics and scientific bodies in the counter-hegemony (Andrée, 2011, 182). Finally, Andrée also draws attention to the power of material forces, noting that "any political project requires appropriate material relationships to underpin it" (Andrée, 2011, 181). In using the context of environmental politics, Andrée has thus outlined some key avenues that can be targeted for effective resistance in the neoliberal era, which can also be used in the analysis of responses to the implementation regulatory systems. Before concluding this chapter, it is important to briefly outline the discourse and theoretical concept of food sovereignty.

\subsection{Food Sovereignty}

The term "food sovereignty" was brought into the international realm by La Via Capensina (a global peasant movement), and was later supported and adopted by Canadian food organizations such as the National Farmers Union (NFU). It was initially defined as "the right of each nation to maintain and develop its own capacity to produce 
its basic foods, respecting cultural and productive diversity" (Desmarais, 2007, p.34). This definition was expanded in 2000 to include the "right of peoples to define their agricultural and food policy". (Desmarais, 2007, p.34). Starting in 2007, Food Secure Canada - Sécurity Alimentaire Canada (FSC-SAC), an umbrella organization for the community food security movement, has worked alongside left-leaning farm organizations, anti-biotechnology activists, international solidarity non-governmental organizations and the newly formed People Food Policy Project (PFPP) to integrate this definition into their policy positions (Kneen, 2010). Food sovereignty has come to mean a variety of different things to different people. In $\mathrm{BC}$ it has been associated with a variety of factors including the right to maintain a rural lifestyle on a small-scale mixedfarm, the maintenance of skills and knowledge, a way of assuring animal diversity and welfare, and a way of engaging in resistance to industrial agriculture and supporting environmentalism. As a discourse and theoretical concept, it has informed this research, as well as offering a potential link between the MIR in BC, and the large global movement.

\subsection{Conclusion}

This chapter has used existing literature and previous case studies to bring together Gramscian, Foucauldian, and scalar theory in the context of neoliberalization and resistance. These authors touch on many factors that appear to be relevant to regulatory systems, showing that the combination of these theories could prove useful for better understanding the dynamics associated with meat regulation in Canada and specifically the MIR in BC. The discourse of food sovereignty, not only appears to tie the case of the 
MIR to a larger global movement, but has also, as a theoretical concept, informed the research process and the approach taken to this study. This theoretical framework will allow for a deeper understanding of the power relations that have not only shaped the implementation of the meat regulation in $\mathrm{BC}$ and Canada, but have also shaped the avenues for resistance. 


\section{Chapter: Small-scale Agriculture in BC Before and After the MIR}

\subsection{Introduction}

British Columbia's rural and agricultural landscape reflects a diverse range of lifestyles, business operations, economies, and communities. This chapter explores the empirical realities of the MIR in the context of Alternative Food Networks (AFN) and the previous regime for meat production in $\mathrm{BC}$, which will then be unpacked theoretically in chapters four and five. This is demonstrated by first looking at meat production in the Canadian context, discussing the shift to large-scale agriculture and the resiliency of small scale abattoirs. The chapter then looks at BC's agricultural landscape and the central role of small-scale agriculture and AFNs, reflecting discourses of food sovereignty. The chapter then outlines the three options that were available to producers and processors upon the enactment of the MIR, as well as discussing the devastation that the MIR caused throughout $\mathrm{BC}^{\prime}$ 's rural and agricultural communities. The chapter begins by looking at meat production in the Canadian context.

\subsection{Meat Production in the Canadian Context}

To fully understand the case of the MIR, it is important to first understand the central role that small-scale abattoirs play in the Canadian context. Small-scale abattoirs' role has shifted throughout Canada's agricultural history due to the effects of past and present realities, discourses and organizations relating to the production, processing, distribution, and consumption of meat. This section illustrates the small-scale abattoir's role in 
Canadian context through a discussion of: the shift to large-scale, specialized, industrialized, and market-oriented agriculture; large-scale slaughter and processing; large-scale production; and the resiliency and value of small-scale agriculture.

Over the past century Canada has seen a drastic shift in the way meat is produced and processed. Historically Canadian demographics, which comprise a small population spread over a vast geographic space, has encouraged small-scale and locally oriented slaughter (MacLachlan, 2001, 136). This trend changed drastically in the 1950s and 60s due to increased export to Britain, at which point government regulation and Henry Ford's influence on the disassembly of livestock encouraged rapid agricultural industrialization and specialization throughout Canada's meat industry (MacLachlan, $2001,8,136,137)$. This push to increase production capacity to meet export demands continues to be a priority of the federal government and large-scale industry, and is encouraged by powerful lobbying campaigns, such as the Canadian Federation of Agriculture's 2011 National Food Strategy (CFA, 2011). Economies of scale have become vital for cattle production, slaughter and processing, and following trends in the United States, Canada's meat industry has become highly concentrated (MacLachlan, $2001,60)$

At the producers' end, 70\% of Canada's beef cattle are now grain finished in Alberta feedlots. Feedlots consist of a grid of pens that each hold up to 250 animals, with larger feedlots having a one-time capacity of 25,000 or more cattle, their sole purpose being to feed cattle (MacLachlan, 2001, 6, 52). These "agricultural enterprises" are more like commodity trading than farming with the "commodity chain of cattle" or "beef complex" involving a number of highly specialized activities, each with its own 
geography - the same animal can change owners up to six times before slaughter (MacLachlan, 2001, 87, 89). This has led to a series of health and environmental concerns for local residents due to manure management, odor, and water pollution (MacLachlan, 2001, 79, 80).

This shift to large-scale feeding operations runs alongside a shift to large scale slaughtering and processing operations. The small-scale slaughter and processing facilities are rapidly vanishing and being replaced by "an aggressive new generation of packinghouse titans" that can process 20,000 or more head of cattle each week, with a total of 650 million animals being slaughtered every year in Canada (MacLachlan, 2001, 213; Global Action Network, 2011). Canada's slaughtering and processing industry is dominated by three large companies that control $89 \%$ of Canada's beef processing market is (National Farmers Union, 2008). This shift towards large-scale industrialized agriculture and meat processing has not only altered farming practices, but has also enormously affected the structure of rural communities and Canadian consumption patterns.

Despite the drastic increase of agricultural enterprises, there is still a significant level of on-farm slaughter and butchering, as well as hundreds of small- and mediumscale packing plants in Canada (MacLachlan, 2001, 165-166). These plants typically kill a mixture of species and combine custom killing with livestock purchasing on their own account, often serving local and niche markets (MacLachlan, 2001, 166). In these plants, often run as family businesses, employees tend to share many social and family ties and have close relationships to their customers and communities (MacLachlan, 2001). 
Small-scale plants are able to compete with large-scale processing plants because of their flexibility and ability to respond to the specialized needs of their customers (MacLachlan, 2001, 168). Rather than competing in the same markets as large firms, small- and medium-scale abattoirs are instead often part of strong localized economies that market to regions within a radius of 200 kilometers (MacLachlan, 2001, 168). These meat packers tend to sell to consumers who prefer to buy their meats fresh at the point of slaughter, not only for reasons of quality and health, but also for reasons of environmental sustainability, animal welfare, and community capacity (MacLachlan, 2001, 168).

The values and reasons behind localized food production are shifting and this form of agriculture and lifestyle now represents a form a resistance to industrialized agriculture, as well as a way of building capacity in communities and ensuring food security in the case of a food crisis (I-33, 2011). Although we are seeing a rapidly aging population of farmers, we are simultaneously seeing a new movement in which the younger population entering farming is interested in organic and sustainable farming as an alternative to large-scale industrialized agriculture. In order for this strong form of resistance and community capacity to exist, it is necessary that the links in the food supply chain remain strong.

The implementation of more stringent regulations has created challenges for abattoirs across the country. The recent enactment of the Meat Inspection Regulation (MIR) in BC has led to the loss of two-thirds to three-quarters of its abattoirs (BCFPA, 2008), leading to a decrease of small-scale farming and a re-adjustment of BC's rural 
economies, communities, and traditions. Before discussing the enactment and outcome of the MIR, this chapter first looks at BC's meat landscape prior to the MIR.

\subsection{The Role of Small-Scale Agriculture and AFNs in BC}

Small-scale agriculture and AFNs play a central role in the sustainability of rural and agricultural communities throughout $\mathrm{BC}$, reflecting both discourses of food sovereignty and the emergence of a food sovereignty movement. Small-scale agriculture and AFNs reflect discourses of food sovereignty through lifestyle choice, the protection of plant and animal diversity and welfare, the maintenance of skills and knowledge, resistance to industrial agriculture, environmentalism and emergency preparedness. Before looking at these reflections of food sovereignty, it is important to draw out the important role of small-scale abattoirs in BC's rural and agricultural communities.

The scales of livestock agriculture in $\mathrm{BC}$ vary widely. The province is home to Canada's largest cattle feedlot as well as a significant number of small- and mediumscale farms. For example, BC is home to Canada's largest ranch, holding 15,000 head of cattle, as well as many thousand-head ranches, and over two thousand 5-10 head ranches (I-16, 2011). In terms of slaughter and processing capacity, a community-based BC abattoir may slaughter approximately 1,500-2,000 head of cattle a year, compared to Canada's two largest packing companies, Cargill and XL that can slaughter 4,500 in a single day (I-25, 2011).

Out of the 20,000 farms in $\mathrm{BC}, 15,000$ of them are defined as small-scale or hobby farms. In terms of livestock, 2,000 of the 4,000 beef producers in $\mathrm{BC}$ are small scale, producing only 5-10 head a year. Although this demographic of farmers is quickly 
aging and farmers are retiring, there has also been a resurgence of farmers who have chosen to adopt the mixed-farming system as a form of food sovereignty and resistance to the negative environmental, health, and social issues that have been attributed to largescale industrial agriculture. Taking into account this unique livestock agricultural landscape, $\mathrm{BC}$ 's meat producers and processors have functioned without a provincial meat inspection system, avoiding the stringent and standardized regulatory systems that have led to the loss of small- and medium-scale abattoirs throughout the rest of Canada.

Small-scale abattoirs play a central role in BC's rural and agricultural communities due to their ability to respond to the diverse and unique needs of producers and consumers. Although large-scale beef packing operations have become more specialized, allowing for an increased production capacity, this has also meant that they are "anything but flexible" (MacLachlan, 2001, 288) and are unable to meet the needs of small-scale and alternative producers. For example, large-scale abattoirs are unable to follow the procedures necessary for organic certification, nor are they able to guarantee that the same animal will be returned to the farmer (I-18, 2011). Furthermore, many small-scale operations fit perfectly with the unique needs of rural lifestyles. For example, abattoirs that are seasonal and part-time and can complement BC's unique demographics that are well suited to seasonal livestock production (I-25, 2011; I-27, 2011; I-26, 2011). This means that, although small-scale abattoirs do not necessarily follow standard fulltime business models that require a reliable and steady source of input, in the case of many alternative food networks the seasonality compliments the part-time work needed by ranchers in the community, as well as supplementing their income and providing a cheap way to process their animals $(I-27,2011)$. Not only do small-scale abattoirs play a 
central role in the sustainability of BC's rural and agricultural communities, but they also, in turn, allow for the expression of food sovereignty in a variety of different ways.

Central to the discourse of food sovereignty in $\mathrm{BC}$ is the maintenance of the lifestyle and type of farming of one's choosing. Producers explain that "it's not a ticket to heaven, but it's a way of life and it's a lifestyle choice" $(I-33,2011)$ that "has everything to do with local agriculture" and feeding neighbors, friends and family. (I-21. 2011). One producer explains that his lifestyle reflects "every person's right to grow and produce their own food" (I-28, 2011). Finally, consumers reflect discourses of FS, with a local politician stating that "this is about community, it's about resiliency to climate change, it's about resiliency period, it's about food security, it's about a lifestyle, it's about good food, it's about choice. It's about a whole lot of things" (I-23, 2011). Central to this lifestyle is self- (or community-) sufficiency, in which on-farm slaughter is central.

For a number of reasons, producers choose to slaughter livestock on-farm and the importance of maintaining this right is central to BC's food sovereignty movement. There are various reasons why producers refuse to bring their animals off-farm for slaughter, including cost, time and animal welfare. Transporting the livestock is costly in terms of time and money, and these challenges are exacerbated in remote and isolated regions (I30,2011 ). This is not only stressful on the farmer, but it is also very stressful on the animal, which is a concern for farmers in terms of both animal welfare and the quality and quantity of the meat $(\mathrm{I}-28,2011, \mathrm{I}-21,2011)$. For these reasons many farmers have always had their animals slaughtered on farm because it provides a low-stress kill (I-28, 2011, I-21, 2011). This connects to another expression of food sovereignty, which is plant and animal welfare and diversity. 
In $\mathrm{BC}$, food sovereignty is reflected through the right to maintain high standards of animal welfare and the diversity of increasingly endangered breeds of animals and plants. Simultaneous to the large-scale industrial push towards "cookie cutter chickens," (I-33, 2011) food sovereigntists in British Columbia have chosen the mixed farm model as a way to protect and encourage animal diversity and the maintenance of rare breeds. Many small-scale producers in $\mathrm{BC}$ also strive to achieve a standard of animal welfare that cannot be achieved through industrial agriculture. Several farmers describe that when they kill their animals "their heads are down, they are eating grass" (I-21, 2011) and it is done in a way that is quick, respectful and caring $(I-33,2011)$. "We may eat less animals, but the ones we do eat will be raised in ways that we will all be happy and proud of' (I$33,2011)$. These relationships to plants and animals are dependent upon the maintenance of unique skills and knowledge.

Food sovereignty in $\mathrm{BC}$ was expressed through the maintenance of valuable and unique skills, which are being lost due to an aging population of small-scale farmers and an increasingly industrializing agricultural sector. One small-scale farmer explains that "when the ability to grow your own vegetables is lost, the knowledge is hard to get back" (I-33, 2011). This knowledge is not only being lost due to an aging population, but also due to technological change in large-scale industrial kill floors which has replaced the need for skilled tradesmen with jobs that involve a singular task along a disassembly line (MacLachlan, 2001, 234). Developing programs and strategies to share and pass on this knowledge has increasingly become a focus of the food sovereignty movement and passion of small scale farmers (I-33, 2011). The maintenance of skills and knowledge is 
also seen as a form of resistance to industrial agriculture and as a strategy for food security in the case of emergency.

Finally, food sovereignty was expressed as a form of resistance to industrial agriculture by maintaining the right to grow and eat good quality food, promoting environmentalism and maintaining food security in the case of emergency. As resistance to industrial agriculture, one small-scale farmer described mixed farming and seed saving as "a strike back at the domination by Monsanto" (I-33, 2011). AFNs and niche markets allow for small-scale farmers to exist despite the dominance of large-scale agriculture. Furthermore many small-scale producers, processors and consumers equate large-scale agriculture with the outbreak of food-borne illnesses that have plagued national and international markets, and view AFNs as resistance to this trend. One producer argues that "We are being poisoned on every level, and it is time people got control of their food" (I-33, 2011). A large part of this resistance reflects environmentalism and alternatives in the case of natural of systemic disasters.

Many small-scale producers view farming practices as environmental resistance, with decreased levels of transportation being central to this movement. One processor prides himself on the fact that $99 \%$ of his product will stay within 50 miles of his facility (I-28, 2011). Other producers view farming practices as part of a holistic system that promotes healthy and sustainable environments (I-13, 2011; I-33, 2011). Furthermore, British Columbians are increasingly recognizing the value of local agriculture as a form of emergency preparedness in the case of food-borne-illness outbreaks, natural disaster, or the demise of long-haul transport. This concern is magnified in BC's remote regions, where challenges due to isolation have given an extra initiative to develop strong and 
local food networks in the case of emergency. The Gulf Islands, for example, are only accessible by ferry, yet large distributers import approximately $95 \%$ of their food (Reichert, 2006). The Emergency Planning Operations estimates that in the case of an earthquake or other such disaster that may disrupt ferry service, the island only has enough food to last about 3 days (Reichart, 2006, p.14). Under these circumstances community farming is recognized as playing a very valuable role, not only as a fall back in the case of disaster, but also for fear of the demise of long-haul fossil-fuel dependent agriculture. Therefore small-scale abattoirs have come to play a central role in the sustainability of rural and agricultural communities throughout $\mathrm{BC}$, reflecting both discourses of food sovereignty and an emerging food sovereignty movement, for reasons including the ability to meet the diverse and unique needs of small-scale and specialized producers and markets, the protection of plant and animal diversity and welfare, the maintenance of skills and knowledge, as resistance to industrial agriculture, environmentalism and emergency preparedness. These expressions of food sovereignty were suppressed almost overnight with the enactment of the Meat Inspection Regulation (MIR).

\subsection{The Enactment of the MIR and its Effects}

The MIR required that all meat and meat products be processed in licensed slaughter establishments, and retracted the right to on-farm slaughter, severely limiting the sustainability of AFNs across the province. Furthermore, the stringent standards that the MIR demanded of abattoirs not only forced many operators to upgrade to a size that was disproportionate to their targeted market, but also downloaded unnecessary costs that hampered their financial sustainability and forced two-thirds to three-quarters of abattoirs 
to shut down. This loss of both producers and processors has been devastating to BC's rural and agricultural communities, as well as suppressing the right to food sovereignty.

Operators who decided to comply with the regulations were faced with a series of requirements that meant they would have to either upgrade their existing facility, or build a new one. The costs involved in doing this were so high that an industry consultant recognized that many small-scale abattoirs would be forced to shut down $(\mathrm{I}-25,2011)$. Nevertheless, many operators decided to attempt to transition into a licensed facility. One owner who came together with a cooperative of ranchers to build a facility in order to support their regional producers ultimately spent 1.5 million dollars building an abattoir and meat processing facility (I-27, 2011). Another operator claims that although his original budget was $\$ 300,000$, he ended up spending just over $\$ 1.5$ million building his slaughter and processing facility. Those who chose to upgrade their facility rather than building one from scratch found themselves spending between $\$ 80,000$ and $\$ 500,000$ (I20, 2011; I-27, 2011; I-24, 2011; I-26, 2011), and a consultant estimates that "a basic upgrade is probably about $\$ 350,000$ no matter which way you jump, and it goes up from there" (I-25, 2011). The majority of the costs that were downloaded onto the individual included cosmetic upgrades, water, the disposal of waste, mobile abattoirs, and costs associated with the needs of inspectors ${ }^{10}$. Taking into account these costs, abattoirs in the province were left with three options: upgrade, go underground, or shutdown (I-25, 2011).

The operators who decided to go through the process of upgrading, all faced high financial and personal costs during the process. When operators brought their building

\footnotetext{
${ }^{10}$ See Appendix $\mathrm{C}$ for details of the requirements in each of these three categories
} 
plans to the CFIA, many were told that their planned facility, which was purposefully designed small in order to match the demand of the small-scale economies of their regions, was too small or inefficient and were sent away to have their plans redrawn to meet criteria that were acceptable to the CFIA, with no regard to the size of market that these operators intended on serving (I-29, 2011). Of the operators interviewed, only one was able to finally draw sufficient slaughter plans to demonstrate to the inspectors that his small scale operation could work effectively and efficiently. Other operators were forced to 'go big,' building an operation that was much larger than initially intended, not only adding unanticipated costs (in one case $\$ 1.5$ million rather than $\$ 300,000$ ) but also undergoing extreme challenges along the way $(I-29,2011)$. Another operator explains that financial institutions told him he couldn't solely build an abattoir but would also have to build a value added meat processing plant, claiming that that was where the money would be made $(I-27,2011)$. He explains that being pushed into building a large facility "snowballed and went off the rails," growing bigger than its market could handle (I-27, 2011). Another operator explains that

we became a bit of a testing ground for who was able to exert the most authority over what we were doing... We were the first ones out of the gate and it was a bit of a political pissing match really between the different government agencies and who was going to exert the most authority over us and we were the ones who had to pay the bill at the end of the day. It pushed us from being a plant that was originally designed to be much smaller... to being a plant that had to be bigger just to get enough chickens throughout to pay the bills. So the size of this business was dictated by what happened at the time. (I-19, 2011)

This process changed the initial design and function of the plant from being one that would serve as a custom processor to provide the necessary services to the farms on Vancouver Island and the Gulf Islands, into a facility that was forced to access commercially raised lines of birds from the bigger growers in order to provide enough 
input for the excessively large plant $(I-29,2011)$. Therefore, these two operators were both forced to build a facility into a larger scale than intended, not only forcing them through unnecessary personal and financial upheaval, but also leaving them with insurmountable amounts of debt (I-27, 2011; I-29, 2011). Other producers and processors, who found upgrading unfeasible, were forced underground.

There were two separate groups of underground slaughter after the implementation of the MIR, the first being those who simply went underground and planned on staying there (I-28, 2011), a second group who decided to go "quiet" while waiting for their transitional license or funding to upgrade (I-32, 2011; I-24, 2011). One tradesman who is now conducting underground on-farm slaughter spoke of the helplessness that he felt when he was told that he was no longer allowed to slaughter, and could not understand how the "mom and popper" that he has built over the past 25 years that has never produced unsafe meat, is now declared illegal $(I-28,2011)$. Others explain how they "just went quiet" (I-33, 2011), while awaiting a transitional license. Although these producers and processors are now licensed, they nevertheless underwent the stress and anxiety of having their living, which was respectable and provided a great service to the community $(\mathrm{I}-28,2011)$, suddenly be declared illegal and forced underground ${ }^{11}$. Therefore both groups that were forced underground not only suffered financially, but also personally and emotionally as a result of a legislation that was imposed on them. The deeper effects that this had on discourses surrounding safety, knowledge and

\footnotetext{
${ }^{11}$ During this time, despite the fact that their income was solely or largely derived from on-farm revenue, they could no longer declare this income to the government. This in turn affected their farm-status which affected land tax rates, and applicability to the Agricultural Land Reserve. Although they continued producing quality and safe meat for some of their close customers, they could no longer advertise or engage in any form of public marketing.
} 
discrimination towards farmers and rural culture has also been enormous, as will be discussed in chapter six. Although some chose to upgrade or go underground, the majority of producers and processors were forced to shut down.

The numbers of producers and processors who were forced to shut down was devastating, with one producer stating that "abattoirs left, right, and sideways closed their doors" (I-21, 2011). In the North Okanagan there were 11 small processors and one mobile facility, all of which were forced out of business (I-17, 2011), "they just all shut their doors... all of them. We had nobody" $(\mathrm{I}-21,2011)$. In one case a family business that was in its third generation was forced to shut down because they couldn't' afford the costs resulting from the MIR, which was "heartbreaking for that family and the community" (I-21, 2011). Thus, for various reasons, after the implementation of the MTR, the majority of abattoirs were forced to shut their doors and this enormous loss rippled throughout BC's rural and agricultural communities.

Although the BCFPA has estimated "for every abattoir in BC that manages to upgrade or build a new facility and achieve licensing, 2 or 3 have been lost" (BCFPA, 2008), one of the most disturbing aspects of the outcome of the MIR is that there is no precise way of measuring the devastation. Because so many of the farmers and abattoirs that went out of business were working at such a small scale, many of these operations weren't recorded and by the time feasibility studies and reports started being conducted and circulated, many farmers had already stopped raising livestock and many abattoirs had already shut down. One industry consultant stated that government did not know how many people were performing slaughter in $\mathrm{BC}$ prior to 2004: it could have been 2-3,000 if you include "truck and gun" services, including possibly 2-3000 small fixed facilities 
(I-25, 2011). Of the tradesmen who provided on-farm slaughter services, there is a small number that are still operating underground, although the exact number is unknown and of the 200 abattoirs, there are now 33 provincially licensed abattoirs in $\mathrm{BC}$. Taking into account these numbers, it is clear that, as a small scale farmer stated, the "meat regulation is like a train wreck in slow motion... at the time people were just going out of business. Quietly going out of business everywhere" (I-33, 2011). Of the three regions that were part of this research; The North Okanagan, The Gulf Islands and Powell River; each experienced different effects and challenges after the implementation of the MIR. Despite the diversity, all interviews reflected the tragedy and loss that $\mathrm{BC}^{\prime}$ 's rural landscape underwent after the implementation of the MIR

Despite the North Okanagan's history of supporting a diverse range of small- and medium-scale farms, after the implementation of the MIR this number dropped drastically. In this region, farmers are not necessarily suffering due to a lack of licensed facilities, but instead from either a lack of licensed facilities that meet their unique needs or because these farmers, for a variety of reasons, have never and will never bring their animals off-farm for slaughter. One small scale farmer in the North Okanagan who has been raising livestock for 6 or 7 generations has lost this ability due to the regulations (I21,2011 ). One of the leading reasons for this loss has been attributed to the rising costs of slaughter due to the stringent regulations, with one farmer explaining that the cost to have livestock slaughtered is so high that small-scale farmers can no longer make a profit, stating "it's just decimated the industry" (I-21, 2011). Another farmer in this region explains that the butcher shop that he previously used couldn't afford the upgrades and shut down, leaving him with only 2 abattoirs who were each charging $30 \%$ more than 
his previous operator. This higher price is too high for his small business where he is directly selling his lamb to farm-gate customers, and he can no longer afford to absorb the increased costs $(I-18,2011)$.

Furthermore, many farmers either do not trust that they will get the same animal back or have been told by the abattoir operators that they will not be able to get the same animal back $(I-21,2011)$. This is problematic because many of these small scale farmers that have raised their animals with a great deal of integrity, investing extra costs into producing a high quality product, need to have the assurance that they are going to get the same animal back and are not going to have their meat switch with a commercially raised animal (I-32, 2011). Other farmers are either unsatisfied with the distance they would have to travel to have their animals slaughtered or would never bring an animal off-farm for slaughter for various reasons, such as animal welfare, meat quality and environmentalism.

These small scale farmers are therefore demanding the right to be able to slaughter on-farm and sell to their neighbors, or in other cases, have given up farming because they refuse to bring their animals to the existing facilities that are unable to meet their needs. On the other hand, the existing abattoir operators in the region are facing extreme financial troubles due to a lack of business, which although they attribute to an increase in underground slaughter, is more likely due to the number of farmers who have decided to stop producing meat for the reasons mentioned above. In the North Okanagan, there is therefore a great deal of tension between the small-scale farmers and underground tradesmen and abattoir operators who have been unable to find common ground, with the abattoir operators putting blame on underground tradesmen for their 
lack of business, and small-scale farmers and underground tradesmen feeling that abattoir operators are acting as if they have "bought a monopoly" (I-18, 2011) and are unwilling to meet the needs of small-scale farmers.

The Gulf Islands have also been hit hard, with many of the challenges and costs exacerbated due to ferry service. Before the implementation of the MIR, Salt Spring Island was renowned for its sheep herd and this local industry played an important role in the Island's economy and community. Over the past 4 years, the sheep herd on the Island has dropped by $44 \%$, with one farmer claiming that she stopped breeding her sheep between 2006 and 2009 because the costs in terms of money, stress and time that it takes to bring the animals to be slaughtered on the mainland were too high (I-30, 2011). This loss has had a rippling effect across the Island's farming communities and tourism economy.

Finally, in Powell River, which is considered an isolated region, there are no abattoirs; any farmer who continued to raise livestock would not be able to have them slaughtered without being considered illegal $(I-32,2011)$. Many farmers decided to cut back their stock and some "got rid of everything" (I-32, 2011), while others went underground (I-32, 2011, I-33, 2011). Due to the remoteness of Powell River, this has also meant that this region was given priority when the government began consultations and they have thus been heavily involved in the development of the class D and E licenses, which will be discussed further in chapter six.

Although the exact numbers are uncertain, it is obvious that the MIR has led to a drastic drop in the number of livestock and in turn small scale farming across BC. A large part of this loss is not solely due to the fact that there is now a lack of local abattoirs 
throughout $\mathrm{BC}$, but to the fact that the abattoirs that have remained are not necessarily designed or operated in a way that can serve the unique needs of small-scale farmers, discussed above. Whether due to lack of quality services or a reluctance to transport animals, many farmers have decided to sell off their animals and have left farming. This phenomenon has resulted in a major re-adjustment of $\mathrm{BC}$ 's rural landscape, caused increased problems for those abattoirs that decided to invest in upgrading, and created tensions between stakeholders. One farmer who sits on BC's agricultural council has stated that "the way it is going now is that we are sniping at each other rather than working together... there is a lot of tension... It's one of the outcomes of a poorly considered meat regulation environment... [stakeholders] are just backed up against the wall with both guns drawn... nobody's willing to compromise and talk anymore" (I-18, 2011). Therefore, not only has the enactment of the MIR devastated rural and agricultural communities, suppressing food sovereignty, but it has also fostered tensions between stakeholders, limiting the potential for a unified response.

\subsection{Conclusion}

This chapter explored the empirical realities of the MIR in the context of AFNs and the previous regime for meat production in $\mathrm{BC}$. This was demonstrated by first looking at meat production in the Canadian context, discussing the shift to large-scale agriculture and the resiliency of small scale abattoirs. The chapter then looked at BC's agricultural landscape and the central of role that small-scale agriculture and AFNs play, reflecting discourses of food sovereignty. Finally, the chapter outlined the three options that were available to producers and processors upon the enactment of the MIR, as well as discussing the devastation that the MIR caused throughout BC's rural and agricultural 
communities. In order to understand the design, enactment, and implementation of the MIR and the subsequent effects throughout the province, the next two chapters will draw on neo-Gramscian, Foucauldian, and scalar theories. 


\section{Chapter: The MIR as a Reflection of Dominant Discourses}

\subsection{Introduction}

Since the imposition of the new MIR in BC, two-thirds to three-quarters of small-scale abattoirs in the province have been lost (BCFPA, 2008). This loss occurred as a result of the poorly designed and implemented MIR that was not scaled appropriately to fit the needs of small-scale producers and processors. This chapter argues that the MIR was poorly designed and implemented, because it reflected three dominant discourses under the current neoliberal hegemony, which are: standardization equals safety; bigger is better; and one-size-fits-all. These three discourses are prevalent under neoliberalization, especially at the federal level, and exemplify the interconnections between industry and government, demonstrating the ways in which regulations are used as "tools of governance" and have allowed for state intervention in the market while maintaining the neoliberal illusion of laissez-faire. This chapter begins by analyzing the three dominant discourses that are reflected in the MIR.

\subsection{Standardization equals Safety: Managing Risk and Claiming Truth}

This section demonstrates that the implementation of the MIR, which led to the loss of small- and medium-scale abattoirs across $\mathrm{BC}$, is reflective of the dominant assumption that if meat is inspected it will be safe, and inspection is the only way it will be safe. Beginning by addressing the first half of this assumption, this section argues that the MIR is reflective of the dominant discourse 'standardization equals safety.' This dominant discourse awards authority to certain stakeholders and limits the potential for debate, as well as supports the needs of international trading partners while transferring the cost 
onto plant operators. This discourse is partly a result of the role consumer fears have played in encouraging governments to engage in strategies of risk management.

Food-borne illness outbreaks across Canada have created a sense of fear among individuals and corporations, leading governments to engage in strategies of risk management to regain the confidence of consumers. This lack of confidence is exacerbated by the media, government and politicians (I-18, 2011, I-25, 2011). BC's Agriculture Council member states that "we are living with a culture driven by food fears right now," which is by and large manufactured by the media (I-18, 2011). Local and rural newspapers, such as Country Life, have furthered this fear by featuring stories that present the image that uninspected processors and farmers are producing a "poisonous" product that is entering the food chain (I-18, 10, 2011). Given the federal government's priority to support Canada's meat industry by ensuring the confidence of trading partners, it has attempted to protect its production and export capacity through the implementation of risk management techniques. These techniques depend on science-based measurements, standardization, and an auditable process, but have failed to address the complexity of social and political factors that are at play.

Despite the complexity of issues regarding food-borne illnesses, there are many issues that are being overlooked. This lack of critical analysis has meant the state's perception of risk management is based in a set of unchallenged assumptions that value science-based measurements, standardization, and an auditable process. These discourses of risk management have shaped the direction of meat safety and regulation in Canada, resulting in poorly designed and implemented policies that do not fit the needs of smalland medium-scale agriculture. One industry consultant suggests that the government 
needs to start asking "what are the risks we are managing, what's the business activity involved here, what level of effort is needed to address the risk? If the effort to address the risk causes the business activity to cease..." then maybe the risk management strategy needs to be re-examined $(I-25,2011)$. Rather than asking these very basic, yet complex questions, the government has simply assumed that standardizing the production process by implementing, or increasing the stringency of, regulations is the best response to ensure food safety.

Engaging in unexamined strategies of risk management can be compared to the old story of a man who loses his keys in a dark alley, but instead decides to look for his keys down the road under a street lamp because that is where it is well lit (I-25, 2011). Although the causes of food-borne-illnesses are complex, as are the wide range of strategies that can be undertaken to reduce risk, the state has chosen a path that can be easily measured and audited. For example, the highest levels of risk for food contamination are in the home kitchen, but because this is an area that cannot be regulated, the government has focused its attention on the abattoir (I-25, 2011). Another example looks at safety regulations in the plant, pointing out that in many cases the inspectors are there to inspect the animal pre- and post-mortem, but are not present for the cutting and wrapping, which is arguably where there is the highest risk of contamination (I-26, 2011). Not only are these basic contradictions being overlooked, but the assumption that the risks are high enough to warrant intervention is not being questioned. A representative from the BC Cattlemen's association compares the actual level of risk of contracting BSE to the chance of "winning the lottery and being struck by lightning on the same day" (I-16, 2011). An industry consultant seconds this point, 
suggesting, as one example, that the CFIA's assumption that every pound of specified risk material $(\mathrm{SRM})^{12}$ is contaminated may not be an effective application of the precautionary principle $(\mathrm{I}-25,2011)$. Because these questions are not being asked and assumptions are not critically analyzed, the widespread discourse that equates inspection with safety has played a dominant role in strategies of risk management.

The use of scientific discourse and standardized processes has come to play a dominant role in risk analysis techniques not only because of the ability to transform risk into something that is calculable and manageable, thus transforming an uncertain situation into one that can, seemingly, be rationally overcome (Andrée, 2007), but it is also being increasingly adopted into policy-making because of its ability to support and legitimize political decisions, as well as affecting what types of evidence are and are not acceptable in policy circles (Van Zwanenberg \& Millstone, 2005, 27). The internalization of scientific norms across many industries and governments has empowered certain actors, such as governments, corporations, intergovernmental bodies, and universities, with an element of authority to their interpretations of risk and it places them in a strong position in the development of regulations and policy (Andrée, 2007, 76). Many civil society groups that are underfunded and unable to engage in science-based research are excluded from discussions and consultations, and consequently their voices are silenced in policy formation $(\mathrm{I}-11 \mathrm{~b}, 2010)$. The use of scientific discourse and standardization is reflective of Foucauldian concepts of veridiction and jurisdiction and the reinforcing

\footnotetext{
${ }^{12}$ Specified risk material (SRM) are the tissues in cattle that have been demonstrated to present a higher potential for infectivity of Bovine Spongiform Encephalopathy (BSE). SRM include the skull, brain, trigeminal ganglia (nerves attached to the brain), eyes, tonsils, spinal cord and dorsal root ganglia (nerves attached to the spinal cord) of cattle aged 30 months or older, and the distal ileum of cattle of all ages. All removed SRM are to be diverted away from the food supply. (Health Canada, 2003). For a more detail description of the SRM see Appendix A.
} 
nature of knowledge and power to create and reproduce norms and standards of truth. Barry points to the ways in which "an increasing importance of measurement and information in the economy" has adopted a dominant role in discourse and arguably has "anti-political effects" by suppressing avenues for contestation and placing limits on the potential for debate (Barry, 2009). In doing so the potential space of political conflict has been reduced and "questions of value become debated as questions of fact" (Andrée, 2007, 76-77). The use of scientific discourse and standardization processes has thus come to maintain a dominant role in risk management not only due to its ability to present an image of certainty and control, but also due to its tendency to award an element of authority to policy makers, while simultaneously excluding actors and limiting debate.

This discourse that values science and standardized processes connects to the need to present an auditable process to trading partners, reflecting a broader trend towards "disciplines of audit," in which coercive forms of discipline or direct surveillance are replaced by factories being disciplined from the inside out (Dunn, 2005, 176, 185; Lang T., Barling D., \& Caraher M., 2009, 162-163). "Discipline of audit," also referred to as, "ritual of verification," in which documentation is required at all stages of the process, increases transparency, thus eliciting trust and making it possible for managers and investors to judge profitability, while simultaneously transferring the cost and onus of standardization onto plant operators (Dunn, 2005, 176,177, 184, 186). These regulatory systems have been criticized as taking a "cybernetic approach," which relies "on the system to do a job...it takes the human responsibility out of the system and makes it into an inspecting machine" (I-7, 2010). Thus, 'discipline of audit' not only allows for 
international traders to control and audit all stages of production, but it also transfers the cost and onus of these systems onto the plant operators.

This section has demonstrated that the valuation of science-based measurements, standardization, and an auditable process has not only created a discourse that awards authority to certain stakeholders, thus limiting the potential for debate, but it has also supported the needs of international trading partners, while simultaneously transferring the cost and onus onto plant operators. The discourse 'standardization equals safety' has contributed to the unexamined assumption that if meat is inspected it will be safe. The second part of this assumption, that inspection is the only way that meat will be safe, will be discussed throughout the following two sections that look at the dominant discourses that claim bigger is better and one size fits all. These two assumptions are connected yet separate; the first reflects the dominance of government implemented, standardized inspection systems, and the second reflects the inability to recognize and value alternative systems of food safety and traceability that are present in local and alternative food supply networks. Together these assumptions create the connotation that "if your meat was inspected, it will be safe, and it's the only way that it will be safe" (I-23, 2011).

\subsection{Bigger is Better: Prioritizing Large-Scale Production and Economies}

The implementation of the MIR in BC is rooted in the assumption that not only declares that if meat is inspected it will be safe, but also presents inspection as the only way that it will be safe. The previous section demonstrates the discourse that has led to the first half of this assumption, this section analyzes one of two factors behind the second half of this assumption. The assumption that presents inspection as the only way to produce safe food 
is the result of two factors. The first is the discourse that 'bigger is better' and the government-industry historical bloc that supports this discourse. The second, yet connected, discourse is 'one size fits all', which points to the inability to recognize the value and importance of diversity of scaled of operations and economies. This section argues that the dominant discourse 'bigger is better' has contributed to the implementation of a poorly scaled meat regulation in $\mathrm{BC}$, resulting in devastation across its rural and agricultural landscape. Furthermore, many of the regulations that have been implemented with the goal of ensuring Canada's export and import markets have been confused with those regulations directly relating to food safety, thus placing unneeded costs on local processors.

Canada is currently witnessing the domination of the discourse 'bigger is better.' This discourse can be seen in both federal and provincial government policies. At the federal level, and particularly within the AAFC, there is a strong focus and concern for Canada's production capacity. Not only does this mean that a main focus of regulation is to present a specific perception to consumers ${ }^{13}$, but it also means that there is a push to support large-scale industrial agriculture. One advisor in AAFC stated that:

You have to look at your costs and keep in mind that most of the meat in Canada is exported... you might get a bigger bang for your buck...to put money into Cargill to improve the efficiencies on that plant so that it can compete better internationally... Perhaps you want to broaden the processing capabilities that you have in Canada, compared to just strict abattoirs and a couple families. $(\mathrm{I}-8,2009)$

This focus on export and large-scale agri-business has been felt by many small-scale farmers, processors and rural communities, with a representative from the national NGO, Beyond Factory Farming (BFF) noting Canada's high priority on trade, stating that the

\footnotetext{
${ }^{13}$ Consumers includes both individual consumers (eg customers in supermarkets) as well as corporations
} and procurement agencies 
government is "really pushing export and trade to the sacrifice of the domestic system" (I-7, 2010). Another representative of small-scale farmers agrees, stating that "the federal government does not seem to have any interest whatsoever in the smaller producers" (I-9, 2010). She furthers this comment saying that "it's short sighted and so depressing. I have people call me and tell me that they are going to have to sell their farms...because of federal policy around export" (I-9, 2010).

Among proponents of the food sovereignty movement, there is a lot of scepticism about the sustainability of large-scale agriculture for reasons relating to the environment, the spread of disease, food security, and the sustainability of rural communities (I-10, 2009). Representatives from AAFC and the CMC, on the other hand, support industrial agriculture, seeing it as the most effective way to increase Canada's production capacity and regard the scepticism as being over-exaggerated (I-5, 2009; I-8, 2009). Furthermore, one representative from AAFC feels that many of these issues are beyond the scope of many government agencies, referring to the global factors influencing policy change, stating, "How many ulcers do you really need over worrying about issues that are, in a sense, out of your control" (I-8, 2009). Thus many actors at the federal level do not see industrial agriculture as being problematic, but instead see it as necessary to increasing Canada's production capacity, relating back to the clear domination of a discourse that values large-scale production, at the expense of small-scale production. This discourse is also dominant at provincial levels.

An interesting point can be drawn when looking at the provincial scale, with the $\mathrm{BC}$ government reflecting an attitude that not only fails to recognize small-scale agriculture, but fails to recognize all scales of agriculture in the province, pointing to the 
power of non-action. This research has drawn out that there was a strong disconnect between the $\mathrm{BC}$ government and its agricultural sector, which is primarily small- and medium-scale. When the provincial government received pressure from the federal government to implement the regulation, they did so without consultation or a full understanding of what the consequences would be of this regulation. This brings up the point that discourse can also be recognized through non-action. Because BC's agricultural sector does not play a large role in its economy, the government did not invest the resources needed to ensure that the MIR was designed and scaled in a way that would take into account the needs of various scales of producers and processors throughout the province $(\mathrm{I}-17,2011 ; \mathrm{I}-21,2011)$. At the time of implementation the provincial government had one aim; "to have all meat in the province going through either an A or B licensed facility, and the agricultural side of it was very much on the periphery" $(\mathrm{I}-23,2011)$. One local politician in the North Okanagan claims that when she started speaking with staff at the provincial level, including bureaucrats from the Ministry of Agriculture, the Ministry of Health, the BC Centre for Disease Control and the BCFPA, and tried discussing the effects on small-scale farmers, "they didn't care. Not the point. They weren't interested in accommodating the needs of small scale farmers. They were very much focused on, 'needs to be inspected, that was the bottom line"' (I-23, 2011). Not only did the provincial government seem to lack an understanding of the amount of small-scale agriculture throughout BC (I-32, 2011), but they also seemed to be disconnected and misinformed about who the MIR was going to affect. Not recognizing the abattoir's central role in supply chains, the government did not take into account the rippling effects that the MIR would have on both producers and consumers (I-21, 2011). 
Therefore, although the provincial government does not promote large-scale agriculture with the same zeal as the federal government, their lack of concern for their provincial agricultural sector allowed for federal discourse to be facilitated down to the provincial level. The MIR was in turn implemented with little attempt at consultation or concern for the effects it would have on BC's agricultural and rural sectors.

The MIR came out of federal legislation and was based on a design that was built for huge economies of scale and export (I-20, 2011). This meant that the MIR is incompatible with the needs of BC's agricultural sector. As one farmer states, "it doesn't fit with what this industry needs, at all" (I-21, 2011). Therefore instead of respecting and appreciating the value and accountability of the small scale, "there is a perception with this government, that economically the small scale producers are not worth their time. That from a business point of view, that from an economic point of view, that larger scale agriculture is where we want to go" (I-23, 2011) and so many operators were pushed into building a facility that was larger than they originally desired, and ultimately ended up not scaled to the size of their economy and causing problems (I-27, 2011). One operator explains how financial institutions told him that his size of facility was not sufficient and he was talked into increasing the scale of his operation, which is ultimately "when it snowballed and kind of went off the rails. It grew bigger than the market up here" (I-27, 2011). Another operator had a similar experience in which he was pushed "from being a plant that was originally designed to be much smaller ... to being a plant that had to be bigger just to get enough chickens through to pay the bills" $(\mathrm{I}-29,2011)$. He further explains that "the size of this business was dictated by what happened at the time" and if the CFIA hadn't stepped in, he would have had a much smaller operation $(I-29,2011)$. 
Due to the dominant and unexamined assumptions, the MIR's design and implementation reflected the 'bigger is better' discourse, which has shown to be "problematic because it doesn't leave room for the small scale" (I-24, 2011). This connects to the next point, which discusses the lack of recognition for scale.

\subsection{One Size Fits All: Failing to Scale Appropriately}

This section demonstrates that a lack of recognition for the value and importance for a diversity of scales, which is reflected in the 'one size fits all' discourse, has led to the assumption that inspection is the only way that meat will be safe. This discourse is both productive and disciplinary (Andrée, 2007) in that it both defines what is valuable and acceptable, as was demonstrated in the last two sections, as well as defines what is not acceptable by delegitimizing other views. The 'one size fits all' discourse fails to recognize the importance of small scale economies and operations, therefore showing no recognition for the value of a diversity of scales, leaving small scale operations and economies no option but to adapt or shut down. This section argues that the lack of recognition of small scale operators is due to the lack of value placed on small and local economies and a failure to recognize the effectiveness of accountability that is built into alternative food networks. These two factors have led to the support of large-scale exportoriented production and economies at the expense of small-scale and alternative forms of production and economies.

The dominant discourse 'one size fits all', fails to recognize the connection between the scale of an operation and the scale of its targeted market. Due to the federal government's priority on Canada's "overarching economy," it fails to recognize that on 
the ground level there is a complex network of a myriad of diverse and separate, yet interrelated, economies. Regulations must in turn be scaled to match the diversity of scales of operations and their economies. This recognition of the value of a diversity of economies and the need for equally diverse regulations is especially important in the province of $\mathrm{BC}$ because of its wide variance in scales and types of operations (I-16, 2011), which are mutually dependent on a diversity of scales and types of economies. One farmer in $\mathrm{BC}$ states that "there really needs to be consideration for provincial plants and the kind of trade they do as different from the export trade and decisions that are made for export. The domestic end needs to be looked at and questions need to be asked. Does this have any negative impact on the domestic situation?" (I-29, 2011). One underground tradesman agrees that if you are shipping overseas then that is a scale and realm that requires inspection; but $99 \%$ of his product is staying within 50 miles of his operation and so he requires a different standard (I-28, 2011). One abattoir owner who fought to have his unique type of abattoir approved by the CFIA explains that the provincial government tried to push him to build a larger facility because they don't understand "the economics in this area. You cannot justify that size in this area... so you have to downsize it to a very small efficient plant that can run with 4 or 5 people working in it" $(I-26,2011)$.

Not only are these economies important to the sustainability of the operation, but they are also important for a variety of other factors. A local politician felt that it is extremely important for the legislation to recognize and value the need for different types of economies and to recognize that different scales of operations will market in different economies $(\mathrm{I}-23,2011)$. These differently scaled economies, whether niche markets or 
alternative food networks, are often masked and not as visible, despite the important role that they play. One small scale farmer stated "we play a big role in the economy. A huge role, but it's masked. It's a subtle one that's down there at a low level. It's not big and so it lacks visibility" (I-21, 2011). Not only does the dominant discourse fail to recognize the value and importance of small scale operations and economies and that small-scale abattoirs depend on the recognition and value of localized economies to market their products, but it also fails to recognize the "inherent accountability" $(I-23,2011)$ that is built into alternative food supply networks as efficient systems for safety and traceability.

Small-scale food supply networks are part of very unique and specific relationships, communities and economies that provide accountability. A local politician explains that at the small-scale there is a relationship that exists between the farmer and consumer that is community based, resulting in relationships that are "inherently accountable," which "can't be mimicked by regulation" (I-23, 2011). She further states that "these producers are not going to poison their neighbors, and if something does go wrong, word gets out fast and you are out of business. It's been going on for generations and generations where people are growing animals on farm and slaughtering them on farm, and selling them to neighbors or bartering or whatever, and it's not a safety issue" (I-23, 2011). This accountable relationship is much more than can be said for large scale operations which is where the large majority of food-outbreaks have not only originated (I-23, 2011), but also where there is a disconnect between producers, processors, distributors and consumers that has disabled accountability. One farmer explains that "we may be small producers, but we are as serious about food safety as everyone else. I am feeding my grandchildren, and I am feeding my friends and I am living in a really 
small community. How safe are you going to be when you are feeding your kids?" (I-33, 2011). An underground tradesman seconds this point, stating that "they are barking up the wrong tree on my end" (I-28, 2011). He goes on to challenge dominant discourses regarding inspection, stating that if the government can find any case where he has produced tainted meat then "by all means, crack down on me, crack down on people like me, but that's not happening here" (I-28, 2011). These relationships of accountability and traceability cannot be mimicked by inspection or regulation. One factor that contributes to the lack of recognition for the accountability of small scale food safety systems is surrounding a lack of recognition that there are different levels and types of risks that occur in large-plants versus small- and medium scale plants.

A fundamental flaw of the MIR's design is that it does not take into consideration the different levels and types of risks that are found in differently scaled plants. An agricultural economist explains that they are not differentiating between people who are processing 4 beef cattle a day compared to 40 an hour, "they are applying the same standard all across, but the risk is quite different and they don't look at that at all, and that is one of the big problems" (I-17, 2011). For example, regarding waste disposal, "there is not a single waste technology for smaller amounts in rural areas that is affordable. Not one" (I-25, 2011). This has been occurring in Canada and across the globe as "the monoculture of neoliberal globalization...the dominant trajectory is held to be one of upward convergence and homogenization" (Peck, 2002, 334). These assumptions about practices and institutional infrastructures hold that problems that occur in large-scale plants will be the same problems that occur in small-scale plants and this has been a 
critical, yet unexamined, assumption behind the new regulatory structure in British Colombia.

The difference between different sizes and scales of operations must be acknowledged on many fronts and especially in terms of safety, cleanliness, and traceability. All stakeholders interviewed recognize that the levels of risk in a small operations are much different than the levels of risk in a large operations, for example an operation that produces 5-10 head of cattle holds completely different levels of risk than those that do 6000 a day $(\mathrm{I}-16,2011)$. Although this section draws out the perspectives on different levels of risk at different scales, the intention is not to enter this debate, but rather demonstrate that, despite the existence of these various perspectives, meat regulations do not take into account these varying perspectives, and therefore are not scaled accordingly, in turn being more easily adopted by large-scale facilities than smallscale.

At all stages of meat production different scales affect the levels and types of risk. For example, at the 'breeding and feeding' stage there are different risks and many smallscale farmers elaborated in great detail on the various factors that lead to healthier animals that will carry far less risk than ones raised in large-scale feedlots where the risks of disease and e-coli outbreak are much greater (I-21, 2011). There are also different levels of risk at the stage of slaughter and processing. For example, small-scale operations are not necessarily working in a timed fashion, which provides more time to check each animal (I-21, 2011), compared to the "self-inspected" systems in place at large-scale plants that remove the human agency (I-28, 2011; I-7, 2010). Finally, not only is there less risk involved in the production and processing stages, but there is also less 
risk in the distribution stage of the supply chain, with industry representatives explaining that the levels of risk for plants that export or mix animal products is much different than small plants where animals are more likely to be sold whole and not distributed the same distances, presenting a different situation than the nationwide meat recalls that come out of the large plants $(\mathrm{I}-16,2011 ; \mathrm{I}-21,2011)$. This demonstrates that the risks in small-scale versus large-scale plants are very different and regulations should be scaled appropriately to take these differences into account.

Despite these reasons for the importance of small-scale operations and small-scale economies the dominant assumption remains at the government level that there is only one way to achieve food safety, which does not take into consideration the different needs and risks involved in small-scale production and marketing, instead prioritizing large-scale operations and economies. A local politician explains that "We still place a huge amount of value on economic development ... so if we believe that large scale agriculture is better for our economy, then that's going to override anything else" (I-23, 2011). She furthers this idea stating that "the idea that trade trumps community based" is difficult to override because of challenges in presenting the value of economies in a way that the province and federal government will be receptive to (I-23, 2011). This perspective reflects the dominant discourses discussed in the previous two sections that value large-scale and inspection at the expense of small-scale operations and economies. This demonstrates that, despite attempts to homogenize operations, regulations have instead created inequalities. Regulations are acting as tools that are actively disarticulating individuals and businesses from regional and global market structures by creating barriers for smallholder farms (Dunn, 2005, 180, 179). These barriers are created 
through a process that has categorized and assigned value to producers and processors, transmuting difference into impurity and marginalizing those who will not or cannot comply (Dunn, 2005, 183). Throughout the globe, and specifically in Canada, the state's imposition of regulations has advantaged multinational corporations at the expense of citizens working at small- and medium-scales (Dunn, 2005, 180). It is clear that the "one-size-fits-all" attitude that was initially seen in the implementation of the MIR, does not fit-all, and in turn a graduated approach should be applied (I-25, 2011). Before further discussing these possibilities for change and resistance, it is important to take a broader look at how these three discourses are reflected in the broader political economy.

\subsection{The Illusion of Laissez Faire}

Taking into account the previous three factors, this section argues that there has been a conglomeration of regulations designed for market-competitiveness with regulations that have been designed for safety, in turn forcing small- and medium-scaled operations to adopt practices that are neither relevant to food safety, nor relevant to their operations, but have added unnecessary costs. In turn regulations have forced many small-scale operations to shut down, while simultaneously supporting large-scale export oriented operations. This is a reflection of a wider criticism of the political-economic system that debunks the illusion of laissez-faire, demonstrating that in reality the economy has become more rule-bound than ever, and the state has favored large-scale operations at the expense of small-scale agriculture and rural populations.

One of the biggest criticisms of this legislation was the suggestion that the government was doing this benefit of larger-scale meat industries, to the detriment of small-scale producers. One local politician states that "we were under the perception that 
it was just catering to the meat processing industry" and that, despite pressure from the federal level to strengthen the meat processing sector, "it was obviously to the detriment of the remote and rural communities that have been doing it for decades" (I-22, 2011). Thus this politician is very blunt in saying that "the government was selling out to the major meat processing industry, to the detriment of the small local producers" (I-22, 2011). This sentiment is also shared by industry consultants, with one stating that "the larger industry players do the most lobbying" (I-25, 2011). Despite the history of safe and quality food coming out of $\mathrm{BC}$ 's uninspected abattoirs the discourse has evolved that meat sold to the public needs to be inspected (I-26, 2011).

The discourse to promote inspected facilities has been largely driven by abattoirs as a marketing strategy, rather than due to needs for food safety. Due to lobbying efforts there has been a shift in discourse across $\mathrm{BC}$ that has promoted the need for inspection. Ironically, the same abattoir operators who state that they have never had problems in the past, still push the discourse that inspection will equate to safety, with one owner stating, "I'm not saying that the meat is bad, but there are no checks and balances" (I-16, 2011). A representative from the $\mathrm{BC}$ Cattlemen's Association furthers this thought and, referring to uninspected facilities, states "It is not that we are saying that they are doing something bad or wrong, but we feel it is our responsibility to make sure that it is being done to our standards" (I-16, 2011). Both these interviews reflected the discourse that standardizing their process would increase their accountability to market their product. Not only has there been a conglomeration of market and safety needs, as reflected by the marketing needs of abattoir operators and industry representatives, but the government's choice of 
agencies to contract the implementation of the MIR also reflects market-government connections.

$\mathrm{BC}$ 's government has been questioned for its choice to contract the BCFPA, which represents larger scale processors $(I-20,2011)$, to organize and provide resources and support to abattoirs attempting to transition into a licensed facility. There is not only the concern that there is a revolving door between the BCFPA and large industry, but in some cases where the BCFPA has attempted to support the small-scale processors, farmers have argued that they have demonstrated an inability to "understand how small scale processors and small-scale farming works" (I-21, 2011). Small-scale processors are not often members of the BCFPA and although they may belong to the Small Scale Food Processor Association, this group "doesn't have a seat at the table; doesn't have a voice" (I-20, 2011). For these reasons there has been an increased distrust of the BCFPA and a feeling that the government is solely working for the benefit of large industry at the expense of the small-scale processors. This sentiment has been exacerbated due to the perception that the BCFPA has prioritized the needs of licensed abattoirs over small-scale farmers (I-21, 2011). Alongside the distrust of the BCFPA, criticisms have also been made regarding the provincial government's choice to contract the CFIA to implement the MIR.

The CFIA has been criticized for holding a dual mandate, dealing with both food safety in Canada as well as promoting trade and agriculture. In turn its involvement in the implementation of the MIR is criticized as reflecting government-industry connections. Pointing to the fact that the CFIA was formed in 1997, shortly after NAFTA was passed, there has been confusion surrounding their role in increasing Canada's food safety versus 
supporting trade (I-7, 2011). The federal government and many industry representatives, defend this dual mandate as essential for implementing workable regulations, with a representative from the Canadian Pork Council (CPC) stating that,

There is this perception that once the government and industry work together that the requirements get diluted. They don't. They are just reformatted in a way that makes sense for them to actually work. Because if it is just the regulatory agencies putting them together, they often don't work... and it is critical that the two be able to work together. (I-11, 2010)

Although this perception is valid, especially to large-scale export-oriented industries, this dual mandate is detrimental to small-scale producers who have no intention of targeting large-scale markets. This dual mandate has caused confusion because of its lack of differentiation between regulations that are in place for trade and regulations that are in place for food safety.

A representative from the $\mathrm{BC}$ Cattlemen's Association explains that the implementation of the MIR "is a trade issue, not a safety issue, and that's where things get muddled up" (I-16, 2011). The CFIA has become one of our biggest influences on trade, with representatives from the CFIA explaining the federal Meat Inspection Act is primarily a trade piece (I-14b, 2011). Until Canada's recent creation of the trade secretariat and a market access secretariat "we were leaving it up to the likes of the CFIA and some of our embassies, for example, to do the negotiations" (I-16, 2011). Furthermore, representatives from AAFC, BFF, the NFU, the CPC and the CFIA have all stated that federal regulation does not necessarily produce a safer product than provincial regulation, but is more about presenting a specific perception to trading partners (I-1, 2009; I-2, 2009; I-8, 2009; I-7, 2009; I-11 ab, 2010). A former employee at the CFIA also expresses concerns about how these standards, which focus on trade, negatively affect 
abattoirs that do not have the intention of selling products internationally, stating that, "you've got this double standard, where the federal standards are high, as they need to be for the international movement, and that then translates into the standards for the interprovincial movement. So you have a number of things that, some people would say, are as much cosmetic as they are actual direct food safety related" (I-1, 2009).

Taking into account these concerns, many stakeholders argue that the MIR is not about safety, but instead about trade. One politician argues that "this was about trade. This was about convincing our trading partners that our food was safer. We had to be able to demonstrate to them that everything will be inspected" (I-23, 2011). A consultant to the $\mathrm{BC}$ Abattoir's Association recognizes this purpose and, contrary to the needs of small-scale producers and processors, who are not interested in this market, is supportive of inspection, stating that "We want to sell to commercial markets. We are trying to get more into commercial markets and no one is going to buy from us at all if there is no inspection" (I-20, 2011). An abattoir owner and operator seconds this opinion explaining that we need to make sure illegal slaughter doesn't happen "because that jeopardizes the name of our industry" (I-26, 2011). Despite the desire for some abattoirs in BC to become inspected in order to reach these markets, the problem arises not from inspection itself, but when assumptions are made that equate inspection with increased safety. One small scale farmer on the Gulf Islands who has undergone inspection has stated that "my product has not changed one bit since I got inspection," but nevertheless realizes the importance of this system for his marketing initiatives (I-24, 2011). Some stakeholders in $\mathrm{BC}$ have taken into account the market priorities that have taken precedence in the 
implementation of the MIR and are equating it with a form of government intervention in the marketplace.

Many small scale farmers, who are "fiercely independent," explain that they would simply like to compete in the free market and that the government is interfering too deeply not only by implementing this regulation, but also by supporting those who have gone through the licensing process $(I-18,2011)$. One politician shares this concern, asking the question "Why is the government protecting those individuals? Where is the free enterprise? There is a demand for that other product, people should be able to provide that product and that service... Why is it the government's responsibility to support somebody who isn't a good business person, who isn't providing a good service" (I-23, 2011). These are questions being asked by many small scale producers, who are not looking for any support from the government, but merely to be allowed to continue their lifestyle as they have for decades.

Questioning the government's support for abattoirs who have complied with the MIR, one small scale producer explains "small scale producers are free enterprise oriented. They are willing to compete. Processors are not entitled to any protection, they should be competing as well. They have had some financial assistance to upgrade. They have received government funding to do so. The province is in no position to protect that investment, it is not entitled to protect that investment" (I-18, 2011). He furthers this point, drawing the deeper connection between government and industry explaining that "the province is ready to protect their investment because the province has put up money too... it was an investment that was made by the province that was clear. These guys had figured they had bought themselves a territory... For a government to do that is illegal" 
(I-18, 2011). Therefore, a diversity of stakeholders have expressed concerns that BC's ministry of agriculture was ignoring the concerns of small-scale farmers and abattoirs, in order to benefit industry $(\mathrm{I}-20,2011)$.

The BCFPA and provincial government, although now admitting that they made a mistake in the implementation of the MIR, still sides with the licensed abattoirs and supports them over the small-scale farmers lobbying for the right to slaughter on-farm (I$18,2011)$. One politician states that "everything that they are doing now is about supporting those individuals who made the investment. Even though they know that this was a big muck up. Even though they know that there are a whole bunch of farmers that are shutting down and that's a bad thing" (I-23, 2011). Nevertheless, they still believe "that those producers who made the investment should be protected" (I-23, 2011). This was reflected in the first amendment that was intended to protect the people who already had a B licensed facility by disallowing others to apply if they were within a $200 \mathrm{~km}$ radius, unless the abattoir had so much business that it couldn't meet it all (I-21, 2011). This has been extremely frustrating to those farmers who feel that the abattoirs in their region that were first to make the investment do not run a good business and cannot address the needs of small-scale farmers (I-18, 2011). For this reason, many farmers have given up raising livestock due to the lack of trustworthy and well run abattoirs (I-18, 2011). This has in turn created some conflict and tension, because although these abattoirs have been wronged and misled from the beginning by the government, and therefore deserve compensation for their losses, at the same time, this support is not being applied evenly and was not given to some of the smaller operators who did not have the 
finances to make the initial investment. This situation reflects a broader trend of neoliberal intervention that has been analyzed through the field of political economy.

The enactment and implementation of the MIR reflects broader ties between the state and the market in neoliberalism. Regulations have been described as tools of governance that can regulate supply chains "in such a way as to shift where value is appropriated to favor some actors over others" (Guthman, 2007, 460, 466). This can be seen through a neo-Gramscian perspective which illuminates the close ties between the state and private business. Panitch describes how there is "an ideological hegemony emanating from both the bourgeoisie and the state" that is reflected in the view "that the national interest and business interests are at one, and which certainly ensures the smooth functioning of the relationship between the state and the capitalist class" $(1997,13)$. He supports this argument by describing early events that led to such ties, referring to C.D. Howe's strategy of bringing businessmen to manage "the Canadian economy and to head publicly owned enterprises" while they simultaneously maintained "private corporate positions" (1997, 12). Panitch concludes that "it was not surprising that a close relationship should develop and career lines become confused between the corporate world and the public service in and around departments which, though planning, regulations, and defense contracts, came into close contact with industry" (Panitch, 1997, 12). Clement shows how there has been "an increasing interpenetration between the corporate elite and both the state and political systems in the last twenty years" (Clement, 1975, 346). Panitch points to this as an issue of "non-decision," explaining that "the problem is not that political and bureaucratic officials decide to favor capitalist interests in case after case; it is rather that it rarely even occurs to them that they might do other 
than favor such interests. The problem is indeed a systematic one" (Panitch, 1997, 14). This connection between corporate elite and the state is reflected in the food industry as "liberalization and privatization combine to accelerate food circulation globally and restructure food production and retailing along corporate lines. This enables corporate profits" (McMichael, 2009, 42-43). The imposition of regulatory structures that exclude small-sized operations from participation (Guthman, 2007, 461) while profit rates for large agribusiness have soared ${ }^{14}$ (McMichael, 2009, 43), demonstrate these ties and bring into question the neoliberal image of laissez-faire.

Fuianyi's The Great Transformation demonstrates that despite the 1830s' crusading passion for laissez faire, "there was nothing natural about laissez-faire; free markets could never have come into being merely by allowing things to take their course" $(1944,144,145)$. Similar to the way that examples of protectionism were used to debunk the myth of the free trade origins of the cotton industry (Polanyi, 1944, 142), regulations in the meat industry can be used to demonstrate that, despite the image of the rolling-back of the state (Harvey, 2005, 2), regulations allow for state-intervention while still retaining the illusion of laissez-faire neoliberalization. Thus, standards and regulations in the meat industry demonstrate a third way between state intervention and privatization, (Buller \& Morris, 2004, 1080). "Normative (neoliberal) governmentality attempts to integrate new geographic spaces and populations not by overt coercion, but by instituting a host of 'harmonized' regulations, codes, and standards" (Dunn, 2005, 175). Regulations have thus been regarded as "tools of governance," allowing states to "govern individuals without violating their formal rights to autonomy, and control enterprises without impeding their abilities to act in an open market" (Dunn, 2005, 186). Also known as

\footnotetext{
${ }^{14}$ In 2007 Cargill's profits rose $36 \%$, ADM's rose $67 \%$, and Bunge's rose $49 \%$
} 
"acting at a distance" (Keil \& Mahon, 2009, 17), regulations and standards in the food industry have created the appearance of a laissez-faire, neoliberal economy, in reality they have allowed the state to support the growth of large-scale agriculture over smallscale operations. Furthermore, "when power operates at a distance, people are not necessarily aware of how their conduct is being conducted, or why. So the question of consent does not arise" ( $\mathrm{Li}, 2007,5)$. Regulation allows for "the appearance of no government when, indeed, the state has grown considerably and society is more rulebound than ever" (Guthman, 2007, 466). This can be seen as a new variety of capitalism, where "many of the most important institutional structures... depend on the presence of regulatory regimes that are in the preserve of the nation-state" (Hall \& Soskice, 2001). This problem is clearly systematic and results from a diverse and complex range of factors. On the other hand, it also must be noted that although it is not the intention of policy makers to devastate local capacities, they are nevertheless aware that this is happening, yet they continue to push their policies forward.

\subsection{Conclusion}

This chapter discusses the devastation that has been caused by the loss of small- and medium-scale abattoirs in $\mathrm{BC}$ and argues that this loss occurred as a result of the poorly designed and implemented regulation. The MIR was not scaled appropriately to fit the needs of small-scale producers and processors, limiting their ability to maintain sustainable local and alternative food supply networks. The MIR was poorly designed and implemented, because it reflects three discourses that are dominant under the current neoliberal hegemony; 'standardization equals safety;' 'bigger is better;' and 'one size fits 
all.' These dominant discourses are reflected in the assumption that inspection will produce a safe product and it is the only way to produce a safe product. These three discourses are prevalent under neoliberalization, especially at the federal level, and draw out the interconnections between industry and government, demonstrating the ways regulations are used as "tools of governance" and have allowed state intervention in the market while maintaining the neoliberal illusion of laissez-faire. Although this demonstrates the broader neoliberal discourses, two questions remain. First, why was the MIR enacted in the first place, despite BC's history of safe-food? Second, why did it reflect these discourses despite BC's demographic of small-scale agriculture and stated support for local food? These questions are addressed in chapter five, which uses a scalar analysis to draw out the federal government's role as 'scale manager,' and points to the ways that the provincial government's design and implementation of the MIR reflects tendencies central to Zombie Neoliberalism. 


\section{Chapter: From Roll-Out to Zombie Neoliberalization}

\subsection{Introducing the Shift from Roll-Out to Zombie Neoliberalization}

We are currently living in a new era of neoliberalization that is no longer defined by deregulation, but instead by re-regulation. Termed roll-out neoliberalization, one tendency that is often attributed to this era is that of downloading responsibilities from higher levels of government onto lower levels of government, social-service agencies, or private contractors. This chapter uses scalar analysis to provide a deeper and broader understanding of roll-out neoliberalization, arguing that the state, specifically the federal government, has taken the role of "scale manager" to facilitate the scales and interactions between various government and institutional players, with the intention of supporting Canada's production and export markets. On the one hand, the provincial government has also played a role in this facilitation process, through the outcome-based design of the Meat Inspection Regulation (MIR) and their decision to contract the implementation of the MIR to the CFIA, reflecting roll-out neoliberalization. On the other hand, we are also seeing the emergence of 'Zombie Neoliberalization' (Peck, Theodore and Brenner, 2009). This new expression of neoliberalism is described as the "living dead" phase, in which "residual neoliberal impulses are sustained not by intellectual and moral leadership, or even by hegemonic force, but, by underlying macroeconomic and macroinstitutional conditions" (Peck, Theodore, \& Brenner, 2009). Thus despite the lack of gusto for large-scale export-oriented agriculture at the provincial level, because deeply embedded neoliberal tendencies allow the system to be operational as a structural model, it continues to push forward its agenda despite a lack of political leadership on the 
provincial level. This section argues that the case of the MIR reflects tendencies of rollout neoliberalization, by which the needs of large-scale agri-business are facilitated through different scales, putting pressure on provincial governments to enact meat inspection regulations. Furthermore, the actions of $\mathrm{BC}$ 's provincial government reflect Zombie Neoliberalization in which, despite the increased attention drawn to the weaknesses of a neoliberal approach to agricultural policy, the embedded neoliberal structure pushed forward a regulation that is contradictory to the needs of $\mathrm{BC}$ 's agricultural and rural communities. Fortunately, this new era of neoliberalization also means that it is becoming increasingly possible to point to these inaccuracies and target the weak spots in strategic forms of resistance, as discussed in the following the chapter.

This chapter begins by looking at the scalar interactions that have facilitated authority and responsibility throughout various levels of government, with the state acting as "scale manager," ultimately putting pressure on the $\mathrm{BC}$ government to enact the MIR. The chapter then looks at the provincial level and analyzes the factors that reflect Zombie Neoliberalization. Due to the embedded systems of roll-out neoliberalization, despite the intentions of the provincial government, it has nevertheless designed and implemented a regulation that does not fit with the needs of agricultural and rural communities. This has been the result of neoliberal tendencies combined with the provincial government's focus on resolving immediate crises, a lack of resources for consultation, and conflicting agencies' agendas. The chapter demonstrates this by drawing attention to the outcome-based approach to the design and implemented the MIR that returned authority to the federal level, reproducing the dominant discourses that have 
caused the crisis in the first place. Finally the chapter looks at the effects of Zombie Neoliberalization on the ground, outlining the damage it has caused across the province.

\subsection{Scalar Relations and Roll-Out Neoliberalization}

Analyzing the MIR in the wider context of shifting scalar relations allows us to understand it as part of a broader complexity of scalar interactions. It is part of a complex web ranging from international institutions down to ground level abattoir operators. Despite the jurisdictional division of Canada's meat regulations, between federal, provincial, and in some cases, municipal jurisdictions, there are strong relations and interconnections between these jurisdictions and actors at the international scale. Federal inspection regulates facilities whose products will be sold internationally or interprovincially, whereas provincial inspection regulates facilities whose products will remain within the provincial borders. Despite this jurisdictional divide, provincial scales are affected by crises and changes at federal and international scales, and vice versa. Due to an increase in food-borne illness outbreaks coming out of federally inspected plants, the federal government has put pressure on provincial governments to implement meat inspection regulations. This interconnectedness does not occur in a way that distributes power evenly, but instead has allowed for the federal government to maintain a larger degree of power and to set the desired outcome, yet download responsibilities for designing and implementing this system onto provincial scales. Thus the federal government has set the requirement for all provinces to adopt a meat inspection regulation, but download the design and implementation onto the provinces. This can be understood through a scalar analysis. 
Amin writes that although the conventional "territorial idea of the local, national, and the global as separate spheres of social organization and action... It is the resulting interconnectedness, multiplicity and hybridization of social life at every level - spatial and organizational - that [is] perhaps the most distinctive aspect of contemporary globalization" (Amin, 1997, 129). He furthers these thoughts in later works stating that "those concerned with the politics of regulation and governance associated with globalization are right to note the very real and felt contest of jurisdiction and control between local, national, and global state and non-state organizations..." (Amin, 2002, 396). This is relevant to the analysis of meat regulation in that although there is a jurisdictional divide between provincially and federally inspected abattoirs, in practice the actions at one level affect happenings on all levels. For example, the Listeria outbreak at a Maple Leaf processing plant, which was federally inspected, created distrust among Canadians and led to numerous investigations, which ultimately affected regulations in small-scale abattoirs, despite the different levels of risk that are present at smaller plants. The shifting of authority and responsibilities, such as increased authority to international institutions such as the IMF, WTO, and the World Bank and increased responsibilities to government agencies and local operations to achieve prescribed outcomes, has meant that the state's role has been redefined as a facilitator, or "scale manager" in the emergent structures for metagovernance (Mahon \& Keil, 2009; Peck 2002).

The state's new role as scale manager is reflected through the structure of Canada's meat regulations in which, although divided jurisdictionally, the federal state retains a strong level of authority and influence over the direction of provincial systems for meat regulation (I-22, 2011), demonstrating that "boundaries can nonetheless be quite 
permeable" (Miller, 2009, 53). Export priorities have been facilitated through "tools of governance", which allow states to act at a distance (Dunn, 2005). By doing so, "people are not necessarily aware of how their conduct is being conducted, or why, so the question of consent does not arise" ( $\mathrm{Li}, 2007,5)$. The term 'boundary objects,' which are defined as objects that are transferred from one community to another, can be used to describe the ways in which regulatory functions can "shift scales" (Miller, 2009, 55). 'Scale shifting' is becoming more widely recognized as one of many strategies used by both political and social groups in contentious politics, by which higher level institutions can establish the scope, policy, and action at lower-level scales preventing (although in some cases also enabling) democratically made decisions (Miller, 2009, 55). Peck discussed this phenomenon stating that "highly exposed localities are pitched in an asymmetrical competitive battle against an unyielding global market, their only realistic response being to adapt" (Peck ,2002, 334). Regarding meat regulatory systems, this is demonstrated between a variety of scales, beginning with relations between international and national scales.

Due to the federal government's priority to ensure a standard of regulations that enables and supports its export and import markets, relations between international and national scales have had a major affect on Canada's federal meat regulations, which are in turn facilitated down to provincial and local levels. Because of Canada's reliance on foreign capital and dependency on international markets (Panitch, 1997), especially concerning its large-scale meat industry $(\mathrm{I}-17,2011)$, many regulations are ultimately tied to facilitating international trade (I-14b, 2011). Standards in international processing plants are not solely determined by the Canadian government, but are hugely influenced 
by trading partners and international bodies (I-1 la\&b, 2011). The increased fear resulting from food-borne illness have led trading partners to demand an insurance that all meat in Canada, despite its destination, has gone through inspected facilities as a tactic of riskmanagement $(\mathrm{I}-11 \mathrm{~b}, 2011)$. This reflects a broader trend in neoliberal governance, demonstrating that although "economic and extra-economic structures, imperatives, and dynamics may be separable through abstraction... they are organically connected in practice..." (Peck, 2002, 336). The state's role as 'scale-manager' has been essential to coordinating the demands at global levels with the processes at local levels (I-14b, 2011). This is reflected through the federal government's responsibility to carry out programs and policies that will meet the demands of international institutions and trading partners, in which import and export regulations set the bar for Canadian meat industries (I-8, 2010; I-11b, 2010; I-14b, 2010). Thus the federal government has worked to facilitate this by putting pressure on provincial governments to enact systems for meat regulation with no regard for the size of the operation or its intended market (I-22, 2011).

Despite the jurisdictional division of Canada's meat regulations, it was still necessary for the federal government to be able to assure trading partners that there would be no traces of uninspected meat entering in the international food chain, and therefore with little recognition and appreciation for importance of scale, pressure was increasingly put on the provinces to follow suit, regardless of their history of, or lack of, food-borne illnesses. In turn, the "inherently accountable" regulatory systems in local and alternative food networks were replaced by a provincial level regulatory system that was designed for "huge economies of scale and export" (I-20, 2011). This imposition prioritizes the needs of large-scale export oriented agriculture, over the needs of the 
numerous small-scale operations that are present across the country $(I-8,2010 ; \mathrm{I}-14 \mathrm{~b}$, 2011). One local politician in BC's interior recognizes these priorities, stating "there is a perception with this government that economically the small scale producers are not worth their time. That from a business point of view, that from an economic point of view, that larger scale agriculture is where we want to go" $(I-23,2011)$. Across BC, many stakeholders criticize the motivations behind the MIR. One farmer refers to her MLA who explained "that the regulation was put in place at the behest of the federal government" which was "concerned about being able to help farmers in Canada export their meat" and helping "the people who are big players" (I-21, 2011). These points demonstrate that the MIR's implementation reflects the interconnections between levels of government and demonstrates the complexity of factors that are facilitated through the scales. Not only were the needs of federal scales facilitated onto provincial levels, but furthermore the provincial government downloaded of responsibilities onto the CFIA.

Due to the pressures from the federal government, BC's provincial government designed the MIR, but due to a variety of factors discussed below, they contracted the CFIA to implement the new regulation, reflecting tendencies of roll-out neoliberalization. Although, neoliberalization can be defined as "a flexibly mutating regime of market rule" (Peck, Theodore, Brenner, 2009, 95), reflecting the self-regulating market, trade liberalization, deregulation, and limited state involvement (McCarthy \& Prudham, 2044), it has more recently become associated with the "rolling-back" of the state and deregulation (Peck, 2002, 396). Despite the illusion of laissez-faire, "in practice neoliberalization has produced significant re-regulation: new rules, new rule-making bodies, and new spheres of rule making" (Guthman, 2007, 466). Although these 
tendencies reflect the federal government's new role as "scale manager," the following section will demonstrate that the subsequent actions by the provincial government to design the MIR and contract it out to the CFIA are more reflective of Zombie Neoliberalization.

\subsection{The Emergence of the Zombie}

Although this case reflects neoliberal tendencies in which the federal government acts as a "scale manager," facilitating the regulatory needs of trade and export, this section will demonstrate that the provincial government's actions to implement the MIR reflect a new expression of Zombie Neoliberalization. Zombie Neoliberalism is a result of the federal and provincial government's focus on resolving immediate crises and their lack of consultation, combined with the intention of policy to be open to interpretation. BC's provincial government has demonstrated some perplexing contradictions between its perceived support for local food campaigns (Government of British Columbia, 2011) and its food policies and regulations that have inhibited the growth and sustainability of local food supply networks. Many individuals and groups interviewed throughout $\mathrm{BC}$ have attributed this contradiction to the provincial government and CFIA's disconnect from agriculture and rural communities in $\mathrm{BC}$, and although this is a legitimate claim that will be discussed further below, this section will demonstrate that the poorly designed and implemented MIR is part of a much deeper and complex systematic problem, which can be described through Zombie Neoliberalism. Peck, Theodore, and Brenner describe the emergence of a "living dead" phase, in which embedded tendencies recreate the neoliberal hegemony, despite recognitions of its faults (Peck, Theodore, \& Brenner, 2009). This concept can be applied to the case of meat regulation in BC in that, despite 
the provincial government's support for local food, the systems of neoliberalization have functioned almost instinctively to implement the MIR. These tendencies have inhibited governments and individuals from affecting the desired change that is needed to fulfill its goals of creating a more sustainable network of local food production in $\mathrm{BC}$. This contradiction is not only a result of roll-out neoliberal tendencies and the scalar relations discussed above, but also the government's concern for resolving immediate crises and lack of resources for consultation. The provincial government has acted as a zombie, instinctively pushing forward a federally-based policy that supports the dominance of large-scale, export-oriented agriculture.

One reason for the emergence of Zombie Neoliberalization is due to the government's focus on immediate problems, such as food-borne-illnesses, which has prevented the government from paying attention to long-term issues of food-security and sovereignty. Ironically, many of these immediate crises, such as nation-wide food-borne illness outbreaks, have originated from large-scale industrial agriculture and are a product of our current hegemonic order; but the government has been so busy trying to repair the damage, that they are unable to see the larger picture and unwilling to address the root causes of these issues. At the federal scale, the government and AAFC are overwhelmed with resolving immediate issues and often find it difficult to give attention to the longterm picture, stating that "government policy is always knee jerk. Most times they react to crises problems and they put in solutions that try to tackle that problem, without fully considering what other problems... [they] are causing" (I-8, 2009). As was mentioned above, this attitude is partly a response to the criticisms that the federal government and CFIA faced for underestimating the risks of BSE, which has in turn altered their process 
of risk management and policy making (Leiss, 2004, 233). Therefore, the strong focus on resolving immediate issues tends to dissuade provincial and federal governments from looking into long-term issues and food sovereignty. This exasperation is partly to blame for the lack of consultation, which added to the poor design of the MIR (I-17, 2011).

Although the government eventually began a consultation process after the implementation of the legislation forced large numbers of abattoirs to shut down, prior to the legislation's implementation the Ministry of Health not only failed to engage in public consultation with the individuals and communities that this legislation would be directly effecting, but their consultation with the Ministry of Agriculture was also very limited (I-21, 2011; I-23, 2011). As one local farmer explains, "they didn't ever take the time to find out what it was that a small scale abattoir actually did" (I-21, 2011). Had they engaged in a consultation process they would have found that there was no evidence or recorded cases of there ever being a problem with tainted meat coming from their small scale facilities $(\mathrm{I}-23,2011)$. One small scale farmer draws attention to the fact that although the government touts food safety "they will not and have never been able to tell me what meat grown locally, slaughtered locally, and sold locally has ever harmed anyone. There is absolutely no indication of that anywhere" (I-21, 2011). The BC Cattlemen's Association seconds this point that you won't ever find any data on numbers of contamination coming out of the small facilities (I-16, 2011).

Despite the lack of evidence pointing to food safety issues on the small scale, they decided to go ahead with a "one-size-fits-all" approach which forced all sizes of operations to abide by the same regulations. One operator points out that "they did everything backwards... it appears to us that somebody decided to come up with some 
pretty lofty ideas for meat inspection in this province and they didn't really think through what the ramifications would be... They just hucked it at the wall to see if it would stick, and now they have been trying to clean up ever since" (I-29, 2011). Due to the need to implement meat safety legislation and lack of consultation "they didn't anticipate what would happen. They just thought it would be easy ... they never anticipated that it would be such an issue" $(I-23,2011)$, but instead pushed through the MIR. The structure of BC's bureaucracy and the role and intention of policy design, has also contributed to the poor design and implementation of the MIR.

The policy design has accorded increased authority to bureaucrats and contracted agencies who implemented policy, which in the case of the provincial government's contract with the CFIA, has awarded excessive authority to this federal agency over provincial matters. Officials at the CFIA explain that policy is written with the intention of being open to interpretation and for this reason is often written very broadly to allow for individuals working on specific cases to be able to address the unique and everchanging factors that affect and are affected by specific regulations (I-14b, 2011). Although the intention of this process is to allow for governments to better represent the needs of civil society, at the same time this has also meant that the bureaucracy has gained a higher level of control and in many cases suppressed the democratic process (I34, 2011). Many British Columbians interviewed were very distressed about the provincial government's attitude of arrogance and control, with one instructor at a local college explaining that

our biggest problem is that the bureaucrats think they are running the system... when you are a government official... you are to serve the public, not dictate to the public or industry... That has been very 
frustrating, they haven't listened, they have dictated... the level of arrogance is disturbing. (I-17, 2011)

This attitude of the provincial government and its various agencies has been a problem and it is not being recognized that "the bureaucracy has a function and it's a very clear function. It's not a governance function. It is implementing the results of policy" (I-17,

2011). The interviewee added that

The regulatory climate within $\mathrm{BC}$ and the way that those regulatory requirements are being implemented by a civil service that has lost touch and believes that they know what is the right thing, is very disturbing and it's very destructive... this is not serving the public interest. This is reducing consumer choice, this is reducing the ability of what was an economically viable sector... If you look at other civilizations throughout history and what happens when the bureaucracy takes control... everything is linked. The whole justice system, the middle class is gone, people feel dispirited and all sorts of social ills come up and we get in a pretty nasty down turn cycle... evidence is available to use if we look to history... Neoliberalism, it's not liberal, it's not liberal. $(\mathrm{I}-17,2011)$

This moves us into the a more detailed discussion of the ways in which the MIR's outcome-based design transferred authority back to the federal level, reflecting Zombie Neoliberalization.

\subsection{Outcome-Based Regulation}

Zombie Neoliberalism demonstrates that neoliberal tendencies have not been replaced, but instead that these embedded systems are a central aspect to this new era by allowing for the hegemony to recreate itself, despite contradictions to the intentions of its leaders. "Outcome-based" legislation, which allows for an outcome or target to be set at the provincial level, but downloads the process to achieve that outcome onto private or public agencies, reflects trends of roll-out neoliberalization. This has allowed the provincial government to dictate an outcome of the MIR - safe meat through inspected facilities - 
but download the process, responsibilities and onus for achieving this outcome onto the CFIA. The design is made to be non-prescriptive, which in theory enables ground level agencies to take into account all the variants and have a built in flexibility, but in reality the effects are quite different $(\mathrm{I}-23,2011)$. One politician explains,

It's not just with this legislation, this current government is quite enamored with outcome based legislation... They feel they run into too many different factors when you create a piece of legislation that attempts to be prescriptive, because you can't anticipate all the things that will come up in the implementation of it... By not being prescriptive they believe that they are enabling local government to reach that outcome [safe food] in a way that suits them [through] built in flexibility. That hasn't actually worked. (I-23, 2011)

Although the devastating effects of the outcome-based regulation are partly due to an inability to find a balance between consistency and flexibility, it is also a result of the choice to contract the MIR to the CFIA, challenges deriving from conflicting agencies, and the issue of liability that results from roll-out neoliberalization.

Unless outcome-based legislation can balance consistency and flexibility, it will face major challenges. One politician states that "the idea of outcome-based regulation is good, but at the same time you need to have very clear criteria in terms of steps along the way, particularly for the staff that are implementing it and... make sure there is consistency in the message going out... So you have to find a balance between that and flexibility" (I-23, 2011). Because the MIR is open to interpretation by the CFIA "you're being told different things when you talk to different people about what you have to do to achieve that outcome" $(I-23,2011)$ and there is an attitude of "now you've done that, we need you to do this" (I-21, 2011), which transferred a great deal of the onus onto the individuals. One small scale farmer explains that "we get pushed through the door, and if the door closes, it's our heads getting chopped off. It's our head getting chopped off' (I- 
32, 2011). Even if the MIR had found this balance, there are nevertheless remaining tensions with the outcome-based approach, including the choice to contract the MIR to the CFIA, numerous conflicting agencies, and liability issues.

Contracting out the regulation's implementation to the CFIA, which is a federal agency, has now been recognized as problematic because of the discourse that values large-scale, standardized operations that is dominant at this level. Furthermore, not only does the CFIA fail to recognize the value of scale, but it also has little experience with, or knowledge of, the unique needs of small-scale operations and economies. A representative from the BC Cattlemen's Association explains that he would put most of the blame on the CFIA and the fact that "they are basically working under what should be BC laws, but they are still trained under CFIA, so they enact a whole bunch of those regulations, that maybe aren't there or shouldn't be there" (I-16, 2011). One farmer explains that, "the CFIA had no rules to follow. So they went by their own, "which were designed for large scale" and "they just didn't ever take the time to find out what it was that the small scale abattoir actually did" $(\mathrm{I}-21,2011)$. This problem is partly due to the fact that, as mentioned above, this legislation was drafted as outcome based and so there is nothing to guide them "so they could only do what they knew, which was federal" (I21, 2011). The representative from the BC Cattlemen's Association connects these ground issues to larger problems of distribution and transfer of authority stating that the government must "get control of the CFIA, because the CFIA is its own entity. They've got the rule book there and no matter how much politicians say they want to fix it and they understand it, for some reason, the CFIA just has this control that we have a tough time breaking" (I-16, 2011). This authority given to the CFIA has limited democracy 
surrounding the MIR by removing it from the realm of politics into the realm of experts. This clearly points to Zombie Neoliberalization, in which democracy has been thwarted by embedded neoliberal tendencies that recreate themselves despite a lack of leadership. This problem has been exacerbated by challenges that have arisen from the number of conflicting agencies that abattoir operators must circumvent to maintain inspection.

The large number of agencies who play a role in the regulation of abattoirs and the disconnect between these agencies is another systematic issue that has inhibited actors from implementing the MIR in a way that can address the needs of British Columbians. In order to have their facility licensed, an operator must deal with up to 6 different agencies, which include the $\mathrm{BC}$ Centre for Disease Control, the Health region, the Canadian Food Inspection Agency, the Ministry of Environment, the Ministry of Agriculture, and the Agricultural Land Reserve (I-17, 2011). The BCFPA recognizes these challenges, explaining that "it's difficult to get agencies together such that crosscutting regulatory issues can be sorted out. Abattoir operators have found it difficult, sometimes impossible, to fully comply with the MIR and all other related requirements" (I-25, 2011). Agencies "don't always talk to sister agencies and then come up with constraints that are outside of their jurisdictions to reply" (I-17, 2011). One politician recognizes these structural problems, explaining that "Our governance structure is cumbersome... because it is such a big organization. How do you communicate within it effectively and how do you communicate with citizens" (I-23, 2011). This structure has inhibited both civil society and government officials from navigating the agencies in order to design the MIR in a way that reflects the needs of British Columbians (I-32, 2011). Not only does the inability to find a balance between consistency and flexibility, 
rolling-out to the CFIA, and numerous conflicting agencies create a systemic problem, but these issues are further exacerbated by the liability concerns of professionals implementing the regulation.

Liability is becoming increasingly recognized as an issue in terms of risk management and it played an important role in the implementation of the MIR. An industry consultant explains that "the regulatory regime drives to the gold-plated (and unaffordable) standard, to protect regulators, their staff and contractors from liability" (I$25,2011)$. This has been extremely frustrating to plant operators. This is not only an issue between the CFIA and agencies, but an agricultural economist explains that the decision to download it to the CFIA in the first place may have been partly due to the bureaucracy's disinclination to carry liability $(\mathrm{I}-17,2011)$.

The MIR reflects Zombie Neoliberalization by allowing for the priorities of largescale export-oriented agriculture to be pushed through in $\mathrm{BC}$, despite its clear contradictions to the needs of many British Columbians. This is a result of the systematic scalar relations that were facilitated down to provincial levels and were instinctively pushed through because of the government's exasperation with resolving immediate issues, the lack of consultation, and the role and intention of policy to be open to the interpretation of bureaucrats. Furthermore outcome-based design of the MIR was problematic because 1) it didn't have set guidelines or rules, which meant that 2) authority was awarded to the CFIA that prioritizes large-scale export oriented agriculture, and was further exacerbated by 3) the numerous and conflicting agencies and 4) liability issues. Thus, despite the government's attempt to make the regulation flexible to the needs of farmers and abattoir operators, because of these four points farmers and abattoirs 
were left in a situation where a federal agency that values large-scale, standardized processes, was given control over their operations. This points to new expressions of neoliberalism such as Zombie Neoliberalization in that, despite attempts to engage with actors on a local level and be flexible to their needs, the embedded structure of neoliberalization recreates itself. The effects of Zombie Neoliberalization have had devastating effects on the ground level for producers, processors, and consumers in BC.

\subsection{Zombie Apocalypse?}

Within this complex scalar web of the intentions, processes and outcomes of governments and institutions, the scale that is most affected and bears the highest cost, despite holding the least power and authority, is the local scale. Small-scale farmers and producers have felt helpless to confront the legislation, with one processor stating "this was just thrown on us really quick" using discourse that reflects this powerless position they were placed in "when the regulations came down" (I-28, 2011). Many farmers, processors, and local politicians place a great deal of blame for the devastation to rural and small-scale economies on the fact that this legislation was top down and was made in isolation from the people it would impact (I-29, 2011; I-22, 2011; I-23, 2011). This ability for rules to be set higher up, but the costs to be downloaded onto the ground level can be seen as result of the roll-out tendencies of Zombie Neoliberalization. Thus, upon implementation of the MIR, abattoirs in BC were left with three options: to conform to the new regulations and upgrade their facility, which was financially unfeasible for most small scale operations; shut down their business; or go underground. In one fell swoop, due to the increasingly complex interconnections between scales and neoliberal 
tendencies, the landscape of rural and agricultural communities in BC was forever changed.

\subsection{Conclusion}

The case of the MIR in BC draws out an important question that is starting to be asked in the field of political economy surrounding motivations behind neoliberalization. Although we see tendencies of roll-out neoliberalization, there are also several inconsistencies. For example, the outcomes of the MIR are in contradiction to the provincial government's campaigns to support local food. Chapter four outlined how food-borne illnesses and consumer distrust has motivated the government to take action to secure its import and export markets. This chapter uses a scalar analysis to demonstrate the federal government's role as a scale-manager, in turn facilitating the needs of stakeholders on international and national levels by pressuring the provincial government to implement a meat inspection regulation. Furthermore, this chapter argues that the way in which the provincial government followed suit designing the regulation, and the factors that played out in its implementation, reflect Zombie Neoliberalization, whereby hegemony is recreated, despite a lack of clear leadership. Although the government had the right intention, the embedded systematic tendencies of neoliberalization and failure to take into consideration the importance of scale, have had devastating effects for smallscale operations and economies throughout BC. Nevertheless, Zombie Neoliberalization has meant that it is becoming increasingly possible to recognize and draw out the "weak spots", opening new avenues for resistance both within government and civil society that 
have the possibility of being able to support local and alternative food systems in BC's future. 


\section{Chapter: Implications for a Response and Counter-Hegemony}

\subsection{Introduction}

Since the implementation of the MIR there have been a number of unique and diverse responses by individuals and groups throughout $\mathrm{BC}$. The three initial options for producers and processors in 2004 - go underground, shut down, or upgrade - have merged into three responses to the MIR - resistance, compliance, or adjustment. This chapter argues that due to the increased authority of social movement organizations (SMOs), the development of unlikely alliances, and the power of market-based strategies, neoliberalism has opened new possibilities for resistance, allowing for individuals and groups to attain localized successes. Nevertheless, a political-economic and discourse analysis draws out remaining tensions that have been left unexamined, further arguing that tensions have arisen between the ability to attain localized success that can address the unique needs of individual actors and the ability to engage in more widespread resistance that can act as a counter-hegemony to the root causes of the MIR's implementation. These tensions result from neoliberal tendencies that limit and define responses, allowing it to capitalize on and grow from the very crisis situations that it has created. If left unexamined, this phenomenon could potentially lead to an increasingly dichotomized and regulated food landscape. However, this chapter finally argues that through a scalar approach to resistance, individuals and groups in BC could not only work towards localized solutions that take into account their unique needs, but could also begin developing the networks and the capacity to respond to the root causes of the MIR, leading to more long-term, broad-reaching, counter-hegemonic opportunities that reflect 
food sovereignty and improve the sustainability and strength of Canadian food systems and communities. This chapter begins with an analysis of three responses to the MIR.

\subsection{Resistance, Compliance, Adjustment}

Although the MIR was implemented as a 'one-size-fits-all' policy, a diversity of factors has meant that the MIR has not only affected different individuals, groups and communities in different ways, but these factors have also affected the forms of resistance that have been undertaken within different groups. The three regions studied and compared during the course of this research, the North Okanagan, Powell River, and the Gulf Islands, each demonstrate different challenges, goals, strategies, actors involved, actions, timelines and scales that have resulted in various responses. These responses can be grouped into three categories: resistance, compliance, or adjustment, and although for the most part these responses are regionally divided, this is not always the case. Furthermore some groups or individuals have engaged in more than one of these responses, whether simultaneously or at different times.

The category "resistance" reflects forms of underground and localized resistance in the form of farmers and underground tradesmen who have continued along with their lifestyles despite its illegality, as well as the consumers who support these individuals through material, organizational or discursive support. The North Okanagan is a region where there has been a large amount of resistance by both small-scale farmers who have continued on-farm slaughter, and a small number of underground tradesmen who have continued their operations, despite the threat of enforcement (I-21, 2011; I-28, 2011). The category "compliance" reflects farmers and operators who have complied with the regulation by building or upgrading a facility to the required standards, bringing their 
livestock to an inspected facility to be slaughtered, or conversely have complied by shutting down their business. These three types of compliance have been seen throughout the province, although not all three options were available to all individuals. For example, compliance through upgrading or bringing livestock to a licensed facility was not an option for those living in isolated and remote areas. For farmers in these regions, upon the enactment of the MIR, their only way to comply was by shutting down (I-32, 2011; I33, 2011) Finally, the category "adjustment" represents those who have targeted or worked with the government to change the regulation through amendments that will cater to their specific needs. Many individuals or groups have engaged in more than one of these three tactics, and as is argued further below, the ability to engage in multiple responses has increased the rate of achieving success. This chapter now outlines three separate cases of response to the MIR that have attained a certain degree of individual success.

\subsection{Individual and localized "Successful" Responses}

Three responses that were able to achieve a relative degree of localized success were the amendment process led by the remote region of Powell River, the development of niche markets by abattoir operators in the province's rural mainland, and the continuation of on-farm slaughter by farmers and underground tradesmen throughout the province adjustment, compliance, and resistance, respectively. All three cases demonstrated unique challenges, goals, strategies, actors involved, actions, timelines and scales, resulting in different yet successful localized outcomes.

A small group of individuals in Powell River, in collaboration with individuals in similar situations in the remote and isolated regions of Lasqueti Island, Texada Island, 
Bella Coola, Bella Bella and Haida Gwaii, chose to employ the strategy of adjustment, which aimed to amend the MIR. The choice to amend the regulation reflects their unique challenges, goals, strategies, actors, actions, timelines and scale. The remote and isolated regions faced particularly difficult challenges after the implementation of the MIR because there were no abattoirs in these regions and producers relied solely on on-farm slaughter. Because of the unique demographics, consisting of small populations in remote areas, it was not feasible to build an abattoir. The implementation of the MIR left no option for farmers to legally have their animals slaughtered, with the exception of bringing the animals to Vancouver Island or the mainland by ferry, which was unfeasible for a variety of reasons relating to cost, stress, and time (I-32, 2011; I-33, 2011). Thus, in Powell River, as well as other isolated regions, farmers were either forced underground or to stop producing meat. An industry consultant explains that once the isolated regions began presenting their case and demonstrating that it was not feasible for them to build a facility, the government sent someone from the Ministry of Healthy Living and Sport to go and look at the problem (I-25, 2011). In April 2009 the Minister announced the Remote Sites Consultation, to take place in Bella Coola, Haida Gwaii and Powell River. A team from the (then) Ministry of Healthy Living and Sport and the BCFPA worked with producers in those communities (including Texada and Lasqueti Islands) to develop a risk assessment of on-farm slaughter, and a training program and Food Safety Plan based on identifying and mitigating food safety risks at critical steps of the on-farm slaughter process. This involved watching farmers go through the steps of slaughter to see exactly what they were doing (I-32, 2011). The training program and Food Safety Plan became the key elements of the $\mathrm{D}$ and $\mathrm{E}$ licensing approach when it was introduced 
in April 2010 by amending the MIR. This process had a fairly short time-line and, although the outcome of the actions may eventually have province-wide affects, the majority of the actions took place on a local scale. Keeping this response local was a deliberate strategy by government officials and farmers, who expressed a strong sense of individuality reflecting their primary goal of to keep their "own part of the province working" (I-17, 2011). The combination of these challenges, goals, strategies, actors, actions, timelines and scales resulted in the enactment of Class D and E licenses. Up to this point, Class D licenses have only been granted to the small number of individuals in the isolated and remote regions that were involved in this amendment process ( $\mathrm{I}-32$, 2011; I-33, 2011), although potential Class $\mathrm{E}$ licenses will be granted to individuals in other regions on a case by case basis.

The development of niche markets by abattoir operators in rural and mainland $\mathrm{BC},{ }^{15}$ represents a second response that was employed by operators who have complied with the MIR by upgrading to or building a licensed facility, and turned to market-based strategies to strengthen their operations. Many of the abattoir operators who complied, but were forced to upgrade to a larger size than they had planned are now facing challenges from both the production end (challenges finding sufficient input to keep their operation running efficiently) as well as from the consumption end (challenges finding sufficient markets that can sustain the scale of their operation) (I-29, 2011; I-27, 2011; I26, 2011). Despite their ability to comply with the requirements of the MIR, many abattoir operators are now facing bankruptcy and feel betrayed by the government, which obliged them to build such large facilities (I-27, 2011; I-29, 2011). As a result, operators

\footnotetext{
${ }^{15}$ Stakeholders have also developed niche markets in other regions, including Vancouver Island and Powell River (I-29, 2011; I-33, 2011)
} 
have focused their response on the realm of the market, and have set the goal of targeting or developing niche markets to sell their products $(\mathrm{I}-29,2011 ; \mathrm{I}-26,2011)$. Strategies to attain this goal include not only individual attempts at promoting niche products, but also the formation of the $\mathrm{BC}$ Abattoirs Association (BCAA) to coordinate various abattoirs across the province and develop a BC label $(\mathrm{I}-26,2011)$. The BCAA has also developed a secondary strategy to address the input challenge, targeting the state and lobbying them to engage enforcement in order to wipe out underground tradesmen (I-20, 2011). There are a number of different actors involved in these strategies and although abattoir operators have played the largest active role, their efforts rely on the support of producers, consumers, other lobby groups, including the British Columbia Cattlemen's Association (BCCA), and government officials.

The actions involved in their strategies include finding avenues to market their products locally through newspapers, specialty stores and farmers markets $(1-27,2011)$, and tapping into niche markets such as high-end restaurants and wineries (I-26, 2011). This involves promoting niche traits such as a healthier product due to advanced processing systems, halal and kosher meats, meat from grass-fed livestock, the biodynamic philosophy, and Seznia beef (I-26, 2011; I-25, 2011; I-20, 2011). Many of these efforts have been developed by individuals, with one processor explaining "I've pounded on many doors, walked a lot of pavement, drove a lot of miles... when developing those niche markets, you have to really work at it" (I-26, 2011). Groups have also developed marketing strategies, for example the BCAA is developing a $\mathrm{BC}$ label to better connect the consumer to the product and promote licensed facilities (I-20, 2011). The BCAA has also engaged in other actions such as displaying signs as a way of getting the brand out 
there and developing the discourse that equates BC's inspected facilities with quality (I$20,2011)$. This response targets short, medium, and long-term timelines and although focuses on local scales, is moving towards targeting provincial scales. The combination of the above factors has resulted in the development of niche markets as a way of responding to the implementation of the MIR through compliance.

Finally, resistance through the continuation of on-farm slaughter, by farmers and underground tradesmen represents a third response. Although this response has been undertaken across the province, this section will specifically focus on the case of farmers in the North Okanagan, who have been particularly outspoken about their choice to resist the MIR. Upon enactment of the MIR, many small-scale farmers, who had been conducting on-farm slaughter for generations, faced unique challenges in that their lifestyles were suddenly defined not only as illegal but as unsafe and unsanitary, severely stigmatizing their traditions. This threatened the ability for farmers to express food sovereignty for any number of reasons, including food sovereignty reflected through lifestyle and type of farming, the maintenance of skills and knowledge, plant and animal diversity and welfare, and resistance and environmentalism. These small-scale farmers therefore maintained the goal to be able to continue on-farm slaughter, which entailed strategies to preserve local knowledge and skills, maintain the "inherent accountability" of community-based systems for food safety, and maintain the structures of localized economies and alternative food supply networks. Resistance involved a number of actors, including small-scale farmers, underground tradesmen, and supportive consumers; it excluded government officials, inspected abattoir operators, and mainstream retail outlets. Small-scale farmers and underground tradesmen targeted the local scale with a 
timeline aimed at both providing an emergency response in the short term, as well as maintaining long-term goals of food sovereignty. On the one hand factors that have affected their strategy have led to relative success as an emergency response and the preservation of localized and unique skills and knowledge, which supports discourses of the counter-hegemony. On the other hand, due to its illegality, the resistance has been limited in scope, restricting its ability to act as a counter-hegemony, as will be discussed further below. Each of these cases, reflecting the options to adjust, comply, or resist, has engaged in a very different response, due to its unique challenges, goals, strategies, actors involved, actions, timelines and scales. Part of the reason these responses were successful was because of the new avenues and possibilities for resistance that have been opened through neoliberalization.

\subsection{New Avenues and Possibilities}

The effectiveness of the three strategies discussed above can be attributed to the new avenues and possibilities for responses that have been opened through neoliberalization, specifically the increased authority awarded to SMOs, developing unlikely alliances, and the increased role of market-based strategies in resistance. The increased authority to SMOs is demonstrated primarily by those engaged in compliance and in adjustment. The development of unlikely alliances is demonstrated primarily by those engaged in adjustment and resistance. The increased role of market-based strategies has been demonstrated primarily by those who complied, but also by those who chose to adjust or resist the MIR. 
The development of the BCAA to promote marketing initiatives and the use of farmer's institutes in the adjustment process demonstrates the increased role of SMOs in the neoliberal era. A common theme that came out of interviews has been the value of groups over individuals, in order to not only provide the support and energy to sustain a movement over time but also in order to present a unified voice when lobbying in political and economic realms (I-10, 2009; I-33, 2011, I-17, 2011). A consultant to the BCAA states, "it's no good everyone working in silos and not knowing each other" (I-20, 2011). This message has come from farmers, politicians, consultants, and industry associations, with one representative stating "if the government is getting 60 different messages, they are not going to do anything for us. So it is very important to us as an organization to make sure that we have the right message to take forward" $(I-16,2011)$. These SMO's play an important role in providing information to both consumers in the case of niche markets, and to the government, in the case of the BCAA's lobbying efforts and Powell River's adjustment process (I-20, 2011; I-32, 2011).

In all regions across the province, actors have pointed to the increased ability of SMOs to gather appropriate knowledge and information to move their goals forward. In Powell River, as well as in other regions, the production of feasibility studies has been important to help communities determine what is best for them, as well as a strategy to educate the government on the importance of small-scale regional processors in rural regions $(\mathrm{I}-29,2011 ; \mathrm{I}-32,2011)$. A farmer explains that once the isolated regions began presenting their case and demonstrating that it was not feasible for them to build a facility, the government started sending officials to analyze the problem (I-32, 2011). These points demonstrate the increased authority that has been gained by SMOs and in 
turn their ability to engage the government and influence the directions of a response. Not only have these responses depended upon the new authority awarded to SMOs under neoliberalism, but they have also been dependent upon the development of unlikely alliances.

As argued in the previous chapter, we are now seeing a new expression of neoliberalism, termed Zombie Neoliberalization, by which neoliberal policies are pushed forward by embedded neoliberal tendencies rather than intellectual or moral leadership (Peck, Theodore, \& Brenner, 2009). Although this indicates that neoliberal structures have limited the success of counter-hegemonic movements, it also indicates that there are an increasing number of alliances working within these structures that are becoming aware of the weakness of neoliberal approaches to agriculture and are willing to support the aims of counter-hegemonic forces (Andrée et al., forthcoming). This has been the case within $\mathrm{BC}$ 's provincial government and industry associations, in which strong and dedicated officials have enabled the success of some individuals and groups engaged in counter-hegemonic responses to the MIR.

The efforts of certain actors can be particularly seen in the adjustment of the MIR, in which certain industry and government actors played a key role in its success. Key stakeholders worked to promote the importance of small-scale farming and encouraged other industry and government officials to value and respect the knowledge of these local farmers $(I-25,2011 ; \mathrm{I}-32,2011)$. One farmer in Powell River speaks of the government liaisons stating that "They really value what we have to say... Trust has been built in this working group... I don't feel that I am just a stupid farmer with no education... They really listen to what we have to say" (I-32, 2011). An industry consultant emphasized the 
importance of having mutual respect in consultation, stating "the hope is that when an environmental health officer walks onto a farm, that there is a mutual respect such that they can learn from one another" (I-25, 2011). This discursive shift was enabled by strong personalities that were found not only in the government, but also throughout Powell River's farming community.

Respectful communication is important to the process of finding common ground and building alliances. A small-scale farmer who was very active in leading this consultation explains that she and another farmer have "brought an attitude that's been different... we've always kept a positive attitude and... it has fostered that way of working together" (I-32, 2011). Another farmer who worked on this amendment process echoes this comment, stating that there was "a lot of respect on both sides for the process, and it came together" $(\mathrm{I}-33,2011)$.

Not only were unlikely alliances essential in the response to adjust the MIR, but they have been key to the ability to engage in underground slaughter either as the primary form of resistance, as well as a secondary strategy used in compliance and adjustment. As a secondary strategy, underground slaughter was used as avenue to maintain financial stability while awaiting the outcomes of compliance or adjustment (I-32, 2011; I-24, 2011). One abattoir operator explains the importance of a "gentlemen's agreement" with a government official that allowed him to continue slaughtering despite the fact that his facility had not yet attained licensed status (I-24, 2011). In the case of Powell River, government officials initially looked the other way while farmers engaged in underground slaughter $(\mathrm{I}-32,2011)$. Eventually these farmers were awarded transitional licenses enabling them to legally continue slaughtering, despite the officials' knowledge 
that the farmers had no intention of transitioning into a licensed establishment (I-32, 2011). The development of unlikely alliances was central to enabling both the positive consultation during the adjustment process, as well as the exceptions made that support the processes of compliance and adjustment. These alliances thereby played a key role in the success of many individuals and groups. Not only did many responses depend on the new authority awarded to SMO's and the development of unlikely alliances, but they also depended on use of market-based strategies, which have gained strength through neoliberalization.

Actors engaging in all three responses - resistance, compliance, and adjustment have pursued market-based strategies, which have gained strength under neoliberalization, enabling their success. Groups, including the BCAA and the BCCA, engage in market-based strategies that are not only effective due to increased strength of market-based resistance, but have also drawn attention and support from provincial and federal governments. The BCAA and the BCCA have both recently received funding from provincial and federal governments for marketing initiatives (I-20, 2011; I-16, 2011). This increased recognition of market-based initiatives can be attributed to the federal and provincial governments' increased attention to consumer rights and protection (I-3, 2009) A representative from CIELAP explains the importance of contextualizing issues in a way that can draw in the federal government's interests in consumer rights and market efficiency $(I-3,2009)$.

Resistance to the MIR has also employed market-based strategies, but rather than using public marketing campaigns, they have instead fostered the development and maintenance of underground localized and alternative food supply networks (I-28, 2011). 
Although these strategies are limited by being unable to access government support and conduct broader marketing campaigns, they have nevertheless strengthened community ties and consumer support for on-farm slaughter (I-28, 2011). Finally, adjustment strategies have depended on market-based strategies, by which they not only depended on underground markets similar to the resistance above, but they also relied on publically marketing and selling other products in order to maintain their legal farm revenue and farm-status (I-33, 2011). One farmer in Powell River explains the importance that the development of a market for garlic played in her ability to bring in revenue and keep her farm status $(\mathrm{I}-33,2011)$. Whether complying, resisting, or adjusting the MIR, marketbased strategies, which has gained considerable strength under neoliberalization, have been key features to the success of individuals and groups.

The increased authority awarded to SMO's, the development of unlikely alliances, and the strength of market-based campaigns have all led to varying degrees of relative localized and individual successes, demonstrating the new avenues for response that have been opened through neoliberalization. These new avenues help one to understand and explain the success of these responses and begin to draw attention to the relations of force that have been present in both the implementation of, and the response to the MIR. Nevertheless, this analysis fails to address tensions that have arisen between the ability to attain individual localized successes, which offer varying degrees of short-, medium-, and long-term outcomes, and the ability for these movements to unite in a way that can offer a counter-hegemonic response to the hegemonic systems and the discourses that have been foundational to the design and implementation of the MIR. To address these tensions, the paper turns to a political-economic analysis, drawing on neo-Gramscian 
discussions of counter-hegemony and bringing in insights from Foucault's discourse analysis and thoughts on governmentality. The following section analyzes the ways in which neoliberalization has limited and defined the possibilities for resistance, resulting in real and perceived tensions between the ability to attain individual success and contributing to a broader counter-hegemonic force that can address the root challenges of the MIR.

\subsection{Limits of Neoliberalization, and Perceived Tensions}

This section argues that the ability to form a counter-hegemonic response to the MIR has been limited through neoliberalism's tendency to define and limit avenues for resistance, resulting in tensions between localized successes and the goals of the broader food sovereignty movement.

Gramsci understands resistance as the amalgamation of coercion and consent $(\mathrm{Li}$, 2007 ) in the realm of counter-hegemonic politics. A counter-hegemony requires what Gramsci terms a 'war of position' that is "waged in every sphere of society and at every level of intervention" ( $\mathrm{Li}, 2007)$. 'Trench warfare' reflects an important aspect of wars of position, explaining that struggles are both offensive and defensive, in which the key terrain for trench warfare is in the realm of ideas and beliefs (Adkin, 2009). In order for "wars" to be won, large numbers of individuals must "sacrifice, plan, and work for every advance" (Adkin, 2009, 13). The formation of 'historical blocs' plays a central role in trench warfare by calling into question the legitimacy and naturalness of the hegemony and replacing the dominant discourse with a vision of their own ( $\mathrm{Li}, 2007)$. 
Taking into account this understanding of resistance through counter-hegemony, this paper perceives that the ultimate goal of responses to the MIR should be to counter the legitimacy and naturalness of hegemonic discourses of 'standardization equals safety,' 'bigger is better,' and 'one size fits all.' These discourses must be replaced with those of the counter-hegemony, the inherent accountability and safety of on-farm and destandardized slaughter, the importance of small-scale operations and economies, and recognizes the potential for a variety of scales to sustainably exist simultaneously. Although forming a response rooted in this counter-hegemonic goal would allow for the combined success of all stakeholders involved, due to neoliberalism's ability to limit and define avenues for resistance, some responses have exacerbated perceived tensions between stakeholders and limited the potential for the formation of a united counterhegemonic force.

Neoliberalization not only creates crises, but it also has a tendency to limit and define the avenues for resistance to these crises. By shaping the relations of power within which resistance takes place, responses have the tendency to reproduce the very discourses and systems that have caused the initial challenges (Peck, Theodore, \& Brenner, 2009). Not only is this done by defining the avenues for resistance and the power relations within them, but furthermore neoliberalism's view of the "good citizen" the self-reliant individual- equates individual autonomy with independence from the state, failing to recognize "relational identities or social solidarities" (Adkin, 2009, 4). Efforts to support local abattoirs by resisting the trend towards industrial agriculture, have been met with challenges because "for activist projects, neoliberalization limits the conceivable because it limits the arguable, the fundable, the organisable, the scale of 
effective action, and compels activist to focus on putting out fires" and thus "activism and resistance have to be seen as something more complex than as simple reactions to an impact" (Guthman, 2008, 180, 181). Neoliberal tendencies have limited the responses to the MIR by fragmenting individuals, groups, and regions, and restricting the avenues that are defined as acceptable

Although the "attack" on small-scale farming has been implemented in a top down fashion, as a large hegemonic and powerful force, because it affects so many regions, communities, and individuals differently, they have been forced to engaged in different forms of resistance, fragmenting the response. This reflects Gramsci's thoughts on social transformation. Gramsci recognizes that the social groups engaged in struggles, which are a reflection of their unique experience and cultural ideas, are often more diverse than the groups driving the change $(\mathrm{Li}, 2007)$. Although this fragmented resistance allows for individuals to address their unique needs, it also limits the scope of the resistance and possibilities for a counter-hegemony because of the responses' inability to push back with the same united force used to push down upon them. This fragmented resistance allows for individual needs to be met, but at the same time disallows the hegemonic discourse of inspection and risk management to be challenged. The resistance is fragmented in two different ways, regionally and between stakeholder groups.

As a result of the diversity of challenges faced in each region, individuals and groups have been forced to respond separately, which on the one hand allows for individual needs to be addressed, but on the other hand, suppresses the potential for a larger counter-hegemonic response. One community farmer and activist explained that 
"in BC they were getting people to move in all the pockets. People were starting to get together and act together, but there were different pockets" (I-33, 2011). Interviews in three separate regions across the province demonstrate that each region points to other regions as being "a little microcosm" $(I-17,2011)$ or "a breed apart from the people in the hinterland" (I-17, 2011). Not only is resistance fragmented regionally, but it is also fragmented between and within stakeholder groups.

Stakeholder groups including, farmers, community members, and abattoir operators are fragmented both within the group as well as between the groups. This lack of unity has exacerbated tensions and has limited the potential to develop a strong voice that is capable of forming a counter-hegemonic force. One farmer explains that "part of the reason that there is a disconnect is because farmers are very independent people traditionally" and it is hard to get them to advocate for themselves (I-21, 2011). This attitude has created challenges for those who have tried to organize a more directed response (I-30, 2011). Not only has there been a lack of unity among farmers but until the recent formation of the $\mathrm{BCAA}$, the meat industry has also been hesitant to share information and work together (I-29, 2011). One abattoir operator explains that networking is very difficult to do in this industry and "you could spend a lot of money and make a lot of mistakes because you don't know what you are doing and no one is willing to tell you or help you out" (I-29, 2011). A consultant for the BCAA explains that this tends to be an industry where "everyone is working in silos and not knowing each other" (I-20, 2011). Therefore because of the individuality of farmers in the region and the competition reflected in the meat industry, there has been a lack of unity, which has prevented the movement from more efficiently lobbying government and building 
capacity. Therefore the response to the implementation of the MIR is fragmented in two ways, by region and by stakeholder group. Although this fragmentation allows for some regions, such as Powell River, to achieve success in their own region, which they might not have achieved had they joined a broader movement, it nevertheless has the affect of preventing the response from forming a broader front that is capable of pushing back with a united voice.

Another way that neoliberalization limits and defines the response is by defining the acceptable and unacceptable avenues for resistance. As has been demonstrated throughout this chapter, the market and government realms have been defined as acceptable avenues for resistance, both legally and due to factors that lead to the success of a movement. Avenues, such as the underground markets and resistance through noncompliance, are deemed unacceptable and illegitimate through neoliberalism. This means that the state is able to control the outcome of resistance by restricting the avenues in which responses can exert influence. The state can exert influence directly, for example in the state-centric avenue that adjustment took place, or indirectly, for example in the market-centric avenue that compliance too place. Resistance to the MIR, on the other hand, can be engaged outside of the neoliberal state and market, freeing the response from discursive and institutional limits. If this form of resistance were legal its discursive freedom would allow for the formation of a counter-hegemony capable of resisting the foundational discourses of the MIR.

A Foucauldian discussion of governmentality is useful at this point as a way of analyzing the state's ability to engage in both governance and disciplinary actions in order to effectively limit and define the possibilities of resistance. Adjustment and 
compliance were acceptable because they took place in the realms of the market and state, in which neoliberal systems can indirectly encourage "subjects to act in particular ways" (Guthman, 2007, 466) as will be demonstrated below. Furthermore, discussions of governmentality recognize that although tactics of governance are central to neoliberalization, disciplinary strategies still play a role and are reserved for sub-groups (Li, 2007). In the case of the MIR, disciplinary tactics of coercion have been reserved for resistance tactics, such as underground slaughter, that are not being engaged in state or market realms, and are therefore outside of the hegemony's ability to set "conditions artificially, arranging things so that people following their own self-interest will do as they ought" (Scott, 1995, 202). Although this chapter will now draw out specific examples to demonstrate the tensions between individual needs and broader goals of counter hegemony, it must be noted that in reality the ways in which these discourses and systems interrelate are not necessarily dichotomous. Rather, they are connected through a complex web of responses and outcomes.

Strategies of compliance, such as the BCAA's marketing campaigns and lobbying efforts to encourage the government to begin policing underground slaughter, have led to the individual success of abattoir operators. These strategies have nevertheless been undertaken at the expense of other stakeholders by stigmatizing on-farm slaughter, and by fragmenting the resistance and suppressing the potential for a counter-hegemonic response. The success of the BCAA's marketing campaigns has relied on a discursive shift that has stigmatized on-farm slaughter and unlicensed facilities. By equating inspection with quality products, which fails to recognize the effects of scale, the BCAA simultaneously stigmatizes on-farm slaughter. This discursive shift is seen in newspapers 
that claim on-farm slaughter is producing a "poisonous product" (I-18, 2011), and through the actions of lobby groups. The BCAA and BCCA engage in discursive warfare by lobbying the government to begin policing of underground tradesmen (I-16, 2011; I$20,2011)$. This lobbying effort reflects the abattoirs' struggle to find sufficient input for their operations, which they have blamed on "poaching" by underground tradesmen (I$20,2011)$. In reality the reasons for the low input is more likely due to the decreased number of farmers raising livestock, whereas the work of underground tradesmen is primarily in support of farmers who have never used an abattoir in the first place and always had their livestock slaughtered on-farm (I-17, 2011). Nevertheless, this demonstrates one of the outcomes of perceived tensions that have developed because of financial stress that has been faced by operators due to a poorly designed and implemented regulation. Rather than targeting the foundational discourses that have led to a poorly scaled regulation and caused financial stress, operators have instead lobbied to encourage the policing of underground tradesmen. This short-term response promotes an easier target, but in reality is unlikely to actually increase numbers of livestock coming into their facilities $(I-17,2011)$. This exacerbates tensions and limits the ability for the response to form into a wider counter-hegemonic force.

As discussed in chapter four, the MIR reflects three dominant discourses 'standardization equals safety,' bigger is better,' and 'one size fits all.' Despite the challenges that came out of the MIR, strategies employed by abattoir operators have further reinforced these discourses. The discourse 'standardization equals safety' is further reinforced by the BCAA marketing campaign that meat from inspected facilities is of better quality. The discourse 'bigger is better' is reinforced by the operator's need to 
purchase commercially raised livestock in order to maintain efficiency in their operations that have been forced into a larger-scale than intended. Finally, the discourse 'one size fits all' is reinforced by the BCAA's lobbying efforts to encourage the government to engage in enforcement campaigns against small-scale underground tradesmen. Although each of these tactics is seen as necessary to the success and sustainability of the individuals involved, they nevertheless reinforce the dominant discourses that have caused their plight in the first place. At its current stage, while leading to individual success, the response to comply has furthered the perceived tensions between stakeholders, limiting the ability for a counter-hegemonic movement.

Resistance through underground slaughter has maintained and promoted the discourses and material realities needed to form a counter-hegemony, but due to its illegality, the response is limited to localized levels, suppressing the potential of a counter-hegemonic force. Resisting through underground slaughter challenges the neoliberal discourses that are foundational to the MIR. The maintenance of alternative systems for food safety challenges the discourse 'standardization equals safety.' The maintenance and preservation of local knowledge and skills challenges the discourse 'bigger is better.' The effective maintenance and promotion of localized economies and alternative food supply networks alongside mainstream markets, challenges the discourse 'one size fits all' and demonstrates the ability for a variety of scaled operations and economies to exist simultaneously. In his discussion of 'green states,' Barry argues for the necessity of informed and radicalized citizens and their oppositional practices, which include civil disobedience (Barry, 2006). Adkin furthers this point, stating that "citizenship should be critically understood not only as rights granted by a government, 
but also as practices through which the limits of established rights are (re)defined and (re)affirmed...citizenship is therefore not only a set of formal rights, but rather is a continual process of construction and constitution" (Adkin, 2009, 6, 14). This radical form of resistance is capable of addressing the unique needs of individuals while simultaneously resisting the root causes of the MIR, demonstrating its importance to the formation of a counter-hegemony. Furthermore, by taking issues out of the realm of 'experts,' and bringing them into the realm of politics, resistance becomes central to establishing the rights of citizens within democratic states. Nevertheless resistance in the form of maintaining this traditional lifestyle has been declared unacceptable and punishable by law, thus limiting its potential of attaining a counter-hegemonic force.

Adjusting the MIR has employed successful consultation between government and farmers, which has played a central role in shifting the dominant discourse to recognize the value of small-scale operations, demonstrating the potential for on-farm slaughter to produce a safe product. Although such a discursive shift has great potential for contributing to a wider counter-hegemonic discourse, there are perceived tensions regarding fragmentation and the prioritized treatment of farmers in remote and isolated regions such as Powell River. In some cases there is tension building between those who have been awarded Class $\mathrm{C}$ licenses and those who have not yet been given the option. One community farmer complains that those in Powell River have been very good at advocating and finding a compromise that will work for themselves but they are "not so worried about working for the rest of the province" (I-17, 2011). One farmer in Powell River has explained that farmers in the region as well as the ministry have been making efforts to not flaunt the licenses that they have been awarded, explaining that "we don't 
make a big buzz over what we are doing and the steps we are taking because we don't want to, you know, poke them and irritate them more" $(I-32,2011)$. Although this attitude of individualism has allowed them to address their unique needs and led to the creation of Class $\mathrm{D}$ and $\mathrm{E}$ licenses which will benefit certain individuals, there has been debate over whether this response has benefited the rest of the province and whether it can reach the size and capacity necessary to form a counter-hegemony.

The increased authority of SMO's and the value of unity has been demonstrated throughout this chapter. However, this case demonstrates an interesting exception whereby the ability of the remote regions to isolate their response has drawn attention from the government as an achievable fix, thus enabling them to engage in successful consultation. By framing their criticism as a specific and repairable glitch in the MIR, they were able to amend the legislation, benefiting their unique needs. Although this tactic, at first glance, seems individualistic, the creation of class $\mathrm{D}$ and $\mathrm{E}$ licenses has actually opened the gate for the rest of the province because it has successfully debunked the assumption that inspection is the only way to achieve safe food. By creating this amendment, the government has admitted that inspected facilities are not the only way to produce a safe product, thereby making it difficult for them to deny the rights of on-farm slaughter throughout the rest of the province. Although the response to adjust the MIR initially gave priority to the isolated and remote regions, with the government required to take action because of the lack of infrastructure, this has in turn laid the groundwork for a strong discursive shift that, under the right conditions, could allow for on-farm slaughter throughout the rest of the province. 
Taking into account the discussion throughout this chapter, it is demonstrated that compliance, which has been the most successful at addressing the individual and localized needs of producers and processors, simultaneously reproduces the very discourses and systems that continue to stigmatize small-scale, uninspected production. On the other hand, resistance to the MIR, which demonstrates a strong ability to support a counter-hegemonic movement, has been defined as unacceptable and illegal, suppressing its potential to support the counter-hegemony. The response to adjust, although originally appearing fragmented and individualistic, has nevertheless shifted the discourse in a way that may enable on-farm slaughter throughout the rest of the province and could potentially support a counter-hegemonic movement across the province. Despite these possibilities, there are nevertheless remaining tensions between stakeholders that have developed both unintentionally, such as the fragmentation caused by the diversity of regions affected by the MIR, and intentionally, such as the discursive tactics employed by the BCAA.

Although this current situation, which is the result of actual and perceived tensions, has the potential to lead to an increasingly dichotomized agricultural sector, the remainder of this chapter demonstrates that through the use of scalar resistance, the various goals of different stakeholders in BC are not necessarily contradictory but are actually complementary. There is the potential for these responses to address the unique and diverse needs of individual stakeholders, as well as forming a broader counterhegemonic force that could counter the legitimacy and naturalness of the hegemonic discourse that is foundational to the MIR. 


\subsection{The Centrality of Scale and Need for its Recognition}

It is important to form a response that can both maintain localized groups that can address the unique and diverse needs of various actors, as well as develop networks that can unite to form a counter hegemony to the dominant discourses that the MIR is rooted in. This next section will draw on a scalar analysis to demonstrate ways that responses can be targeted to simultaneously allow for localized success and the development of broader movements.

Efforts to support local abattoirs by resisting the trend towards industrial agriculture, have been met with challenges because neoliberalization limits and defines responses in a way that "compels activists to focus on putting out fires" rather than building capacity (Guthman, 2008, 180). "Activism and resistance have to be seen as something more complex than simple reactions to an impact" (Guthman, 2008, 181). This was initially the case in $\mathrm{BC}$, as farmers and abattoir operators were so focused on trying to make ends meet after the devastation caused by the MIR that they were not able, due to various factors including time and resources, to unify and respond more broadly to the roots of the MIR. This section will argue that stakeholders in BC are now reaching a degree of stability and are now at a point where they can begin networking and taking a more proactive and complex approach that can target the foundations of the MIR and influence BC's and Canada's food and agricultural policy. A scalar approach offers a way in which the movement can organize that will allow for on-farm slaughter, support a network of local abattoirs, and develop strong local and alternative food supply networks, while simultaneously resisting the normalized and hegemonic discourses that have led to the implementation of the MIR. The concept of "scale shifting" (Smith, 1992) points to ways that scale can be incorporated in movements by shifting the avenues and targets 
upwards and downwards to gain advantage (Keil \& Mahon, 2009; Miller, 2009). Miller uses the example of how social movements can change the power dynamics by rescaling their efforts in a way that will bring in, or exclude, actors and resources (Miller, 2009). Across Canada, local abattoirs and farmers have demonstrated 'scale shifting' by referring to Canada's federalist system. The jurisdictional divide between federal and provincial governments allows small scale farmers to exclude federal opponents, while developing cooperatives and systems that are beneficial to their unique needs. Simultaneously, movements can draw in alliances in areas where resistance could benefit from federal support. For example, some counties are discussing forming cooperatives that would set up their own grading systems so that farmers can obtain a higher price for beef within their localities without having to rely on federally inspected abattoirs (I-10, 2009). At the same time local movements can contextualize issues, such as organics and animal rights, in ways that the federal government responds to, such as consumer protection and food safety, which would in turn affect the local level and support the sustainability of small-scale abattoirs (I-10, 2009). Therefore, although a scalar analysis has shown ways that regulations have forced small-scale abattoirs to shut down, a scalar approach may also be used to reverse these effects, supporting the sustainability of abattoirs and rural communities.

This section will demonstrate that resistance needs to be engaged on a variety of scales and that strategies and language of the resistance need to change depending on the targeted scale and stakeholders involved. A balance must be achieved between, on the one hand, adopting strategies and discourses that are valued under the hegemonic order in 
order to influence policy when working with government and industry, and on the other hand, working to maintain and strengthen the discourse of the counter-hegemony.

In order for a successful scalar resistance to form, it must involve the unification of regions and groups that have, up to this point, remained fragmented. The problem itself is one that involves a complex network of interconnected issues and systems, thus the resistance in turn must also recognize these interconnections and unite in a way that will allow for the outcomes to be sustainable across all fronts. Jessop's writings on resistance complicate Polanyi's double movement by explaining that society's fightback must "move beyond dispersed, disorganized and temporal contradictory struggles" and "attention must be paid to the ways in which 'society' acquires a relative unity and cohesion in resisting capital's unhampered logic" (Jessop, 2001, 222). This does not mean dismantling local groups, which retain a key role in addressing unique and specific needs. ${ }^{16}$ but instead developing better networks between these groups that can target provincial and federal governments with a strong and unified voice. This paper now moves on to suggest strategies that can be engaged on various scales, using "scale jumping" to both create and target spaces for resistance, as well as limit the ability of detrimental forces from disrupting the movement's progress and capacity.

When focusing on the local scale, an appropriate target of resistance should be working within the current MIR's structure to assure that the newly formed Class E licenses will be accessible to small scale farmers for variety of reasons and motivations, and not solely awarded based of physical distance from a licensed abattoir (I-21, 2011). This will ensure that the right to slaughter on-farm is reflective of discourses of food

\footnotetext{
${ }^{16}$ These groups are regional (eg. Salt Spring Islands Farmer's Institute) and sectoral (eg. BCAA).
} 
sovereignty, rather than viewed solely as a substitute in the absence of inspected facilities. Simultaneously, efforts should be made at building capacity to support smallscale farmers, which could include developing programs and networks to share skills and knowledge, as well as working to de-stigmatize farm-gate sales (I-32, 2011; I-21, 2011). One way of working to assure Class $\mathrm{E}$ licenses are accessible to farmers who wish to sell their products at farm-gate is to take advantage of the MIR's outcome-based design (I-32, 2011). Although the outcome-based system has created many challenges, this system also opens new avenues that can be targeted through positive and constructive consultation. The success of consultation was demonstrated in Powell River and should be employed in other regions, specifically the North Okanagan (I-21, 2011; I-23, 2011). When working on this level it is essential to remain aware of and empower marginalized individuals and groups who have been previously excluded for any number of reasons (I-23, 2011).

When focusing on the provincial scale, an appropriate goal would be the promotion of graduated regulatory systems, by employing strategies that demonstrate the value of scaled regulatory systems (I-25, 2011). This broader strategy has the potential of shifting discourse in a way that encourages governments to acknowledge and respect a diverse range of operations and economies. At the provincial scale, pressure should also be placed on the $\mathrm{BC}$ government to support licensed abattoirs through marketing and public awareness campaigns, demonstrating the value of $\mathrm{BC}$ products in terms of environment, animal welfare, economy, quality, etc (I-20, 2011). Attention should also be given to ensuring that these campaigns are employed in a way that supports licensed abattoirs without stigmatizing farm-gate sales. The different scales of inspected abattoirs and on-farm slaughter should be recognized, thereby viewing these different operations 
as complementary rather than in competition (I-17, 2011). Pressure should also be placed on the $\mathrm{BC}$ government to recognize the newly formed $\mathrm{BCAA}$ as representative of $\mathrm{BC}$ abattoirs and as an important player in the BC meat and agricultural industry $(\mathrm{I}-20,2011)$. Finally, individuals and groups should align themselves with campaigns designed to influence corporate retail policy, with the aim of encouraging more room for local procurement, which can be engaged on both provincial and federal scales (I-4ab, 2010).

When focusing on the federal scale, tactics should focus on drawing attention to the interpenetration of scales to prevent the imposition of export priorities onto local levels. Simultaneously the federal level can be brought in to fund and support niche markets, which is an area where the AAFC recognizes the value of small-scale operations (I-8, 2009). Taking into account federal policy and discourse, which aims to increase Canada's production capacity and support trade, in order to employ the above tactics two strategies should be undertaken. The first should be to engage in further research that can provide 'legitimate' and 'science-based' information to the federal government, demonstrating that small-scale production is safe and produces a quality product, and that these products are not entering national and international food chains (I-23, 2011). This information will have to be presented in a discourse that is not only valued by government and industry, but that can also be presented to trading partners allowing them to secure these markets (I-11, 2010; I-14b, 2011). The second form of resistance at the federal level will be to demonstrate the value of BC's niche markets $(I-16,2011)$. Although niche markets are not necessarily reflective of local and alternative food supply networks, this is an area that federal officials have previously shown support for and can thereby be seen as a small step in long-term struggle that supports alternative food supply 
networks. Drawing on the federal desire to promote production capacity, it is important to demonstrate that if niche markets are supported they can grow and potentially receive international recognition, while at the same time legitimizing and demonstrating the necessity of a scaled approach to regulations in order to enable the success of these unique and diverse enterprises (I-16, 2011).

The use of networks is a valuable strategy in enabling a scalar response by overcoming issues of fragmentation. Throughout the interviews there was a recurring theme that farmers, processors and community activists felt there was a lack of collaboration and that a lot could be gained from setting up networks to encourage the sharing of information, knowledge and strategies (I-27, 2011; I-29, 2011). Although there is still a great deal of movement that needs to be made in developing these groups and networks, out of this recognition of their importance many individuals have already begun forming groups and organizations, such as the BCAA and farmers' institutes (I-20, 2011; I-30, 2011).

One important factor that must not be overlooked when looking at the development of networks is the involvement of traditionally marginalized people within networks and partnerships. This is one area that has often been overlooked due to its tendency to involve alternative methods of governance and communication (Van der Plaat, M \& Barrett, G. 2006). For this reason networks are an excellent area that allow for the effective use of informal governance processes that facilitate the involvement of the traditionally marginalized groups, thus providing an "important new source of social capital for communities" (Van der Plaat, M \& Barrett, G. 2006). Rural citizens and communities are one group that often feels excluded from participation in planning and 
policy processes that shape their future (RCIP Project, 2005; Langille et al. 2008; I-23, 2011). This was confirmed in interviews throughout BC (I-23, 2011; I-32, 2011; I-21, 2011). On the other hand, one politician points to "how influential people can be when they are confident and well spoken and they know how to present the information to council in a way they will hear it" (I-23, 2011). Thus efforts need to be made to engage and empower marginalized populations.

Networks have the potential to support a scaled resistance by enabling the collaboration of communities, universities, governments and other civil society organizations, to influence policy at all levels of governance (Langille et al., 2008). Nevertheless, actors should remain aware of the limitation of networks that can result from their governance processes and power dynamics, which are discussed by authors such as Shorthall and Van der Plaat and Barrett (Shorthall, 2004; Van der Plaat, M \& Barrett, G., 2006). If these limitations are recognized then networks could prove to be an effective structure for BC's counter-hegemony. Networks specifically offer a way to overcome challenges derived from fragmentation and contribute to the development of strong local and alternative food supply networks, as well as supporting a wider counter hegemonic struggle.

\subsection{Conclusion}

The provincial government has now recognized that it made a mistake with the implementation of the MIR (I-22, 2011) and is now engaging in consultation to work towards a graduated system, but the question remains; is it too late for BC's rural and agricultural communities? One small scale farmer states that "the government is now 
admitting that the whole meat inspection regulation is a debacle, but they don't know how to fix it" (I-21, 2011). Furthermore, since the enactment of class D \& E licenses, which will be discussed further below, the government has admitted that it is safe to produce and sell unlicensed meat, despite its initial claims that only inspection would equal safety $(\mathrm{I}-23,2011)$. This has furthered the case of many British Columbians who have been arguing that the regulation was implemented at the behest of the federal government's export and import needs. These factors have encouraged the provincial government to finally enter into meaningful consultation in various regions throughout the province. These efforts are working towards a graduated system that, if executed properly, could allow for the existence of small scale farmers and processors. Unfortunately this effort has come far too late for most small scale farmers, processors, and consumers in rural $\mathrm{BC}$.

The BC Cattlemen's Association recognizes the effects of this delay, with a spokesperson stating that "I believe that the government has stepped up, finally. I think that they were overdue in doing it. I think that if they had done it earlier, we wouldn't have lost some of the abattoirs" (I-16, 2011). It is not inspection that is necessarily the problem, it is the process by which the MIR is being implemented that has been destructive. Over time, BC may be able to work out a very effective graduated licensing system that may support small-scale farmers and processors, but the question of whether this will make up for the operations that have been destroyed and the devastation that farmers, operators, consumers and communities have undergone, will remain.

This chapter has demonstrated that the diversity of challenges, goals, strategies, actors involved, actions, timelines, and scales have affected both the choice of and 
success of the response. This chapter argued that the various responses - resistance, compliance, or adjustment, drew on the new avenues for resistance in neoliberalism, including increased authority of SMOs, developing unlikely alliances, and market-based responses. These strategies allowed for individuals and groups to attain localized successes. Nevertheless a political-economic and discourse analysis drew out remaining tensions that have been left unexamined, further arguing that tensions have arisen between the ability to attain localized success that can address unique needs of individual actors and the ability to engage in more widespread resistance that can act as a counterhegemony to the root causes of the MIR's implementation. These tensions result from neoliberalism's ability to limit and define responses, allowing it to capitalize on and grow from the very crisis situations that it has created. Although when left unexamined this phenomenon could potentially lead to an increasingly dichotomized and subjugated food landscape, this chapter finally argued that through a scalar approach to resistance individuals and groups in BC could not only work towards localized solutions that take into account their unique needs, but could also begin developing the networks and building the capacity to respond to the root causes of the MIR, leading to more long-term, broad-reaching, counter-hegemonic opportunities that reflect food sovereignty and improve the sustainability and strength of Canadian food systems and communities. 


\section{Chapter: Conclusions}

\subsection{Introduction}

This thesis has demonstrated that that the drastic loss of small and medium-scale abattoirs in $\mathrm{BC}$ and across Canada is a result of federal and provincial policies and regulations that are implemented with the intention of supporting Canada's trade and production capacity, and are facilitated through the scales, limiting the possibilities at local levels. Not only has this loss directly and indirectly caused devastation in the lives of individuals and communities through the destruction of local and alternative food supply networks, but it has also limited food sovereignty. Despite these findings, it is important to take into account several factors that may have influenced the research as well as note directions for future research. Building on issues discussed in the methods section, this chapter will further discuss the ways in which stakeholder representation, researching a contentious issue, challenges relating to research and writing, and researching an ongoing issue may have influenced the research findings. Furthermore, taking into account that $\mathrm{BC}$ was one of the last provinces to implement a provincial meat inspection system (Ministry of Health, 2011), inspected abattoirs are still in the transition phase or in their infancy, and have yet to face some of the issues faced by operations in other provinces. By comparing the case in $\mathrm{BC}$ to other Canadian provinces, it can be deduced that over the next decade inspected abattoirs in $\mathrm{BC}$ are likely to face issues surrounding inter-provincial trade, transitioning into federally inspected facilities and HACCP, the procurement and regulatory polices of supermarkets and retail chains, and environmentalism and resistance. Furthermore, future research could also benefit from engaging in a deeper 
discussion of spatial relations, shifting discourse, economics of alternative food systems, and scientific analyses of alternative inspection systems.

\subsection{Factors that may have influenced research process and findings}

Building on issues discussed in the methods section, including preconceptions of the interviewer, interview access and dynamics, and researcher vulnerability, there are four remaining factors that may have influenced the research findings. The first factor that may have influenced the research findings was stakeholder representation. Although there was a wide range of stakeholders interviewed during the research process, including producers, processors, distributors, consumers, civil society groups, industry representatives, politicians and government officials at municipal, provincial, and federal levels, there were nevertheless key actors to whom I was not able to gain access. For example, three officials were interviewed from the CFIA, but none of the "ground-level" inspectors were interviewed. Further, although a broad range of producers and processors were engaged in the research process through interviews and ground level research, due to the wide range of individual and unique outcomes of the MIR, there are likely certain perspectives that were not recorded as part of this research. Finally, although two politicians were interviewed who were very helpful and informative, these perspectives were nevertheless only representative of those politicians who were critical of the MIR. Nevertheless other civil servants and consultants were interviewed who were in support of the MIR, thus I would argue that this study was still able to reflect a balanced opinion of the case study. On the other hand, I also faced challenges related to the large number (38 interviews) of interviews conducted, including challenges relating to conducting the research (cost, time, etc.) as well as challenges concerning analysis and writing, which 
will be discussed further below. This chapter will first address challenges concerning research on a contentious issue.

I faced three issues due to the contentious nature of the case of the MIR. First, there were certain instances where I felt that there was the possibility that information was being withheld to protect certain actors. For example, during one interview with a small-scale farmer and community organizer, she discussed their process for conducting a feasibility study for her region which included contracting a consultant to lead the process. Despite discussing concerns of being over-charged, potential conflicts of interests and the downloading of tasks onto community volunteers, she nevertheless didn't expand on these issues or mention the name of the representative, potentially as a way of protecting this actor. On the other hand certain interviewees may have exacerbated certain issues or focused on certain topics in which they were hoping to push personal agendas. For example, interviews with industry consultants and operators often ended with them requesting that I share certain information with other actors with the hopes of developing networks and promoting personal or industry interests. Although this may have influenced the findings, this type of networking can also be seen as a valuable contribution to the agricultural community and as way of developing academiccommunity connections, which could be valuable for future community-based research. Furthermore, as discussed in the methodology, this type of qualitative research can lead to sentiments of resentment and communities feeling that they are being treated as "research subjects." "Giving back" to interviewees through the requested sharing of information and contacts can be seen as a way to even these negative power dynamics and feeling of uneven gain. Not only is there the possibility that information was either 
withheld to protect certain actors or exaggerated to promote certain interests, but another issue that came out of researching a contentious issue is the ability to obtain consent to use certain information.

Although some actors were extremely helpful by providing reliable and important information and perspectives, as well as suggesting and providing contacts for key stakeholders, proving extremely valuable in furthering the direction of this research, I nevertheless faced challenges obtaining the consent to publish sensitive information. The disinclination to consent to the use of sensitive information was understandable because, despite my efforts to secure confidentiality, there are potential risks of social and/or economic harm, including possible loss of status, privacy and/or reputation and threat to professional status including employment. Still, it affected the research process and findings. This all connects to a third issue that may have affected the results of this research, which are the challenges I faced during analysis and writing.

Challenges that arose during the analysis of research and writing include representation of marginalized populations and writing for various audiences. Although the topic of marginalized voices was briefly outlined in the methodology section, in which I presented small-scale farmers as a marginalized population and discussed the ways in which I addressed these issues during the interview process and attempted to represent these voices throughout my findings, the challenges I faced when doing so are worth further noting. When engaged in the writing process, I quickly realized the obstacle I would face when trying to amalgamate academic theory with information obtained during the interviews. When beginning this research process, I had the intention of focusing more directly on broader theories surrounding governmentality and regulation, 
with the plan to draw on the cases of $\mathrm{BC}$ and Ontario in a comparative analysis, but not as the main focus. Having already conducted a series of interviews at the federal level and for the first case study, in Ontario, I then flew to BC for what I thought would be a final set of interviews to complete the second case study. During this research trip I was shocked and perplexed by the devastation that the MIR had caused. As the word got out that I was researching the topic, stakeholders began contacting me and requesting that they be part of the research as a way of having their voices heard. This step in my research process shifted the direction of my research. I realized that if I used it solely as an example to support a broader argument I would not be able to sufficiently address the complexity of the situation nor fully reflect the stories and perspectives that were being shared during this research. It was at this point that I decided to refocus my research to addressing the case of the MIR in BC. This new direction presented a series of challenges, which included finding a new balance between the previous literature and empirical evidence gathered and the research gathered in BC. Throughout the analysis and writing, I continually faced challenges when trying to balance my broader argument that focused on regulations in the neoliberal era, the illusion of laissez-faire, and neoliberal tendencies, with the desire to adequately reflect the personal stories of loss and disruption to $\mathrm{BC}$ agricultural and rural communities. This challenge was exacerbated by the diversity of audiences that have shown interest in my research.

Although the main target of this research is to complete my master's degree in the Institute of Political Economy at Carleton University, the various stakeholders that have shown interest in my findings, including producers, processors, industry organizations, policy makers, and SMOs, have led to questions concerning the potential for presenting 
research findings in a way that can be both academically relevant as well as relevant to a broad range of stakeholders. During my research, analysis and writing I have put a great deal of thought and effort into this dilemma and have come across different and creative ways of presenting information. For the purpose of this paper, although I have touched on a broad range of issues, the information has been presented in a way that will be most relevant to academics in the field of political economy. Nevertheless, I hold the intention of writing further documents that can be circulated more widely and be more reflective of, as well as being presented in a way that will be more relevant to, the unique needs and concerns of a variety of stakeholders. This connects to the final factor that may have influenced my research process and findings, which are the challenges involved in researching an ongoing issue.

The final factor that may have influenced my research process and findings is the challenges that are involved in researching an ongoing issue, presenting problems due to changes in both the structure of the MIR and the resulting effects, discourses and responses. Changes to the MIR, including a restructuring of the bureaucracy, the various amendments, and the outcome-based design presented obstacles to my research. First, during the time in which I was engaged in researching this case, the structure of the BC's provincial government's bureaucracy changed, with the Ministry of Healthy Living and Sport being dissolved and replaced by the Ministry of Health. This in turn presented challenges to my research, specifically regarding the removal of websites and ability to access information that I have cited in earlier analysis and writings. The changing amendments also presented challenges in keeping up-to-date information and sufficiently reflecting the issues, specifically regarding the recent enactment of class D and $\mathrm{E}$ licenses 
and the phasing out of the class $\mathrm{C}$ license. The outcome-based design also meant that many of ways in which the regulation was implemented were subject to interpretation and change, meaning that depending on the actors, regions, and timeframes, my findings would vary widely. These factors made it difficult to identify and analyze the effects, discourses and responses, not only due to their diversity but also due to serious transformations over time. Discourse was especially difficult to analyze as it shifted. For example, one abattoir operator was adamantly opposed to the MIR initially, but over time became one of the key supporters of the new regulation (I-24, 2011). Effects also changed over time, with one small-scale farmer initially discussing the tragedy and loss that the MIR had caused, then later in a follow up email, discussing the possibilities that it offered her $(\mathrm{I}-21,2011)$. Finally, as the responses changed and I witnessed individuals and groups change their key strategies as time passed $(\mathrm{I}-21,2011)$. Although, on the one hand, researching an ongoing issue has presented challenges to my research process, analysis, and writing as well as drawing questions to the future relevancy of my research, on the other hand this gives further importance to conducting this research.

The lack of research and documentation of BC's agricultural landscape pre-MIR, as discussed, has made it difficult to know for certain how much diversity there used to be in BC's agriculture and rural communities. Similarly, if it weren't for these research findings, the process and transition into a provincial inspection system may have never been sufficiently recorded. Although the Ministry of Health's website addresses the changes in $B C$ 's meat sector, I would argue that it presents a fairly biased perspective that doesn't sufficiently address the loss that has resulted from the MIR. For example, information provided on the Ministry of Health's website discusses the ways in which the 
MIR benefits consumers, the $\$ 11$ million that was provided by the government to support industry transitioning, the ways in which the meat processing sector has "transformed and modernized significantly over the last six years as a result of the regulation," and the increased numbered of licensed facilities (Ministry of Health, 2011), yet it fails to record the number of abattoirs lost and the rippling effects of this loss. Despite the challenges that were faced due to researching an ongoing issue, engaging in this process is nevertheless extremely important as a means of recording the effects, responses, and discourses throughout this transition. This research attempts to represent voices that are being suppressed and record the process in order to learn from it and improve the design and implementation for future regulations and policies. The discussion of the case as an ongoing issue draws attention to future areas of research.

\subsection{Future Research}

This thesis has drawn out important findings by analyzing the case of the MIR through a political economy framework. However, there is still more to learn through analyzing this topic through other disciplines and theoretical frameworks as well as engaging in research that focuses on topics that are relevant to the MIR but for various reasons were not given priority in this report. Analyzing the topic through other frameworks would allow for a deeper analysis of discussion of spatial relations, shifting discourse, economics of alternative food systems, and scientific analyses of alternative inspection systems. Furthermore, taking into account that $\mathrm{BC}$ was one of the last provinces to implement a provincial meat inspection system, the inspected abattoirs are still in the transition phase or in their infancy. By comparing the case in BC to other Canadian provinces it is important to note four issues that inspected abattoirs may face over the 
next decade, including: inter-provincial trade; transitioning into federally inspected facilities and issues concerning HACCP; the procurement and regulatory polices of supermarkets and retail chains; and environmental resistance.

Abattoirs in BC are currently focused on marketing opportunities within the province of $\mathrm{BC}$, but as time passes, some of these abattoirs may begin seeking marketing opportunities across provincial borders, pointing to the issue of inter-provincial trade (I16, 2011). Inter-provincial trade is currently a very important issue to both policy makers at the federal level $(\mathrm{I}-8,2010 ; \mathrm{I}-14 \mathrm{abc}, 2011)$, industry representatives $(\mathrm{I}-16,2011 ; \mathrm{I}-11 \mathrm{~b}$, 2010), and some abattoir operators who have discussed its potential relevancy in the near future (I-27, 2011). Currently, officials from Agriculture and Agri-Food Canada and the CFIA are engaged in a project with the aim of developing a new level of regulation in Canada that would allow for inter-provincial trade, without meeting all the requirements of federal inspection (I-8, 2010; I-14abc, 2011). This project's progress and outcome is worth further research, as it will affect abattoir operators in BC who wish to sell their products across provincial borders. Related to the issue of different levels of inspection is that of HACCP and federal regulation.

Furthermore, if abattoirs in BC develop an interest in exporting, further research concerning HACCP, a program utilized by federal regulation, would be necessary. The Hazard Analysis and Critical Control Points system (HACCP) is a system that was first developed by NASA to ensure the safety of food in outer-space, and was quickly adopted into the commercial food sector as a preventative approach to food safety that addresses physical, chemical, and biological hazards as a means of prevention rather than finished product inspection. This system is arguably an effective way of ensuring food safety 
through collaboration with individual plant operators, but has been criticized for giving too much authority to plant operators, with a recent PBS report stating that "the fox is guarding the chicken coop" and referencing inspectors who are critical of the system stating that the acronym has come to stand for "Have A Cup of Coffee and Pray" (PBS, 2011). Although in theory this authority granted to plant operators could support cases for a less standardized system of meat inspection that would allow for a diversity of needs to be addressed, in practice this system is only accessible to large-scale plants who can afford the high implementation and operating costs of the program, excluding small-scale facilities (I-7, 2010). Furthermore its reliance on an auditable process has been criticized for removing the human element from the inspection system (I-7, 2010). Taking into account these issues, the HACCP program warrants further research in order to fully assess the issues surrounding federal inspection. Not only does federal inspection and HACCP warrant further research, but the effects of the increased dominance of supermarket and retail chains over food-supply chains and importance of corporate procurement and regulatory policies warrant further research.

The exclusion of small- and medium-scale abattoirs has not only been the result of government intervention, but it has also been exacerbated by factors on the corporate level, including the domination of food supply chains and corporate procurement and regulatory policies, which are increasingly becoming dominant in food governance. This has presented a series of challenges for medium-scale abattoirs, which, despite their ability to make the investment and upgrade to become an inspected facility, are unable to sell their products to supermarkets because of corporate polices to only buy federally inspected meat and the supermarket's tendency to support large-scale production. 
The 'macro' processes of globalization, market liberalization, and pro-corporate regulation have not only led to the growth of supermarkets (Lawrence \& Burch, 2007, 5), but have also transferred power from political organizations onto corporate entities. "Procorporate regulation has resulted from the 'rescaling' of state power, leading to both deregulation and re-regulation," and the "re-alignment of power between transnational corporate entities and those firms bounded by the national state" (McMichael \& Burch, $2007,6)$. Supermarkets no longer rely on markets to purchase products but have developed "supply chain management" as the dominant mode of procurement, increasingly integrating the entire production process into the retailer's operation (Konefal, Bain, Mascrenhas \& Burch, 2007, 268, 284; McMichael \& Friedmann, 2007, 301). The supermarkets control over the supply chain has been criticized for favoring large producers, while forcing small-scale operations out of business (Konefal, Bain, Mascrenhas \& Burch, 2007, 277).

This is partly due to their strategy of going "beyond compliance," in which they exceed, rather than meet, standards by national governments and the GATT framework (Campbell \& Le Heron, 2007, 134), thus excluding small-scale operations who cannot afford the increased costs imposed by such regulations. Furthermore, because of federally inspected warehouses, supermarkets often have policies to only purchase federally inspected meat (I-4, 2009; Carter-Whitney, 2008), not only disarticulating small-scale producers, but also contributing to the stigma that federal inspection produces a safer product than provincial $(\mathrm{I}-9,2010)$. This is due to the strong authority that supermarkets hold as "gatekeeper of food standards" as well as a "food-and-lifestyle" authority (Lawrence \& Burch, 2007, 9, 14;), therefore granting their policies the power to affect 
public and private perceptions of safety. Although procurement policies, such as Sobey's policy to only buy meat from federally inspected facilities (Mathieu, 2009), are rooted in needs for volume, consistency, and price, they nevertheless reflect on levels of safety that are offered from federally inspected plants (Crawford, 2009; Ransom, 2006, 166). Despite the challenges that corporate policies have presented to small-scale operations, the increased attention to consumer politics and market-based strategies have opened new avenues for resistance and the ability to influence food retailers and supply chains (Konefal, Bain, Mascrenhas \& Burch, 2007, 284). Although up to this point in BC these issues of corporate procurement may have taken a back seat to the MIR, as provincially inspected abattoirs gain strength these issues will likely take precedence in food safety, procurement and resistance debates in $\mathrm{BC}$, thus warranting further research.

A final area that warrants further research is the possibilities for uniting the responses to the MIR with environmental resistance as a way of gaining strength and addressing broader hegemonic discourses. Before neoliberalization began to spread and take hold as the dominant worldview, the Keynesian state had achieved a great deal in terms of environmental protection (McCarthy \& Prudham, 2003). Therefore just as neoliberalism was a clear attack on Keynesian ideologies, "assaults on Keynesian-era environmental regulation have been as central to neoliberalism as assaults on labor and social entitlement programs that have received far more critical attention" (McCarthy \& Prudham, 2003, 278). Not only does this movement have clear connections to the food sovereignty movement and specifically to many of the effects of the loss of small- and medium-sized abattoirs, but "connections between neoliberalism, environmental change, and environmental politics are all deeply if not inextricably interwoven" (McCarthy J \& 
Prudham S, 2003, 275). Thus topics of environmental resistance and its potential to strengthen responses to the MIR warrant further research.

This section has pointed to the value of analyzing the topic through other frameworks that would allow for a deeper analysis of spatial relations, shifting discourse, economics of alternative food systems, scientific analyses of alternative inspection systems. Furthermore, it has pointed to future areas of research, which include, interprovincial trade; transitioning into federally inspected facilities and issues concerning HACCP; the procurement and regulatory polices of supermarkets and retail chains; and environmental resistance.

\subsection{Conclusion and Overview}

The chapter has outlined factors that may have influenced the research, including stakeholder representation, researching a contentious issue, challenges relating to analysis and writing, and researching an ongoing issue. The chapter also pointed to the benefits that could be gained from engaging in future research from the perspective of other disciplines and using other theoretical frameworks, including deeper discussion of the spatial relations, shifting discourse, economics of alternative food systems, and scientific analyses of alternative inspection systems. Finally, the chapter noted directions for future research. Despite these factors and areas for further research this thesis has demonstrated that that the drastic loss of small and medium-scale abattoirs in BC and across Canada is a result of federal and provincial policies and regulations that are implemented with the intention of supporting Canada's trade and production capacity, and are facilitated 
through the scales, limiting the possibilities at local levels. Not only has this loss directly and indirectly caused devastation in the lives of individuals and communities through the destruction of local and alternative food supply networks, but it has also limited food sovereignty.

This paper has demonstrated that the MIR involved both high costs and set generally unattainable standards, as a reflection of three neoliberal discourses that claim 'standardization equals safety,' 'bigger is better,' and 'one size fits all.' The dominance of these discourses reflects broader political economic trends that have created the illusion of laissez-faire governance, when in reality a deeply interventionist policy is propagated. Furthermore, these discourses were reflected in the MIR due to the scalar relations dominant under neoliberalism whereby the federal government acted as a "scale manager," facilitating the needs of large-scale export-oriented agriculture through a complex network of scale, ultimately putting pressure on BC's provincial government to enact the MIR, in spite of the needs of the majority of its producers and processors.

The BC government's actions surrounding the design and implementation of the MIR reflect neoliberal tendencies, including roll-out and Zombie neoliberalism, which increased the CFIA's authority, a dubious move given the CFIA's parallel mandate to promote Canada's export capacity, and further perpetuating dominant hegemonic discourse. Ultimately, the demands imposed by MIR upon BC's abattoirs were not scaled appropriately, adding unnecessary costs and forcing the majority of producers out of business. Despite the powerful ability of Zombie Neoliberalization to recreate itself, and because Zombie Neoliberalism has no clear driver, this has increased the opportunities 
for response and resistance, as demonstrated by the resilience of $\mathrm{BC}$ 's agricultural producers and processors.

The choice to respond to the MIR through resistance, compliance, or adjustment, was shaped by the unique circumstances of individuals and regions. The outcome of a response was affected not only by the goals, strategies, participants, scales, and timelines of each response, but by each participant's ability to employ tactics, such as increasing the authority of SMOs, establishing unlikely alliances, and engaging in market-based strategies, which have gained strength under neoliberalism. Nevertheless, tensions remain between the ability of these strategies to meet the immediate and unique needs of the individual and the ability of the resistance to address the deep rooted hegemonic discourses embedded in the MIR and ultimately causing the problem. Fortunately, a scalar analysis points to the use of networks as an organizational tool that could support a scaled resistance. By targeting the appropriate scales, a counter-hegemonic movement may be able to address the unique needs of individuals, whilst tackling the hegemonic discourses that the MIR reflects. 


\section{Appendix A:}

\section{Glossary}

\begin{tabular}{|c|c|}
\hline Stakeholders & $\begin{array}{l}\text { The term stakeholders represents actors (individuals and groups) who } \\
\text { have a vested interest, and affect and/or are affected by, the direction } \\
\text { of meat regulation in BC and Canada. Stakeholders include producers, } \\
\text { processors, distributors, consumers, government, and civil-society } \\
\text { organizations. }\end{array}$ \\
\hline $\begin{array}{l}\text { Civil-society } \\
\text { organizations }\end{array}$ & $\begin{array}{l}\text { This paper's definition of civil society organizations reflect Gramsci's } \\
\text { understanding of civil society organizations as "all the 'so-called } \\
\text { private' organizations such as churches, trade unions, political parties } \\
\text { and cultural associations which are distinct from the process of } \\
\text { production and from the public apparatuses of the state. All the } \\
\text { organizations which make up civil society are the result of a complex } \\
\text { network of social practices and social relations, including the struggle } \\
\text { between the two fundamental classes, capital and labour" (Simon, } \\
\text { 1982,69). }\end{array}$ \\
\hline $\begin{array}{l}\text { Cow-calf } \\
\text { operations }\end{array}$ & $\begin{array}{l}\text { Cow-calf operations are the first stage in the beef-commodity chain } \\
\text { and consist of the breeding and raising of the calves. Calves will } \\
\text { generally stay in these operations between } 6 \text { and } 16 \text { months, before } \\
\text { being shipped to feeding operations. Cow-calf operations are the most } \\
\text { traditional stage in the beef-commodity chain and in Canada we see a } \\
\text { large number of small-scale and hobby cow-calf operations. } \\
\text { (MacLachlan, 2001) }\end{array}$ \\
\hline $\begin{array}{l}\text { Meat } \\
\text { Inspection } \\
\text { Regulation } \\
\text { (MIR) }\end{array}$ & $\begin{array}{l}\text { The Meat Inspection Regulation, requires that all meat produced in BC } \\
\text { for sale for human consumption to pass through a licensed, inspected } \\
\text { slaughter facility. Meat from provincially licensed facilities can only } \\
\text { be sold within BC. Policy for BC's meat inspection and licensing } \\
\text { system is directed by the Ministry of Health. The provincial inspection } \\
\text { and licensing system is managed by the BC Centre for Disease } \\
\text { Control, as agency of the Provincial Health Services Authority. The } \\
\text { regulation outlines the obligations respecting the operation of } \\
\text { establishments and rural slaughter establishments, which includes the } \\
\text { inspection standard, the removal of animals, the inspection of animals } \\
\text { before slaughter, emergency slaughter, inspection of carcasses after } \\
\text { slaughter, inspection legend stamps, package labels, equipment, } \\
\text { cleaning and maintenance, storage, refrigeration equipment, equipment } \\
\text { for inedible or condemned carcasses, employee hygiene, animal and } \\
\text { carcass safety procedures, sanitation procedures, records, purchase and } \\
\text { sale of carcasses, excluded animals, pests, storage of animals, recalls, } \\
\text { inspectors and offences. These obligations are nevertheless written to } \\
\text { be open to interpretation by the inspector, who is expected to refer to } \\
\text { federal standards, for example section } 10 \text { states that "In conducting an } \\
\text { inspection of an animal or carcass in a slaughter establishment and in }\end{array}$ \\
\hline
\end{tabular}




\begin{tabular}{|c|c|}
\hline & $\begin{array}{l}\text { determining if an animal or carcass in a slaughter establishment is to } \\
\text { be passed, held or condemned, an inspector must apply the standards } \\
\text { related to food safety and animal health established under the Food } \\
\text { and Drugs Act (Canada) and the Meat Inspection Act(Canada). (Meat } \\
\text { Inspection Regulation, 2004) }\end{array}$ \\
\hline Policy & $\begin{array}{l}\text { Policy can be defined as an argument, plan, or course of action } \\
\text { adopted by a government or institution to guide decisions, aiming at } \\
\text { achieving a specific outcome. It must be made clear that policies are } \\
\text { not just made by the government and that not acting can be just as } \\
\text { strong as a policy as acting. When relating policy to community food } \\
\text { security (CFS) one will quickly find that there is no national food } \\
\text { policy in Canada. Instead policy surrounding food is "the } \\
\text { accumulation of a number of core themes and subject matter; shaped } \\
\text { by different disciplinary inputs and insights; as a tussle between } \\
\text { traditions and schools of thought" (Lang et. al., 2009, 23). Thus, food } \\
\text { policy is an interdisciplinary approach that "involves diverse actors } \\
\text { and institutions, at local, national, regional, and international levels, } \\
\text { not all immediately apparent or open to scrutiny" (Ibid., 23). Keeping } \\
\text { this in mind, when working to influence policy that will advance CFS, } \\
\text { one must keep in mind the interrelations between various } \\
\text { governmental departments, and the dominant ideologies and priorities } \\
\text { that influence the direction of policy in each of these departments. }\end{array}$ \\
\hline $\begin{array}{l}\text { Alternative } \\
\text { Food Networks } \\
\text { (AFNs) } \\
\text { (including } \\
\text { local food } \\
\text { supply } \\
\text { networks) }\end{array}$ & $\begin{array}{l}\text { Alternative food supply networks (AFNs) can be described as niche } \\
\text { markets for products that have been embedded with information and } \\
\text { are being marketed through unique connections with consumers in } \\
\text { ways that are different than those practiced by mainstream agri-food } \\
\text { business (Harris E, 2008; Ilbery et al. 2005). These networks have } \\
\text { more recently been associated with "product and place" and "process } \\
\text { and place" with the first factor associating the product with a sense of } \\
\text { place to add economic value and stimulate rural development and the } \\
\text { second factor referring to a process that emphasizes social and ethical } \\
\text { values associated with particular supply chains (Maye et al, 2001, 7). } \\
\text { AFNs have come to be viewed as "stronger alternatives" (Watts et al., } \\
2005 \text { ) since the processes of both food production and food } \\
\text { consumption are addressed. More recently, discussions of AFNs have } \\
\text { focused on the notion of 'alterity,' emphasizing the "diversity of } \\
\text { production methods, spaces, motivations and identities articulated } \\
\text { through AFN practiced". (Holloway et al, 2007), and in many cases in } \\
\text { recognized as a "counter-hegemony" to agro-food systems. A } \\
\text { common type of AFNs is the local food supply network that have } \\
\text { come to represent food chains (production, distribution, and } \\
\text { consumption) in which all steps take place with } 200 \mathrm{~km} \mathrm{(although} \mathrm{this} \\
\text { distance varies). These supply chains emphasize relationships between } \\
\text { the different links in the chain and arguably address the unique needs }\end{array}$ \\
\hline
\end{tabular}




\begin{tabular}{|c|c|}
\hline & $\begin{array}{l}\text { of small-scale producers, while allowing consumers access to } \\
\text { information regarding product and process. On the other hand Dupuis } \\
\text { and Goodman "understand local food systems not as local 'resistance' } \\
\text { against a global capitalist 'logic' but as a mutually constitutive, } \\
\text { imperfect, political process in which the local and the global make } \\
\text { each other on an everyday basis" (Dupuis and Goodman, 2005). }\end{array}$ \\
\hline $\begin{array}{l}\text { Specified Risk } \\
\text { Material } \\
\text { (SRM) }\end{array}$ & $\begin{array}{l}\text { Specified risk material are the tissues in cattle that have been } \\
\text { demonstrated to present a higher potential for infectivity of Bovine } \\
\text { Spongiform Encephalopathy (BSE). SRM include the skull, brain, } \\
\text { trigeminal ganglia (nerves attached to the brain), eyes, tonsils, spinal } \\
\text { cord and dorsal root ganglia (nerves attached to the spinal cord) of } \\
\text { cattle aged } 30 \text { months or older, and the distal ileum of cattle of all } \\
\text { ages. All removed SRM are to be diverted away from the food supply. } \\
\text { (Health Canada, 2003) } \\
\text { After finding the BSE-positive cow in Canada in May, 2003, Health } \\
\text { Canada took the precautionary assumption that there may be a low } \\
\text { BSE prevelance in Canada. Many countries that have confirmed the } \\
\text { presence of BSE in their domestic cattle have take the public health } \\
\text { protection measure of requiring the removal of specific tissues from } \\
\text { cattle of a defined age at slaughter referred to as specified risk material } \\
\text { (SRM). "The objective of this policy is to reduce the risk of exposure } \\
\text { through the food supply to the BSE agent by establishing a } \\
\text { requirement that SRM be removed at the time of slaughter, and SRM } \\
\text { be diverted away from the food supply. This action is recognized as } \\
\text { having the most direct impact on enhancing the protection of human } \\
\text { health...Based on our review of the current science, the removal of } \\
\text { SRM will eliminate more than } 99 \% \text { of the potential infectivity from an } \\
\text { infected carcass, preventing consumer exposure through foods" } \\
\text { (Health Canada, 2003). } \\
\text { This policy regarding SRM has added increased costs to abattoir } \\
\text { operators "based on the need for identification, segregation and special } \\
\text { processing of target animals (those over } 30 \text { months of age). } \\
\text { Additionally increased costs for inspection could be incurred by the } \\
\text { CFIA and the provinces/territories" (Health Canada, 2003). }\end{array}$ \\
\hline
\end{tabular}




\section{Appendix B:}

\section{Meat Inspection Regulation}

B.C. Reg. $349 / 2004$

Deposited July 23, 2004

O.C. $798 / 2004$

effective September 1, 2004

\section{Food Safety Act \\ MEAT INSPECTION REGULATION}

[includes amendments up to B.C. Reg. 80/2011, April 29, 2011]

\section{Contents}

\section{Part 1 - Definitions and Application}

1 Definitions

$\underline{2}$ Application to establishments

$\underline{3}$ Repealed

\section{Part 2-Designation and Licencing}

4 Designation of slaughter establishment

5 Application for and issue of licence

5.01 Issuing Class D or E licences

\subsection{Repealed}

6 Classes of licences

7 Posting licence

\section{Part 3-Obligations of Operator}

8 Plans and specifications to be approved

9 Obligations respecting the operation of establishments

9.1 Obligations respecting the operation of nural slaughter establishments

\section{Part 4-Operation of Slaughter Establishments}

Division 1 - Inspection and Slaughter

10 Inspection standard

11 Removal of animals

12 Inspection of animals before slaughter

13 Humane slaughter

14 Emergency slaughter

15 Inspection of carcasses after slaughter

16 Inspection legend stamps

17 Package labels

Division 2 - Protection of Carcasses

18 Protection of carcasses from contamination

19 Storage temperature 


\section{Notification of possible contamination}

\section{Division 3 - Equipment and Cleaning}

21 Equipment

22 Cleaning and maintenance

23 Storage

24 Refrigeration equipment

25 Equipment for inedible or condemned carcass

\section{Division 4-Employees}

26 Employee hygiene

\section{Division 5-Operational Safety Management}

27 Animal and carcass safety procedures

28 Sanitation procedures

Division 6 - Records

29 Records

\section{Division 7 -General}

30 Purchase and sale of carcasses

31 Excluded animals

32 Pests

33 Storage of chemicals

34 Recalls

35 Inspectors

\section{Part 5-Offences}

\section{Offences}

\section{Schedule 1}

\section{Schedule 2}

\section{Definitions}

\section{Part 1 - Definitions and Application}

1 In this regulation:

"Act" means the Food Safety Act;

"animal" means, except in section 31, an animal raised for food;

"animal unit" means a combined animal weight, when measured alive, of $455 \mathrm{~kg}$ (1000 lbs);

"carcass" means the body of a dead animal and includes anything derived from or a part of the body of a dead animal;

"condemned" means, for an animal or carcass, determined by an inspector to be contaminated or otherwise unfit for human or animal consumption;

"equipment" means a non-food article that is used in the operation of a slaughter establishment;

"food premises" means "food premises" as defined in the Food Premises Regulation, B.C. Reg. 210/99;

"handwashing station" means a hand basin provided with

(a) hot and cold running water,

(b) soap in a dispenser, and 
(c) a forced air hand dryer or a method of hand drying that uses products

that are designed to be used only once and then discarded;

"held" means, for an animal or carcass, detained by an inspector for further examination or inspection by an inspector;

"inedible" means, for a carcass, determined by an inspector to be contaminated or otherwise unfit for human consumption but suitable for use for animal food;

"inspection legend stamp" means the stamp that an inspector imposes or causes to be imposed on a carcass at the time of inspection to indicate that the carcass is not contaminated and is fit for human consumption;

"licence" means a licence referred to in section 5 of the Act;

"licence holder" means a person who holds a licence for a slaughter establishment;

"livestock area" means the yards or pens of a slaughter establishment where animals are received and contained before slaughter;

"meat products" means anything derived from a carcass and includes organs, intestines and blood;

"passed" means, for an animal or carcass, determined by an inspector to be fit for human consumption;

"pests" includes insects;

"poultry" includes domesticated chickens, turkeys, ducks, geese, guinea fowl, ratites, squab and pheasants;

"process" includes the cutting, deboning, smoking, curing and packaging of a carcass;

"processing area" means an area of a slaughter establishment in which carcasses are processed;

"rural slaughter establishment" means a slaughter establishment for which a Class $\mathrm{D}$ or $\mathrm{E}$ licence has been issued;

"sanitizing station" means a rust resistant metal basin provided with a continuous flow of hot water maintained at a minimum temperature of $82^{\circ} \mathrm{C}$;

"slaughter area" means an area of a slaughter establishment in which animals are slaughtered, eviscerated and sectioned;

"slaughter establishment" means a food establishment in which animals are slaughtered or slaughtered and processed;

"specified area" means an area specified in Schedule 1 to this regulation;

"Stikine Region" means the area comprising all the land in British Columbia that is not within the boundaries of a regional district or the Northern Rockies Regional Municipality;

"storage area" means the area of a slaughter establishment in which carcasses are stored;

"transitional slaughter establishment" means a type of slaughter establishment that (a) was operating before September 30, 2007 in an area of the Province that is outside all the specified areas,

(b) slaughters animals or slaughters animals and processes meat, and

(c) sells the meat referred to in paragraph (b) solely to residents of areas of the Province that are outside all the specified areas and on the condition that the meat is not resold.

[am. B.C. Regs. 299/2007, Sch. B, s. 1; 102/2010, s. 1;

Application to establishments

80/2011, s. 1.]

2 (1) The Act does not apply to

(a) a slaughter establishment that is registered under the Meat Inspection

Act (Canada), or

(b) the slaughter of an animal by the owner of the animal for the owner's

personal use and not for resale.

(2) This regulation, other than sections $1,4,5,6,7,8,16,17,18$ and 30 , does not apply to a

transitional slaughter establishment.

(3) Repealed. [B.C. Reg. 299/2007, Sch. B, s. 3.] 
(4) This regulation does not apply to a rural slaughter establishment, except as follows:

(a) sections 1, 4, 5, 5.01, 6, 7, 9.1, 16, 17, 18, 29, 30 and 33 apply to all rural slaughter establishments;

(b) section 19 applies to rural slaughter establishments operated under a Class D licence.

(c) Repealed. [B.C. Reg. 80/2011, s. 2.$]$

[am. B.C. Regs. 408/2004; 76/2006, s. (a); 299/2007, Sch B, ss. 2 and $3 ; 102 / 2010$, s. $2 ; 80 / 2011$, s. 2.]

\section{Repealed}

3 (1) Repealed. [B.C. Reg. 349/2004, s. 3 (2).]

(2) Spent.

[am. B.C. Regs. 76/2006, s. (b); 349/2004, s. 3 (2).]

\section{Designation of slaughter establishment}

\section{Part 2 - Designation and Licencing}

4 Subject to section 2 (1), slaughter establishments are designated as being subject to Part 2 of the Act.

\section{Application for and issue of licence}

[en. B.C. Reg. 299/2007, Sch. B, s. 4.]

5 (1) In order to obtain a licence for a slaughter establishment a person must

(a) apply to the minister on a form specified by the minister, and

(b) provide the minister with any information the minister reasonably requires in order to evaluate the application.

(2) Repealed. [B.C. Reg. 299/2007, Sch. B, s. 5 (b).]

(3) In addition to the requirements of subsection (1), a person who applies for a class $\mathrm{C}$ licence for a transitional slaughter establishment must establish that

(a) the transitional slaughter establishment was operating on and before September 30, 2007, in a location of the Province that is outside all the specified areas,

(b) one of the following types of plan was submitted and has been approved under section 8:

(i) a plan for the construction of a new slaughter establishment to replace the transitional slaughter establishment for which the licence is sought, or

(ii) a plan for alterations to the transitional slaughter establishment for which the licence is sought to enable that slaughter establishment to meet the requirements for a Class A or Class B licence, and

(c) as of the date this paragraph comes into force, the transitional slaughter establishment is operating in a location of the Province that is more than $100 \mathrm{~km}$, or, if separated by marine waters, 15 nautical miles, from a slaughter establishment that

(i) is operated under a Class A or B licence,

(ii) slaughters animals of the same species as are slaughtered at the transitional slaughter establishment, and

(iii) slaughters animals that are not owned by the licence holder.

(4) If a person holds a Class C licence as of the date subsection (3) (c) comes into force , subsection (3) (c) does not apply to the licence or any application to renew the licence made before December 31, 2009.

(5) An application for a Class $\mathrm{C}$ licence

(a) must be made by June 1, 2010, and

(b) may not be made in respect of a slaughter establishment within an area described in Schedule 2.

(6) In addition to the requirements of subsection (1), a person who applies for a Class D or E licence must do all of the following: 
(a) agree in writing to comply with the terms and conditions set out in the licence;

(b) agree in writing that the person,

(i) in the case of an applicant for a Class D licence, will

slaughter in each year no more than 25 animal units, or

(ii) in the case of an applicant for a Class $E$ licence,

(A) will slaughter only animals that the person owns,

(B) will slaughter in each year no more than 10 animal units, and

(C) will sell meat products to consumers directly from

the slaughter establishment only;

(c) submit evidence of having successfully completed training respecting food safety that, in the opinion of the minister, is relevant to the operation of a rural slaughter establishment;

(d) submit a written food safety plan that identifies

(i) possible sources of contamination in the slaughter

establishment before, during and after slaughter, and

(ii) the steps to be taken to ensure that carcasses in the slaughter

establishment are not contaminated or are not otherwise made

unfit for human consumption;

(e) if section 5.01 (1) or (2) (a) applies, establish that the slaughter

establishment is within an area described in Schedule 2;

(f) if section 5.01 (2) (b) applies, submit the results of a feasibility study

made for the purposes of determining whether operation of a Class A or B

slaughter establishment would be feasible generally in the area in which

the slaughter establishment that is the subject of the application is located.

(7) For the purposes of subsection (6) (f), a feasibility study must address the

appropriateness of issuing a Class $E$ licence outside an area described in Schedule 2 given both of the following:

(a) whether a Class A or B facility is viable in the area in which the slaughter establishment that is the subject of the application is located;

(b) whether any existing slaughter establishments can provide outreach slaughter services in the area in which the slaughter establishment that is the subject of the application is located.

$$
\begin{aligned}
& \text { [am. B.C. Regs. 299/2007, Sch. B, s. 5; 120/2008, s. 1; } \\
& \text { 102/2010, s. 3.] }
\end{aligned}
$$

Issuing Class D or E licences

5.01 (1) A Class D licence may be issued only in respect of a slaughter establishment within an area described in Schedule 2.

(2) A Class $\mathrm{E}$ licence may be issued in respect of a slaughter establishment located

(a) in an area described in Schedule 2, or

(b) in an area outside an area described in Schedule 2, but only on

consideration of the factors set out in subsection (3) of this section.

(3) For the purposes of subsection (2) (b), the minister must consider all of the following:

(a) the population density of the area in which the slaughter establishment is located;

(b) the need for slaughter capacity of the species to be slaughtered in the area in which the slaughter establishment is located;

(c) if the slaughter establishment will offer specialized slaughter, the need

for specialized slaughter capacity in the area in which the slaughter

establishment is located;

(d) animal production levels in the area in which the slaughter

establishment is located;

(e) the geographic location of the slaughter establishment, including

(i) its proximity to a Class A or B slaughter establishment, and 


\section{Repealed}

(ii) whether animals must be transported over marine waters to a Class A or B slaughter establishment if not slaughtered at the proposed Class E slaughter establishment;

(f) the results of the feasibility study submitted under section 5 (6);

(g) whether the applicant has consulted

(i) licensed slaughter establishments within $100 \mathrm{~km}$ of the applicant's slaughter establishment,

(ii) the municipality and regional district within which the slaughter establishment is located, and

(iii) residents of, and business establishments in, the regional district in which the slaughter establishment is located. [en. B.C. Reg. 102/2010, s. 4.]

5.1 Repealed. [B.C. Reg. 102/2010, s. 5.]

Classes of licences

6 (0.1) The following classes of licences are established:

(a) Class A licences, issued for the purposes of general slaughter and processing;

(b) Class B licences, issued for the purposes of general slaughter only;

(c) Class $\mathrm{C}$ licences, issued in relation to transitional slaughter

establishments;

(d) Class D licences, issued in relation to rural slaughter establishments that slaughter animals for retail purposes;

(e) Class $\mathrm{E}$ licences, issued in relation to rural slaughter establishments that slaughter animals for sales only to consumers directly.

(1) A person must not operate a slaughter establishment that both slaughters animals and processes carcasses unless

(a) the person holds a Class A licence, or

(b) in the case of a transitional slaughter establishment, the person holds a

Class $\mathrm{C}$ licence.

(2) A person must not operate a slaughter establishment that slaughters animals but does not process carcasses unless

(a) the person holds a Class B licence,

(b) in the case of a transitional slaughter establishment, the person holds a

Class $\mathrm{C}$ licence, or

(c) in the case of a rural slaughter establishment, the person holds a Class

$\mathrm{D}$ or $\mathrm{E}$ licence.

[en. B.C. Reg. 299/2007, Sch. B, s. 6; am. B.C. Reg. $102 / 2010$, s. 6.]

Posting licence

$7 \mathrm{~A}$ licence holder must post the licence in a conspicuous location in the slaughter establishment. [am. B.C. Reg. 299/2007, Sch. B, s. 7.]

\section{Plans and specifications to be approved}

\section{Part 3 - Obligations of Operator}

8 (1) A person must not construct or alter a slaughter establishment or cause a slaughter establishment to be constructed or altered unless an inspector has approved the plans and specifications for the construction or alteration.

(2) Before starting the construction or alteration of a slaughter establishment, an applicant for approval under subsection (1) must

(a) submit to an inspector a copy of the complete plans and specifications

for the proposed construction or alteration, and

(b) provide the inspector with any other information respecting the proposed construction or alteration that the inspector reasonably requires.

(3) The inspector may approve the plans and specifications submitted under subsection (2) if a slaughter establishment that is constructed or altered in accordance with the plans and 
specifications is, in the opinion of the inspector, capable of being operated in compliance with the requirements of section 9.

Obligations respecting the operation of establishments

9 (1) A person must not operate a slaughter establishment unless the person

(a) ensures that the construction of the slaughter establishment is and remains sound,

(b) operates the slaughter establishment in a manner that ensures that the animals and carcasses are handled in a sanitary manner and without risk of contamination or spoilage of any carcass produced, stored or processed by the slaughter establishment,

(c) ensures that materials from which the slaughter establishment is constructed

(i) are and remain suitable for their intended purpose, and

(ii) are durable, easily cleaned and free from any noxious or toxic substances,

(d) ensures that the slaughter establishment is separate from and without direct access to

(i) living quarters, or

(ii) any area in which activities are carried out that are

incompatible with the sanitary handling of animals or carcasses,

(e) supplies water to the slaughter establishment from a source that is both potable and not capable of contaminating a carcass,

(f) ensures that the slaughter establishment is connected at all times to a waste disposal system,

(g) supplies an adequate quantity of hot and cold water under the pressure necessary to meet the water needs of the establishment,

(h) provides artificial lighting that is adequate in intensity so as to enable the sanitary operation and maintenance of the establishment,

(i) provides staff dressing rooms that allow staff to change their clothing in a private and clean environment,

(j) maintains and uses ventilation equipment so as to prevent any

accumulation of smoke, grease, water vapour and objectionable odours, and

(k) maintains and uses the equipment necessary so as to ensure that the slaughter of animals and the storage and processing of carcasses is done in a manner that is sanitary and poses no risk of contamination or spoilage of any carcasses produced, stored or processed by the slaughter establishment.

(2) A person must not operate a slaughter establishment unless the person

(a) ensures that at all times there is a segregation of activities so that contamination of the animals or carcasses is prevented, including the segregation of the following areas from all other areas of the slaughter establishment:

(i) the livestock area;

(ii) the slaughter area;

(iii) the processing area;

(iv) the storage area,

(b) maintains and ensures that separate rooms, spaces and equipment are used solely for the segregation and disposal of held, inedible or condemned animals and carcasses, and

(c) maintains and uses a sufficient number of sanitizing stations to ensure the effective sanitizing of knives.

[am. B.C. Reg. 299/2007, Sch. B, s. 8.]

Obligations respecting the operation of rural slaughter establishments

9.1 (1) A person must not operate a rural slaughter establishment unless the person ensures that all of the following requirements are met: 
(a) if water is used during slaughter, that only potable water is used;

(b) that an animal in the rural slaughter establishment is kept before slaughter and slaughtered in a humane manner;

(c) that the rural slaughter establishment is operated in a manner that ensures that animals and carcasses are handled, slaughtered and stored in a sanitary manner and without risk of contamination or spoilage of any carcass produced or stored by the rural slaughter establishment;

(d) that each carcass stored by the rural slaughter establishment is stored at a temperature sufficient to prevent the risk of spoilage;

(e) that pests are not present during the handling, slaughter or storage of animals or carcasses;

(f) that equipment is

(i) maintained in a sanitary condition, and

(ii) operated in a manner that is sanitary;

(g) that each employee, while working in the rural slaughter establishment,

(i) wears clean clothing and footwear,

(ii) does not smoke in any area where carcasses are prepared, stored or distributed, and

(iii) washes his or her hands as often as necessary to prevent the contamination of carcasses;

(h) that an animal slaughtered in the rural slaughter establishment is in good health.

(2) A person holding a Class $\mathrm{D}$ or $\mathrm{E}$ licence must take, as required by the minister, food safety training relevant to the operation of a rural slaughter establishment.

$$
\text { [en. B.C. Reg. 102/2010, s. 7.] }
$$

\section{Inspection standard}

\section{Part 4-Operation of Slaughter Establishments \\ Division 1 - Inspection and Slaughter}

10 In conducting an inspection of an animal or carcass in a slaughter establishment and in determining if an animal or carcass in a slaughter establishment is to be passed, held or condemned, an inspector must apply the standards related to food safety and animal health

\section{Removal of animals} established under the Food and Drugs Act (Canada) and the Meat Inspection Act(Canada).

11 A person must not remove an animal from the livestock area unless

\section{Inspection of animals before slaughter}

(a) an inspector permits the removal, or

(b) it is removed in accordance with this Division.

12 (1) A licence holder must ensure that before an animal intended for slaughter leaves the livestock area, it is inspected by an inspector and identified as

(a) passed,

(b) held, or

(c) condemned.

(2) Despite subsection (1), a licence holder may allow poultry or rabbits intended for slaughter to leave the livestock area after an inspector has inspected only a sample of the poultry or rabbits, as the case may be, and has identified the poultry or rabbits as

(a) passed,

(b) held, or

(c) condemned.

(3) Subject to subsection (5), a licence holder may allow an animal to enter the slaughter area only if the animal is identified as passed under subsection (1) or (2).

(4) A licence holder must move an animal that is identified as held or condemned under subsection (1) or (2) to the area specified by an inspector and keep the animal in that area until the inspector approves the animal entering the slaughter area or provides other instructions. 


\section{Humane slaughter}

(5) If the inspector provides approval under subsection (4), the licence holder may allow an animal in the held area to enter the slaughter area.

(6) If an inspector identifies an animal as condemned under this section, the licence holder must slaughter the animal as directed by an inspector and remove the animal to the condemned area for disposal.

13 A licence holder must ensure that an animal in the slaughter establishment is kept before slaughter and slaughtered in accordance with the provisions relating to the humane treatment of animals in section 28 and Part III of the Meat Inspection Regulations (Canada), SOR $90 / 288$.

\section{Emergency slaughter}

14 Despite section 12, if it is necessary to slaughter an animal at a slaughter establishment for humane reasons but an inspector is not present at the slaughter establishment, the licence holder of the slaughter establishment may slaughter the animal without the inspector's approval if the licence holder

(a) identifies the animal as held,

(b) removes the carcass to the held area for inspection by an inspector, and

(c) hangs the carcass with the following attached:

(i) head;

(ii) heart, lungs and liver;

(iii) lymph glands;

(iv) gastrointestinal tract

\section{Inspection of carcasses after slaughter}

15 (1) Unless section 14 applies, a licence holder must ensure that after the slaughter of an animal the carcass is not removed from the slaughter area until

(a) an inspector has inspected the carcass,

(b) an inspector has identified the carcass as
(i) passed,
(ii) held,
(iii) inedible, or
(iv) condemned, and

(c) an inspector or a person authorized by an inspector has placed an impression of the inspection legend stamp on each half or quarter carcass that is identified as passed under paragraph (b).

(2) Subsection (1) (c) does not apply in respect of the carcasses of poultry or rabbits.

(3) If under subsection (1) an inspector identifies a carcass as held, the licence holder must

(a) identify the carcass in the manner the inspector directs, and

(b) remove the carcass to the held area until the inspector provides further instructions with respect to that carcass.

(4) If an inspector identifies a carcass under this section as inedible or condemned, the licence holder must

(a) identify the carcass in the manner the inspector directs,

(b) remove the carcass to the inedible area or condemned area, as the case may be, for disposal, and

\section{Inspection legend stamps}

(c) dispose of the carcass as directed by the inspector.

16 (1) A licence holder of a slaughter establishment must ensure that an impression of the inspection legend stamp is not a part of the establishment's name or logo.

(2) Unless authorized by an inspector, a person must not

(a) have an inspection legend stamp in his or her custody or control, or

(3) A person must not

(b) apply an inspection legend stamp to a carcass.

(a) alter an inspection legend stamp, or

(b) use an inspection legend stamp on any held, inedible or condemned carcasses.

Package labels 
17 (1) A licence holder must ensure that packages containing meat products produced by the licence holder are labelled with the following information:

(a) the name and address of the slaughter establishment;

(b) a description of the contents of the package;

(c) the net weight or volume of the contents of the package;

(d) the identifying number issued by the minister to the slaughter establishment.

(2) A Class C, D or E licence holder must ensure that packages containing meat products produced at a slaughter establishment operated by the licence holder bear a label printed with the applicable words set out in Column 2 of the Table opposite the class of licence held by the licence holder:

\section{Column 1}

\section{Column 2}

Licence

Class

$\mathrm{C}$

Class C - Not Government Inspected; Not for Resale.

$\mathrm{D}$ or $\mathrm{E} \quad$ Class $[D$ or $E$ ] - Not Government Inspected; For sale only in the regional district of [name of regional district in which

the rural slaughter establishment is located].

Class $[D$ or $E]$ — Not Government Inspected; For sale only in the Strathcona Regional District, excluding Vancouver Island.

Class $[D$ or $E]$ - Not Government Inspected; For sale only in the Northern Rockies Regional Municipality

Class [D or E] - Not Government Inspected; For sale only in the Stikine Region.

(3) If a package containing meat products is labeled in accordance with subsection (2), a person

(a) must not remove the label before the package is sold, or

(b) if raw meat products are repackaged, must re-label the new packages in accordance with subsection (2).

(4) Repealed. [B.C. Reg. 80/2011, s. 3.]

[am. B.C. Regs. 299/2007, Sch. B, s. 10; 120/2008, s. 3; $102 / 2010$, s. $8 ; 80 / 2011$, s. 3.]

\section{Protection of carcasses from contamination}

\section{Division 2 - Protection of Carcasses}

18 A licence holder must ensure that all carcasses at the slaughter establishment are

(a) protected from contamination, and

(b) stored, handled, prepared and packaged in a manner that is sanitary and

is without risk of contamination or spoilage.

Storage temperature

[am. B.C. Reg. 299/2007, Sch. B, s. 11.]

19 The licence holder for a slaughter establishment must ensure that each carcass

(a) is stored at a room temperature of $4^{\circ} \mathrm{C}$ or less, or

(b) is kept in a processing area of the slaughter establishment

(i) at a room temperature of $10^{\circ} \mathrm{C}$ or less, or

(ii) for a period of 2 hours or less.

[en. B.C. Reg. 299/2007, Sch. B, s. 12.]

\section{Notification of possible contamination}

20 A licence holder must immediately notify an inspector of any circumstance at the slaughter establishment that might pose an immediate or significant risk of contamination of a carcass.

[am. B.C. Reg. 299/2007, Sch. B, s. 13.] 
Equipment

\section{Division 3 - Equipment and Cleaning}

21 A licence holder must ensure that all equipment in the slaughter establishment is

(a) constructed from materials that are

(i) suitable for their intended purpose, and

(ii) durable, easily cleaned and free from any noxious or toxic substance,

(b) in good working order, and

(c) operated in a manner that ensures that the handling of animals and carcasses is sanitary and is without risk of contamination or spoilage of carcasses.

\section{Cleaning and maintenance}

$$
\text { [am. B.C. Reg. 299/2007, Sch. B, s. 14.] }
$$

22 (1) A licence holder must ensure that the slaughter establishment and the equipment in the slaughter establishment are maintained in a sanitary condition.

(2) Without limiting subsection (1), a licence holder must ensure that the slaughter establishment and the equipment in the slaughter establishment are washed and sanitized in a manner that removes all contamination.

(3) Without limiting subsection (1), a licence holder must provide at the slaughter establishment

(a) the facilities and equipment necessary to meet the requirements of subsections (1) and (2), and

(b) garbage or refuse containers that are

(i) sufficient in size and number to meet the needs of that establishment, and

(ii) pest-proof.

$$
\text { [am. B.C. Reg. 299/2007, Sch. B, s. 15.] }
$$

Storage

23 A licence holder must not permit anything that is not required for the operation of the slaughter establishment to be stored in that establishment.

\section{Refrigeration equipment}

$$
\text { [am. B.C. Reg. 299/2007, Sch. B, s. 16.] }
$$

24 A licence holder must ensure that all refrigeration equipment in the slaughter establishment

(a) is of a type and capacity that is adequate to meet the needs of that establishment,

(b) is capable of maintaining the temperatures required by section 19 , and

(c) is equipped with a thermometer that is accurate to within $1^{\circ} \mathrm{C}$.

\section{Equipment for inedible or condemned carcass} [am. B.C. Reg. 299/2007, Sch. B, s. 16.]

25 A licence holder must ensure that equipment used in a slaughter establishment to collect inedible or condemned carcasses is clearly identified and used only for the collection or conveyance of inedible or condemned carcasses.

\section{Employee hygiene}

\section{Division 4 - Employees}

26 (1) A licence holder must ensure that each employee, while working in the slaughter establishment,

(a) wears clean clothing and footwear,

(b) exhibits cleanliness and good personal hygiene,

(c) takes adequate measures to ensure that carcasses are not contaminated by hair,

(d) does not smoke in any area where carcasses are prepared, stored or distributed, and

(e) washes his or her hands as often as necessary to prevent the contamination of carcasses. 
(2) A licence holder must supply and maintain in the slaughter establishment an adequate number of hand washing stations and ensure that the hand washing stations are located so that each employee has easy access to at least one hand washing station.

(3) A licence holder must ensure that the slaughter establishment contains an adequate number of clean and sanitary washrooms for the number of persons working at that establishment.

[am. B.C. Reg. 299/2007, Sch. B, s. 16.]

\section{Animal and carcass safety procedures}

\section{Division 5 - Operational Safety Management}

27 (1) In this section:

"critical control point" means a location in a slaughter establishment, or a step in the establishment's procedures, where failure to comply with the Act or this regulation might result in the contamination of carcasses or making carcasses otherwise unfit for human consumption;

"critical limit" means food safety standards that must be met at a critical control point.

(2) After December 31, 2008, a licence holder must develop, maintain and follow written procedures that ensure that carcasses in the slaughter establishment are not contaminated or are not otherwise made unfit for human consumption.

(3) The written procedures required under subsection (2) must include the following:

(a) the identification of all critical control points;

(b) the identification of all critical limits;

(c) the method to be followed to ensure adherence to the critical limits;

(d) the actions to be taken in the event that the critical limits are not adhered to.

\section{Sanitation procedures}

$$
\text { [am. B.C. Reg. 299/2007, Sch. B, s. 17.] }
$$

28 After December 31, 2008, a licence holder must develop, maintain and follow written procedures that ensure the slaughter establishment is operated in a manner that is sanitary and poses no risk of contamination or spoilage of carcasses, including, without limitation,

(a) the cleaning and sanitizing requirements for that establishment and for all equipment,

(b) the identification of cleaning and sanitizing agents used in that establishment, including their concentrations and their uses, and (c) the identification of all pesticides used in that establishment, including their uses and their storage requirements. [am. B.C. Reg. 299/2007, Sch. B, s. 18.]

Records Division 6 - Records

29 (1) A licence holder of a slaughter establishment must maintain, for each animal that enters the slaughter establishment, records that show

(a) the location from which the animal was shipped to the slaughter establishment, and

(b) the name, address and telephone number of the person who owned the animal at the time it was shipped to the slaughter establishment. (2) A licence holder of a slaughter establishment need not maintain the records required under subsection (1) for a flock or shipment of poultry or rabbits if the licence holder maintains for the flock or shipment records that show

(a) the location from which the flock or shipment was shipped, and

(b) the name, address and telephone number of the person who owned the

flock or shipment at the time it was shipped to the slaughter establishment. Division 7 - General

\section{Purchase and sale of carcasses}

30 (1) Subject to subsections (2) to (3.1), a person must not sell a carcass or store or process a carcass for the purpose of sale unless the carcass 
(a) has been inspected under the Act or the Meat Inspection Act (Canada) and passed by an inspector under either of those Acts,

(b) was produced at a transitional slaughter establishment, or

(c) was produced at a nural slaughter establishment.

(2) A person must not sell a carcass that was produced at a transitional slaughter establishment

(a) to a person who resides in a specified area, or

(b) to food premises.

(3) A person must not sell a carcass that was produced at a rural slaughter establishment outside the area in which the rural slaughter establishment is located, as that area is described in Schedule 2.

(3.1) A person must not sell a carcass that was produced at a rural slaughter establishment operated under a Class $\mathrm{E}$ licence to food premises.

(4) A person who purchases meat from either of the following must not resell the meat:

(a) a transitional slaughter establishment;

(b) a rural slaughter establishment operated under a Class $E$ licence.

\section{Excluded animals}

[en. B.C. Reg. 102/2010, s. 9; am. B.C. Reg. 80/2011, s. 4.]

31 A licence holder must not permit an animal, other than an animal that is raised for food, to enter the slaughter establishment.

Pests

32 A licence holder must ensure that the slaughter establishment is

(a) free of pests,

(b) free of conditions that lead to the harbouring or breeding of pests, and

(c) protected against the entrance of pests.

Storage of chemicals

[am. B.C. Reg. 299/2007, Sch. B, s. 20.]

33 A licence holder must ensure that chemicals, cleansers and other similar non-food substances that are on the premises of the slaughter establishment are stored in

(a) a room or cabinet separate from any carcasses, and

(b) non-food containers that are clearly labelled to identify the contents.

[am. B.C. Reg. 299/2007, Sch. B, s. 21.]

Recalls

34 A licence holder must develop and maintain written procedures that, when followed, ensure that the licence holder is able to comply with an order under section 12 (4) (c) of the Act for the immediate recall of a carcass distributed from the slaughter establishment.

Inspectors

[am. B.C. Reg. 299/2007, Sch. B, S. 21.]

35 A licence holder must ensure that

(a) an office and a clean and sanitary washroom are conveniently located in or close to the slaughter establishment for easy access by inspectors, and

(b) the office referred to in paragraph (a) contains a locked cabinet and other furniture and equipment that an inspector needs in order to carry out the powers, functions and duties of an inspector under the Act.

[am. B.C. Reg. 299/2007, Sch. B, s. 22.]

Part 5 - Offences

\section{Offences}

36 A person who contravenes section $6,7,8(1)$ or $(2), 9,11,12,13,15(1),(3)$ or $(4), 16$ or 17 to 35 commits an offence.

\section{Schedule 1}

[en. B.C. Reg. 299/2007, Sch. B, s. 23; am. B.C. Regs. 120/2008, s. 4; 209/2009; 102/2010, s. 10.]

The area comprising all the land of Vancouver Island. 
The area comprising all the land within the boundaries of the City of Abbotsford.

The area comprising all the land within the boundaries of the City of Burnaby.

The area comprising all the land within the boundaries of the City of Chilliwack.

The area comprising all the land within the boundaries of the City of Langley.

The area comprising all the land within the boundaries of the City of Maple Ridge.

The area comprising all the land within the boundaries of the City of New Westminster.

The area comprising all the land within the boundaries of the City of North Vancouver.

The area comprising all the land within the boundaries of the City of Pitt Meadows.

The area comprising all the land within the boundaries of the City of Richmond.

The area comprising all the land within the boundaries of the City of Vancouver.

The area comprising all the land within the boundaries of the City of Vernon.

The area comprising all the land within the boundaries of the District of Kent.

The area comprising all the land within the boundaries of the District of Mission.

The area comprising all the land within the boundaries of the District of North Vancouver.

The area comprising all the land within the boundaries of the District of Squamish.

The area comprising all the land within the boundaries of the District of West Vancouver.

The area comprising all the land within the boundaries of the Resort Municipality of Whistler.

The area comprising all the land within the boundaries of School District No. 59 (Peace River South).

The area comprising all the land within the boundaries of the Sunshine Coast Regional District.

The area comprising all the land within the boundaries of the Township of Langley.

The area comprising all the land within the boundaries of the Village of Pemberton.

The area comprising all the land within the boundaries of the former Dewdney-Alouette Regional District incorporated by Letters Patent issued October 27, 1967 and amalgamated into the Fraser Valley Regional District by Letters Patent issued on December 12, 1995.

The areas comprising all the land within the boundaries of Barnston Island, the Corporation of Delta, the City of Surrey, and the City of White Rock.

The areas comprising all the land within the boundaries of the City of Coquitlam, the City of Port Coquitlam and the City of Port Moody.

Schedule 2

[en. B.C. Reg. 102/2010, s. 10; am. B.C. Reg. 80/2011, s. 5.]

Class $D$ and $E$ Licensing Areas

1 For the purposes of section 5.01 (1) and (2) (a) of the regulation, a Class D or E licence may be issued in the following areas:

(a) the area comprising all the land within the boundaries of the Central

Coast Regional District;

(b) Repealed. [B.C. Reg. 80/2011, s. 5 (a).]

(b.1) the area comprising all the land within the boundaries of the Kitimat-

Stikine Regional District;

(c) the area comprising all the land within the boundaries of the Mount

Waddington Regional District;

(d) Repealed. [B.C. Reg. 80/2011, s. 5 (a).]

(e) the area comprising all the land within the boundaries of the Powell

River Regional District;

(f) the area comprising all the land within the boundaries of the Skeena-

Queen Charlottes Regional District;

(g) the area comprising all the land within the boundaries of the Squamish-

Lillooet Regional District; 
(h) Repealed. [B.C. Reg. 80/2011, s. 5 (a).]

(h.1) the area comprising all the land within the boundaries of the Strathcona Regional District, other than the land located on Vancouver Island;

(i) the area comprising all the land within the boundaries of the Sunshine Coast Regional District;

(j) the area comprising all the land within the boundaries of the Northern Rockies Regional Municipality;

Note: this regulation replaces $B . C$. Reg. 54/66.

(k) the Stikine Region.

[Provisions relevant to the enactment of this regulation: Food Safety Act, S.B.C. 2002, c. 28, sections 4 and 23]

1. June 5,2008 
Appendix C:

\section{MIR Requirements}

\begin{tabular}{|c|c|}
\hline Category & Requirements \\
\hline Cosmetic & $\begin{array}{l}\text { Cosmetic upgrades were one of the most frustrating types of requirements } \\
\text { for operators because despite the added costs, these upgrades did not } \\
\text { directly relate to food safety (I-24,2011; I-1,2010). Although the cosmetic } \\
\text { upgrades, such as removing all plywood and anything with a painted surface } \\
\text { and replacing it with stainless steel in order to meet the standards of } \\
\text { washability (I-24, 2011) and closing all vaults-work and improve the } \\
\text { lighting (I-24, 2011) could be costly, they didn't require any major } \\
\text { structural changes to the buildings (I-24,2011). }\end{array}$ \\
\hline Water & $\begin{array}{l}\text { The farmers and abattoirs that faced the biggest challenges and costs to } \\
\text { upgrading their water were those who lived in rural British Columbia, and } \\
\text { therefore did not have access to the municipal water supply. One farmer } \\
\text { complained that the standard that was being asked of her was that of the } \\
\text { national drinking standard, which is the highest standard, as opposed to the } \\
\text { meeting provincial standards (I-21, 2011). Requirements such as these } \\
\text { meant that operators were looking at approximately } \$ 200,000 \text { to install a } \\
\text { water filtration or lagoon water system (I-25, 2011). Many farmers and } \\
\text { abattoir operators interviewed outlined the irony that the water they were } \\
\text { using was considered safe for their families to drink, yet it was still not } \\
\text { considered potable (I-32, 2011). One farmer explained that for it to remain } \\
\text { legal for a mobile slaughter facility to come to his farm he would have to } \\
\text { invest } \$ 2,000-\$ 3,000 \text { into a new water purification system, stating that "we } \\
\text { all drink it, it's perfectly good water... So we can drink the water, but we } \\
\text { can't wash a dead chicken with it" (I-18,2011). }\end{array}$ \\
\hline Waste & $\begin{array}{l}\text { The requirements concerning waste disposal were somewhat more } \\
\text { complicated because the MIR was being implemented the same year as the } \\
\text { CFIA was introducing requirements for the removal of specified risk } \\
\text { material as a post-BSE risk management strategy (I-16, 2011). In some } \\
\text { cases, the waste management solutions cost as much or more than the } \\
\text { facility itself (I-25, 2011). This requirement is a perfect example of } \\
\text { boundary objects discussed above and assumptions surrounding risk as the } \\
\text { BC Cattlemen's Association explains that the government is claiming that } \\
\text { the removal of this amount of waste "will make the consumer, the buyer, in } \\
\text { other countries that much safer," when "in essence it doesn't. It's just extra } \\
\text { costs that we are doing" (I-16, 2011). Nevertheless, because the cost of } \\
\text { incineration is too expensive, abattoirs are forced to truck their waste to the } \\
\text { nearest waste site (I-27, 2011). One operator interviewed had one of the } \\
\text { shorter trips to dispose of his waste, with the site only being } 1 \text { hour away, } \\
\text { but explains that when you consider that } 40 \% \text { of the animal is waste, then } \\
\text { you can understand how the costs add up very quickly (I-27, 2011). }\end{array}$ \\
\hline $\begin{array}{l}\text { Mobile } \\
\text { Abattoirs }\end{array}$ & $\begin{array}{l}\text { The requirements being demanded of mobile abattoirs have been extremely } \\
\text { challenging and in most cases have forced the closure of mobile facilities (I- }\end{array}$ \\
\hline
\end{tabular}




\begin{tabular}{|l|l|}
\hline $\begin{array}{l}21,2011) \text {. In one case, the requirements that were being asked of a mobile } \\
\text { abattoir in the North Okanagan were so unreasonable that they would mean } \\
\text { that the abattoir could no longer function as a mobile (I-21, 2011). For } \\
\text { example the trailer that was currently being used was now considered to be } \\
\text { too low and if the operator were to raise the roof, he would be too big to } \\
\text { enter many of the farms that he serves (I-21, 2011). Not only were there } \\
\text { unreasonable requirements and costs for the operator of the mobile abattoir, } \\
\text { there are also requirements that the customers of mobile abattoirs must } \\
\text { undergo in order for them to legally have the services of on-farm slaughter. } \\
\text { In order for a mobile abattoir to access a farm it first needs to be designated } \\
\text { as a docking station. These requirements include having the water authority } \\
\text { approve the properties water, receiving permits from the ministry of } \\
\text { environment concerning waster and having a paved docking station, all of } \\
\text { which amounted to costs that are unaffordable or unreasonable to the } \\
\text { majority of small-scale farmers in British Columbia (I-21, 2011). }\end{array}$ \\
\hline Inspectors & $\begin{array}{l}\text { There are a number of conditions that are required in order to cater to the } \\
\text { needs of CFIA inspectors. For example, operators are required to build a } \\
\text { separate washroom and office for CFIA inspectors (I-21, 2011). Despite the } \\
\text { fact that this requirement has nothing to do with safety, but instead with the } \\
\text { comfort of the CFIA inspector, points to the fact that costs that should be } \\
\text { absorbed by the CFIA are being downloaded onto the facility. It seems } \\
\text { ridiculous to some of the abattoirs who are only operating a couple days a } \\
\text { week, or seasonally, that they are required to build a separate washroom that } \\
\text { can only be used by the CFIA inspector (I-21, 2011). These types of } \\
\text { requirements add enormous costs with absolutely no benefit to the abattoir } \\
\text { owner or to the quality and safety of the product and "doesn't fit with what } \\
\text { the industry needs at all" (I-21, 2011). }\end{array}$ \\
\hline
\end{tabular}




\section{INTERVIEWS}

I-1, Consultant, 2009, November 17, Ottawa, ON

I-2, National Farmers Union, 2009, November 19, Ottawa, ON

I-3, CIELAP, 2009, November 11, Toronto, ON

I-4a, CCGD, 2009, November 17, Halifax, NS

I-4b, CCGD, 2009, November 17, Halifax, NS

I-5a, CMC, 2009, November 17, Ottawa, ON

I-5b, CMC, 2009, November 17, Ottawa, ON

I-6, Consultant, 2010, March 4, BC

I-7, BFF, 2010, February 24, Saskatoon, SK

I-8, AAFC, 2009, November 10, Ottawa, ON

I-9, Tides Canada, 2010 March 1, Peterborough, ON

I-10, Harvest Hastings, 2009, November 9, Hastings County, ON

I-11a, CPC, 2010, February 17, Ottawa, ON

I-11b, CPC, 2010, February 17, Ottawa, ON

I-12, Professor, 2011, January 24, Lethbridge, AB

I-13, Farmer, 2011, January 26, Ottawa, ON

I-14a, CFIA, 2011, February 1, Ottawa, ON

I-14b, CFIA, 2011, February 1, Ottawa, ON

I-14c, CFIA, 2011, February 1, Ottawa, ON

I-15, Farmer, 2011, January 31, 2011, Cobden, ON

I-16, BCCA, 2011, February 2, 2011, Kamloops, BC

I-17, Consultant, 2011, February 11, BC

I-18, Farmer, 2011, February 9, Falkland, BC

I-19, OMAFRA, 2011, February 10, Guelph, ON

I-20, Consultant, 2011, February 10, BC

I-21, Farmer, 2011, February 10, Armstrong, BC

I-22, BC Government, 2011, 11 February, Prince Rupert, BC

I-23, BC Government, 2011, 11 February, Vernon, BC

I-24, Farmer, 2011, 14 February, Gabriola Island, BC

I-25, Consultant, 2011, 15 February, BC

1-26, Abattoir Operator, 2011, 16 February, Salmon River, BC

I-27, Abattoir Operator, 2011, 15 February, Smithers, BC

I-28, Tradesman, 2011, 16 February, BC

I-29, Abattoir Operator, 2011, 16 February, Cowichan Bay, BC

I-30, Farmer, 2011, 17 February, Salt Spring Island, BC

I-31, Consultant, 2011, 18 February, Nelson, BC

I-32, Farmer, 2011, 22 February, Powell River, BC

I-33, Farmer, 2011, 23 February, Powell River, BC

I-34, Abattoir Operator, 2011, 20 January, Pembroke, ON 


\section{References Cited}

Adkin, L .2009. Ecology, Citizenship, Democracy. In Adkin, L. (ed) Environmental Conflict and Democracy in Canada. Vancouver: UBC Press

AG Canada. 2010. March 4. Beef packers score more support in federal budget. Retrieved March 9, 2010 from the AG Canada website: http://www.agcanada.com/Article.aspx?ID=19088

Amin, A. 2002. Spatialities of globalization. Environment and Planning A (34) p.385399.

Amin, A. 1997. Placing Globalization. Theory, Culture, and Society (14). p. 123-137

Andrée, P. 2007. Genetically Modified Diplomacy: The Global Politics of Agricultural Biotechnology and the Environment. Vancouver: UBC Press.

Andrée, P. 2011. Civil society and the political economy of GMO failures in Canada: a neo-Gramscian analysis. Environmental Politics, 20:2 p.173-191

Andrée P, Cobb M, Moussa L, \& Norgang E. 2011, forthcoming. Building Unlikely Alliances Around Food Sovereignty in Canada. Studies in Political Economy

Ballimingie P \& Johnson S. 2011. The Vulnerable Researcher: Some Unanticipated Challenges of Doctoral Fieldwork. The Qualitative Report, 13:3 p.711-729

Barry, A. 2009. The anti-political economy. Economy and Society. 31(2) London: Routledge. p. 268-284

Barry, J. 2006. Resistance is fertile: From environmental to sustainability citizenship. In, Andrew Dobson and Derek Bell (eds.), Environmental Citizenship. Cambridge, MA: The MIT Press, p.21-48

Berry, R.S.Y. 1999 Collecting data by in-depth interviewing. Paper presented at the British Educational Research Association Annual Conference, University of Sussex at Brighton, September 2-5. Retrieved Oct. 2, 2009 from the Leeds website: http://www.leeds.ac.uk/educol/documents/000001172.htm

BCFPA. 2008. Submission to the BC Farm Assessment Review. BC Food Processors Association. Retrieved March 2011, from the Farm Assessment Review website: http://www.farmassessmentreview.ca/pdfs/BC_Food_Processors.pdf

Bourdieu, P. 1998. Acts of Resistance. Cambridge, UK: Polity Press 
Brenner, N. 2001. The Limits to Scale? Methodological reflections on scalar structuration. Progress in Human Geography. 25(4) p.591-614

Brenner N, Peck J, Theodore N. 2010. After Neoliberalization. Globalizations 7:3 p.327345

Buller H. and Morris C. 2004. Growing goods: The market, the state, and sustainable food production. Environment and Planning A 36(6). p.1065-1084

Campbell, H. and LeHeron, R. 2007. Supermarkets, Producers and Audit Technologies: The Constitutive Micro-politics of Food, Legitimacy and Governance. p.131-153. In Burch, D. \& Lawrence, G. (eds.) 2007. Supermarkets and Agri-food Supply Chains: Transformations in the Production and Consumption of Foods. Northhampton, MA: Edward Elgar Publishing Inc.

Canadian Federation of Agriculture. 2011. National Food Strategy. Retrieved July, 2011 from the CFA website: http://www.cfa-fca.ca/programs-projects/national-foodstrategy

Carter-Whitney, M. 2008. Bringing Local Food Home: Legal, Regulatory and Institutional Barriers to Local Food. Written and researched by the Canadian Institute for Environmental Law and Policy. Toronto, Ontario: 2009 Friends of the Greenbelt Foundation Occasional Paper Series.

Chevalier, J.M. \& Buckles, D.J. 2008. Foundations and Skillful Means. In SAS2: A Guide to Collaborative Inquiry and Social Engagement. International Development Research Centre: Ottawa. p. 15-49. Retrieved Oct. 2, 2009 from the IDRC website: http://www.idrc.ca/en/ev-130303-201-1-DO TOPIC.html

Clement, W. 1975. The Canadian Corporate Elite: An Analysis of Economic Power. Toronto: McClelland and Stewart.

Cohen JL and Arato A. 1994. Civil Society and Political Theory. Cambridge, MA: MIT Press.

Crawford, A. 2009, July 15. Buy local push prompts Ontario grocers to go independent. CBC News. Retrieved February 3, 2010 from the CBC website: http://www.cbc.ca/consumer/story/2009/07/14/f-grocery-stores-independent-buylocal-meat-produce.html

Desmarais, A. A. 2007. La Via Campesina: Globalization and the Power of Peasants. Halifax: Fernwood Pub.

Dixon, J. 2007. Supermarkets as New Food Authorities. In Burch, D. \& Lawrence, G. (eds.) 2007. Supermarkets and Agri-food Supply Chains: Transformations in the 
Production and Consumption of Foods. Northhampton, MA: Edward Elgar Publishing Inc. p.29-50.

Dreyfus HL. \& Rabinow P. 1982. Michel Foucault. Michel Foncualt: Beyond Structuralism and Hermeneutics. Brighton: Harvester

Dunn, E. 2005. Standards and Person-Making in East Central Europe. In Ong, A. and Collier, s. (eds.) Global Assemblages: Technology, Politics and Ethics as Anthropological Problems. Oxford: Blackwell. p. 173-193

Dupuis E M and Goodman D. 2005. Should we go 'home' to eat? Toward a reflexive politics of localism. Journal of Rural Studies 21, p.359-71

Ford, L.H., 2005. Challenging the global environmental governance of toxics:social movement agency and global civil society. In: D. Levy and P. Newell, eds. The business of global environmental governance. Cambridge,MA: MT Press, p.305328.

Forgacs, D. 2000. The Gramsci reader. New York: New York University Press.

Foucault M. 1991. Governmentality. In Burchell G, Gordon C, and Miller P (eds) The Foucault Effect: Studies in Governmentality. Chicago: University of Chicago Press.

Foucault M. 1980. Power/Knowledge: Selected Interviews and Other Writings, $1972-$ 1977. Sussex: Harvester

Global Action Network. 2011. Slaughterhouses. Overview. Retrieved June 25, 2011 from the Global Action Network website: http://www.gan.ca/campaigns/slaughterhouses/index.en.html

Goodman, R.M. et al. 1998. Identifying and Defining the Dimensions of Community Capacity to Provide a Basis for Measurement. Health Education and Behavior. 25(3) p.258-278

Government of British Columbia. 2011. Vision and Mission. Ministry of Agriculture. Retrieved July 23, 2011, from the Government of British Columbia website: http://www.agf.gov.bc.ca/ministry/mission.htm

Government of British Columbia. 2011. Buy Local, In-season, Vegetables and Fruit. ActNowBC. Retrieved August, 2011 from the Government of ACT Now BC website: http://www.actnowbc.ca/everyone/buy local, in season fruits_and vegetables?t pid $=309 \&$ 
Government of Canada. 2009, July. Report of the Independent Investigator into the 2008 Listeriosis Outbreak. Agriculture and Agri-Food Canada, Government of Canada.

Gramsci, A., 1971. Selections from the prison notebooks. New York: International Publishers.

Guthman, J. 2008. Neoliberalism and the making of food politics in California. Geoforum, 39(3) p.1171-1183.

Guthman, J. 2007. The Polanyian Way? Voluntary Food Labels as Neoliberal Governance. Antipode 39 p.456-478.

Hall, S. 1988. The toad in the garden: Thatcherism among the Theorists. In Nelson, C. Grossberg, L. (eds) Marxism and the Interpretation of Culture. Chicago: University of Illinois Press p.35-57

Hall, P.A. \& Soskice, D. 2001. An Introduction to Varieties of Capitalism. In Hall, Peter A. \& Soskice, David (eds) Varieties of Capitalism. New York: Oxford University Press.

Harris E. 2008. Neoliberal subjectivities or a politics of the possible? Reading for difference in alternative food networks. Area. 41(1) p.55-63

Harvey, D. 2005. A Brief History of Neoliberalism. New York: Oxford University Press Inc.

Hawe P. 1994. Capturing the meaning of "community" in community intervention evaluation. Health Promotion International. 9(3) p.199-210

Health Canada. 2003, July 24. Food Directorate Policy on Specified Risk Material (SRM) in the Food Supply. Food and Nutrition, Health Canada. Retrieved August 10, 2011, from the Health Canada website: http://www.hc-sc.gc.ca/fnan/securit/animal/bse-esb/policy_srm-politique_mrs-eng.php

Hendrickson M.K. and Heffernan W.D. 2002. Opening spaces through relocalization: locating potential resistance in the weakness of the global food system. Sociologia Ruralis 42 p.347-69

Holloway L., Kneafsey M., Venn L., Cox R., Dowler E. and Tuomainen H. 2007. Possible food economies: a methodological framework for exploring food production-consumption relationships. Sociologia Ruralis 47 p.1-19

Hubbell, L.D. 2003. False Start, Suspicious Interviewees and Nearly Impossible Tasks: Some Reflections on the Difficulty of Conducting Field Research Abroad The 
Qualitative Report 8(2): 195-209. Retrieved Oct.2, 2009 from the NOVA website: http://www.nova.edu.sss/QR/QR8-2/hubbell.pdf

Ilbery B., Morris C., Buller H., Maye D., and Kneafsey M. 2005. Product, process and place: an examination of food marketing and labeling schemes in Europe and North America. European Urban and Regional Studies 12, p.116-32

Keil, R. \& Mahon, R. 2009. Introduction. In Keil, Roger \& Mahon, Rianne (eds) Leviathon Undone? Vancouver \& Toronto: UBC Press. p.3-23

Kneen, C. 2010. Mobilization and convergence in a wealthy northern country. Journal of Peasant Studies, 37(1): p.229-235

Konefal, Jason, Bain, Carmen, Mascrenhas, Michael \& Busch, Lawrence. 2007. Supermarkets and Supply Chains in North America. p.268-288. In Burch, D. \& Lawrence, G. (eds.) Supermarkets and Agri-food Supply Chains: Transformations in the Production and Consumption of Foods. Northhampton, MA: Edward Elgar Publishing Inc.

Lang, T., Barling, D., \& Caraher, M. 2009. Food Policy: Integrating health, environment, and society. New York, Oxford University Press

Langille L., Munro I., Romanow P., Lyons R., Arthur B., Williams P. 2008. Building Collaborative Capacity for Research and Influencing Policy: The Rural Communities Impacting Policy Project. Journal of Rural and Community Development 3(3) p23-55.

Lawrence, G. \& Burch, D. 2007. Understanding Supermarkets and Agri-food Supply Chains. p. 1-22. In Burch, D. \& Lawrence, G. (eds.) Supermarkets and Agri-food Supply Chains: Transformations in the Production and Consumption of Foods. Northhampton, MA: Edward Elgar Publishing Inc.

Leiss, W. 2004. Two Stinking Cows: The mismanagement of BSE Risk in North America. p. 229-260. In Leiss, W. \& Powell, D. (ed.) Mad Cows and Mother's Milk: The Perils of Poor Risk Communication. Montreal: McGill-Queen's University Press.

Li, T.M. 2007. The Will to Improve. Durham \& London: Duke University Press

Locher-Scholten, E., 1994. Dutch Expansion in the Indonesian Archipelago Around 1990 and the Imperialism Debate. Journal of Southeast Asian Studies, 25(1) p 91-111

MacLachlan, I. 2001. Kill and Chill: Restructuring Canada's Beef Commodity Chain. Toronto: University of Toronto Press. 
Magnan, A., 2007. Strange bedfellows: contentious coalitions and the politics of GM Wheat. Canadian Review of Sociology and Anthropology, 44 (3), 289-317.

Mathieu, E. 2009, July 18. Meat cleaves grocer's tie to Sobeys. The Star. Retrieved February 5, 2010 from The Toronto Star website: http://www.thestar.com/business/article/668180

Maye D., Kneafsey M. and Holloway L. 2007. Introducing alternative food geographies in Maye D, Holloway L and Knefsay M (eds) Alternative food geographies: representation and practice. Elsevier, Oxford 1-20

McCarthy, J. \& Prudham, S. 2003. Neoliberal nature and the nature of neoliberalism. Geoforum, 35 p. 275-283.

McMichael, P. 2009. The World Food Crisis in Historical Perspective. Monthly Review. 61(3). Retrieved from the Monthly Review website: http://monthlyreview.org/2009/07/01/the-world-food-crisis-in-historicalperspective

McMichael, P. and Friedmann, H. 2007. Situating the 'Retailing Revolution.' In Burch, D. \& Lawrence, G. (eds.) Supermarkets and Agri-food Supply Chains: Transformations in the Production and Consumption of Foods. Northhampton, MA: Edward Elgar Publishing Inc. p.291-319.

Meat Inspection Regulation. 2004. Food Safety Act: Meat Inspection Regulation. B.C. Reg. 349/2004. Victoria, British Columbia: Queens Printer.

Miller, B. 2009. Is Scale a Chaotic Concept? Notes on Processes of Scale Production. In Keil, Roger \& Mahon, Rianne (eds.) Leviathan Undone? Vancouver \& Toronto: UBC Press. p.51-66.

Ministry of Health. 2011. Meat Inspection Licensing. Ministry of Health. Retrieved August 2011, from the BC Ministry of Health website: http://www.health.gov.bc.ca/protect/meat-regulation/

Ministry of Healthy Living and Sport. 2009. Abattoir operators. Retrieved November 5, 2009 from the Ministry of Healthy Living and Support website: http://www.hls.gov.bc.ca/protect/mi_abattoir.html

Minister of Justice. 2009a. Meat Inspection Act. Retrieved Septemeber 28, 2009 from the Government of Canada website: http://laws.justice.gc.ca/PDF/Statute/M/M-3.2.pdf

Minister of Justice. 2009b. Meat Inspection Regulations, 1990. Retrieved September 28, 2009 from the Government of Canada website: http://laws.justice.gc.ca/PDF/Regulations/S/SOR-90-288.pdf 
Morrigan, J. 2005. Mobile Abattoirs: Benefits and Challenges. Retrieved Oct. 6, 2009 from the Organic Agriculture Centre of Canada website:

http://www.organicagcentre.ca/NewspaperArticles/na_mobile_abattoir_part2.asp

National Farmers Union (NFU). 2005. NFU Comments on the Saskatchewan Meat Inspection Review. Retrieved Sept. 28, 2009 from the National Farmers Union website:

http://www.nfu.ca/briefs/2005/Saskatchewan\%20Meat\%20Inspection\%20System\% review.pdf

National Farmers Union (NFU). 2008, Nov. The Farm Crisis and the Cattle Sector: Toward a New Analysis and New Solutions. Retrieved Oct. 6, 2009 from the NFU website: http://www.nfu.ca/briefs/2008/LivestockreportFINAL.pdf

Nova Scotia Nutrition Council \& Atlantic Health Promotion Centre. 2005, June. Thought About Food? Understanding the Relationship Between Public Policy and Food Security in Nova Scotia: A Background Paper and Policy Lens. http:www.foodthoughtful.ca

Panitch, L. 1997. The role and nature of the Canadian state. In Panitch, Leo (ed.) The Canadian State: Political Economy and Political Power. Toronto: University of Toronto Press. p. 3-27

PBS. 2011. Evaluating the Inspection System: What is HACCP. Frontline. Retrieved August 10, 2011, from the PBS website: http://www.pbs.org/wgbh/pages/frontline/shows/meat/evaluating/haccp.html

Peck, J. 2002. Political Economies of Scale: Fast Policy, Interscalar Relations, and Neoliberal Workfare. Economic Geography. 78(3) p. 331-360

Peck, J., Theodore N., \& Brenner N. 2009. Post Neoliberalism and its Malcontents. Antipode, 41(S1) p.94-116

Peck J \& Tickell A. 2002. Neoliberalizing Space. Antipode. 34(3) p.380-404

Picard, A. 2011. Krever Inquiry. The Canadian Encyclopedia. Retrieved August 2011, from the Canadian Encyclopedia website: http://www.thecanadianencyclopedia.com/index.cfm?PgNm=TCE\&Params=AlA $\underline{\text { RTA0009152 }}$

Polanyi, K. 1944. The Great Transformation. Boston: Beacon Press

Prudham, S., 2008. Tall among the trees: Organizing against globalist forestry in rural British Columbia. Journal of Rural Studies 24, p. 182-196 
Ramsay, H. 2006, February 8. Can't Slaughter Like You Used To. The Tyee. Retreived February 7, 2010 from The Tyee website:

http://thetyee.ca/News/2006/02/08/SlaughterUsedTo/

Ransom, E. 2006. Defining a Good Steak: Global Constructions of What is Considered the Best Red Meat. In Bingen, J. \& Busch L. (eds.) Agricultural Standards: the Shape of the Global Food and Fiber System. Netherlands: Springer. p. 159-175

RCIP (Rural Communities Impacting Policy) Project. 2005. The Rural Policy Challenge. Prepared by $\mathbf{P}$. Williams in consultation with the RCIP Policy Working Group. Retreived Oct. 9, 2010 from www.ruralnovascotia.ca

Reichart P. 2006. Salt Spring Island Food Security: A Discussion and Planning Paper. Salt Spring Island Community Services. Retrieved February, 2011 from the Salt Spring Island Farmers' Institute website:

http://www.ssifi.org/farmplan/documents/Salt\%20Spring\%20Island\%20Food\%20S ecurity\%20Report.pdf

Richard, D. 1996. Elite Interviewing: Approaches and Pitfalls. Politics 16(3): 199-203

Robertson, G. 2010. Rules are not necessarily sacred, principles are. National Farmers Union-Ontario Commentary. Retrieved February 5, 2010 from the Beyond Factory Farming website: www.beyondfactoryfarming.org

Rose, N. 1996. Governing "advanced" liberal democracies. In Barry A., Osborne T., and Rose N., (eds) Foucault and Political Reason: Liberalism, Neo-Liberalism and Rationalities of Government. Chicago: University of Chicago Press. p. 37-64

Rural Communities Impacting Policy (RCIP) Project. 2005. The Rural Policy Challenge. Prepared by P. Williams in consultation with the RCIP Policy Working Group. Retreived Oct. 9, 2010 from www.ruralnovascotia.ca

Scott, D., 1995. Colonial Governmentality. Social Text, no 43 191-220

Shorthall, S. 2004, January. Social or Economic Goals, Civic Inclusion or Exclusion? An Analysis of Rural Development Theory and Practice. Sociological Ruralis. 44 (1) p.109-123

Simon, R. 1982. Gramsci's Political Thought. London: Lawrence and Wishart.

Smith, N. 1992. Geography, difference, and the politics of scale. In Doherty, J., Graham, E., \& Malek, M. (eds) Postmodernism and the social sciences. p. 57-79. London: Macmillan. 
Smith N, Baugh Littlejohns L \& Thompson D. 2001. Shaking out the cobwebs. Insights into community capacity and its relation to health outcomes. Community Development Journal. 36(1), pp.30-41

Swyngedouw, E.A. 1997. Neither global nor local: "Glocalization" and the politics of scale. In Cox, K. (ed) Spaces of globalization. p. 137-166. New York: Guilford Press.

Van der Plaat, M. \& Barrett, G. 2006, January. Building community capacity in governance and decision making. Community Development Journal 41(1). p. 2536

Van Zwanenberg, P. \& Millstone, E. 2005. BSE: risk, science, and governance. New York: Oxford University Press.

Watts D.C.H., Ilbery B. and Maye D. 2005. Making reconnections in agro-food geography: alternative systems of food provision. Progress in Human Geography $29,22-40$ 